\title{
Schwäbische Urkundenfälschungen des 10. und 12. Jahrhunderts.
}

\author{
Mit zwei Facsimiletafeln 1 ). \\ Von
}

Johann Lechner.

Vor allen deutschen Landschaften darf Schwaben sich rühmen, seit karolingischer Zeit die grösste Anzahl reichsunmittelbarer Klöster auf seinem Boden beherbergt zu haben ${ }^{2}$ ), Hauptsitze culturellen Lebens in den mittelalterlichen Jahrhunderten. Besonders dicht gedrängt liegen sie im Konstanzer Sprengel. Reichenau wetteiferte mit St. Gallen um den Vorrang. Hauck nennt Reichenau geradezu das alemannische Fulda. Bis ins 12. Jahrhundert hat es sich trotz vielfachen Schwavkungen auf der Höhe erhalten. Sein Vorsteher nimmt eine erste Stelle unter den Reichsäbten ein ${ }^{3}$ ). An der meistbenützten Verbindungsstrasse nach Italien gelegen, ist das reichbegüterie Kloster vicht nur politisch zu einer bedeutsamen Stellung gelangt. Durch seine Leistungen in den verschiedensten Zweigen geistiger Cultur bewahrte der Name Reichenau jahrhundertelang einen guten Klang ${ }^{4}$ ). An der mittel-

1) Für die Herstellung der Tafeln bewilligte die Centraldirection der Monumenta Germaniae eine Subvention, für die jch mir den ergebensten Dank auszueprechen erlaube.

y) Ficker, Vom Reichsfürstenstande 1, $331 \mathrm{f}$.

3) Vgl, im al]gemeinen K. Brandi, Quellen und Forschungen zur Gesch. der Abtei Reichenan 1 Bd. 1890 (citirt als Brandi, Urkundenfälschungen), 2. Bd. 1893 (citirt als Brandi, Gall Oehem).

4) Vgl. Watten bach, Deutschlands Geschichtsquellen 6. Aufl. und A. Hauck, Die Kirche Deutschlands unter den sächsischen und fränkischen Kaisern, an zahlreichen Stellen; jüngst auch J. Dieterich, Die Geschichtsquellen des Klosters Reichenau bis zur Mitte des 11. Jahrhunderts, Giessen 1897. 
alterlichen Feschichtsschreibung nahm es hervorragenden Antheil. Die Kunstgeschichte berichtet uns von vielbewunderten Bauten ${ }^{1}$ ). und Wandmalereien ${ }^{2}$ ). Musik, Gesang ${ }^{3}$ ) und Poesie fanden eifrige Pflege. Mathematische und astronomische Studien gewannen unter den Mönchen ihre Vertreter. Dichter-Gelehrte wie Walahfried und Hermann zählte die Abtei zu den Ihren. Die Reichenauer Klosterschule, wenn auch nicht immer in gleicher Blüte, gehörte zu den besten Deutschlands.

Zum Licht gehört der Schatten, soll ein wahres Bild entstehen. Das literarische Leben der Reichenauer bethätigte sich auch auf weniger rühmlichem Gebiete. Dass unter der verhältnisrnässig geringen Anzahl von älteren erbaltenen Kaiserurkunden ${ }^{4}$ ) des Klosters drei grössere Gruppen von Fälschungen, aus dem Ende des 11., aus dem Anfang des 12. und der zweiten Hälfte des 12. Jahrhunderts, sich finden, hat Brandi in seiner fleissigen Arbeit nachgewiesen. Eine vierte, dem 10. Jahrhundert entstaumend, kommt hinzu. Dass diese klösterliche Stätte am Beginne des 12. Jahrhunderts auch den Schauplatz einer von mehreren schwäbischen Reichsabteien gemeinschaftlich ins Werk gesetzten grossen Fälschungsaction bildet, zu der Reichenau die ausführende Hand beistellte, dass diese sozusagen auf genossenschaftlicher Basis beruhende Urkundenfabrikation bereits im 10. Jahrhundet daselbst ein kleines gleichgeartetes Vorspiel hatte, glaube ich, so paradox die These klingen mag, im Folgenden zeigen zu können. Die Untersuchung ist hervorgegangen aus den Vorarbeiten für die Ausgabe der Karolingerdiplome in den Monumenta Germaniae; der grössere Theil der benützten Absciriften, Beschreibungen und kritischen Bemerkungen, die ich verwerten konnte, rührt von A. Dopsch her. Was an gefälschten päpstlichen Privilegien und Diplomen ottonischer und salischer Könige in diesen Zusammenhang gehört, habe ich gleichfalls einbezogen.

I. Die Fälschungsgruppe des 10. Jahrhunderts5).

Die hier zu behandelnden Urkunden sind sämmtlich in Urschrift erhalten : zwei Diplome angeblich Karls III. gleichen Datums, M. 1699 und

1) F. Adler, Baugeschichtliche Forschungen in Deutschland 1, Berlin 1870.

2) F. X. Kraus, Die Wandgemälde der St. Georgskirche zu Oberzell auf der Reichenau, Freiburg i. B. 1884.

3) Brambach, die Reichenaver Săngerschule, Leipzig 1888.

4) Bis 1200 nur 28.

5) $\mathrm{Da}$ ich die zu besprechenden Karolinger Urkunden durch die Nummern von Mühlbachers Regesten der Karolinger 1. (= M.), von denen jetzt eine erste Abtheilung in zweiter Auflage erschienen ist, bezeichne, so bemerke ich gleich eingangs über die Art des Citirens Folgendes: ich bebalte der Einheitlichkeit und Einfachheit haliver auch für jene Stïcke, welche bereits in der zweiten Auf- 
1760, und ein Diplom Ottos I., MG. DD. O. I. n. 277 für Reichenau; ein Diplom Ludwigs des Deutschen für Rheinau, M. 1435. Die beiden erstgenannten liess noch Brandi ohne Argwohn passiren 1); in einer Besprechung der Arbeit Brandis hat sie Dopsch ${ }^{2}$ ) bestimmt für Fälschungen des 10. Jahrhunderts erklärt, anch manche Verdachtsgründe angeführt, ohne bei dem beschränkten Raum die nähere Begründung geben zu können. DO. I. 277 bezeichnete Sickel in der Ausgabe als ein "Diplom zweifelhafter Geltung". Die Rheinauer Urkunde M. 1435 ist von Rieger als Fälschung entlarvt worden; nachdem in dieser Sache noch Ficker, Sickel und. Meyer v. Knonau ${ }^{3}$ ) das Wort ergriffen, formulirte Sickel im Text zu den Kaiserurkunden in Abbildungen 48 das Ergebnis dahin, dass die Urkunde von dem als Poppo C bezeichneten Schreiber nach dessen zugleich mit dem Kanzler Poppo in Jahre 940 erfolgten Austritt aus der kaiserlichen Kanzlei angefertigt worden sei. „Der Kanzler Poppo stand in Beziehung zu Reichenau, und die Mebrzahl der von ihm verwendeten Notare war aus schwäbischen Klöstern hervorgegangen, wird also auch nach Rücktritt Poppos im Jahre 940 in dieselben zurückgekehrt sein. Namentlich Poppo C finden wir noch 965 in Verbindung mit Reichenau, für welches er DO. I. 277 geschrieben bat, dessen Echtheit und Giltigkeit gleichfalls in Frage steht. Somit mag er auch dem benachbarten Kloster Rheinau nach 940 den Dienst erwiesen haben, obiges erweitertes Diplom anzufertigen."

Von den vier angeblichen Originalen, welche die Namen Ludwigs des Deutschen, Karls des Dicken (2) und Ottos I. auf der Stirne tragen, stehen mir gute Reproductionen zur Verfügung; mit Ausnahme des in den "Kaiserurkunden" trefflich abgebildeten Rheinauer Spuriums konnte ich auch die Urkunden selbst einsehen. Dass M. 1699 und M. 1700 von derselben Hand geschrieben sind, hat schon Dopsch

lage (mit geänderter Zählung) enthalten sind, vorderhand noch die Nummern der ersten Auflage bei. Da Mühlbacher in der neuen Auflage die froberen Nummern in Klammern beisetzt. lassen sich die Urkunden auch mittels der alten Nummern obne weiteres in der neuen Auflage aufschlagen. Die am Schlusse dieser Abhandlung gegebene Uebersicht über die besprochenen Urkunden nennt - soweit uöglich - die jetzigen Nummern in Klammern neben den früheren. - Die Citate aus Urkunden sind, soferne Karolingerdiplome in Betracht kommen, den Abschriften der Mon. Germ., sonst dem jeweilig besten Druck entnommen.

1) Schon Waitz, Deutsche Verfassungsgeschichte 7, 230² nannte M. 1699 , zweifelhaft*.

2) In dieser Zeitschrift 14, 669.

s) Die Litera,tur verzeichnet Mühlbacher a. a. 0. 
erkannt; dass M. 1435 und DO. I. 277 beide, trotz der Verschiedenheit der Empfänger, von Poppo $\mathrm{C}$ angefertigt sind, ist zuerst Rieger aufgefallen, Sickel hat ihm beigepflichtet.

Durch DO. I. 277 soll M. 1699 bestätigt werden. Als Dopsch die zwei Urkunden nach ihren graphischen Merkmalen verglich, war er nahe daran, den wahren Sachverhalt zu entdecken. Er lehnte die Verwandtschaft der Schrift ab. Der erste Eindruck spricht für ihn. Und doch scheinen mir die Hände mehr als verwandt; sie sind wahrscheinlich identisch; Poppo $\mathrm{C}$ dürfte es sein ${ }^{1}$ ). Dopsch fehlte das graphische Mittelglied, das uns deu Schlüssel zur Erkenntnis in die Hand gibt: M. 1435. Diese Rheinauer Fälschung ist gleich M. 1699 Nachzeichnung einer Karolingerurkunde; die Vorlage ist in beiden Fällen noch bestimmbar. Nur die Sorgfalt in der Nachahmung ist verschieden; während der ehemalige Notar in der für Reichenau bestimmten Urkunde mit grösster Peinlichkeit zu imitiren sucht, nimmt er sich für das fremde Rheinau weniger Mühe, und lässt seine Schreiberindividualität mehr zur Geltung kommen. War es so bei M. 1435 leichter möglich, seine ldentität festzustellen, so ist das Stück andrerseits für uns ein willkommenes Vergleichsobject, ein sicher beglaubigtes Beispiel für das Aussehen der Hand des Poppo $\mathrm{C}$ in karolingischer Verhüllung.

Das wird zur Orientirung über die Fragen, um die es sich handelt, genügen.

Ich beginne die Untersuchung der einzelnen Urkunden. Die äusseren Merkmale von M. 1699 und 1700 können in ein em besprochen werden. Die Originalität der Stücke ist ausgeschlossen. Schon der Gesammteindruck will zur Kanzleischrift unter Karl III. gar nicht pissen. Die gelegentliche Verwendung von geschlossenem a neben offenem a im Text weisen bestimmt auf spätere Zeit; nur in der Datirungszeile ist schon unter Karl III. das geschlossene a mit der Minuskel eingedrungen. Einzelnheiten, wie die zuweilen wahrnehmbare Verschleifung der Oberschäfte bei s, f, c oder die Form des g und das Kürzungszeichen erinnern eher an die Diplomschrift unter Otto I. Es sind Elemente, welche sich dem Schreiber in unbedachten Momenten in die Feder geschlichen haben. Denn für M. 1699 und 1700 hat er mit anerkennenswerter Sorgfalt M. 1637 (Original Karls III. für Reichenau) nachgezeichnet ${ }^{2}$ ). In den Chrismen und Recognitionszeichen, in der verlängerten Schrift, der Ansetzung der Oberlängen

1) Vgl. unten S. $36 \mathrm{f}$.

9) Seine inhaltliche Hauptvorlage M. 1541 (Original Karls Ill. für Reichenau) ist von demselben Kanzleischreiber. 
und den ct-, st-Ligaturen und nicht zum wenigsten in den Datiruugszeilen wird die Nachahmung offenkundig. Trotz solchem graphischen Befund könnten die Urknnden wenigstens inhaltlich echt sein. Da ergibt die Zurückführung auf die Vorlagen den sicheren Beweis der Fälschung unter starker Benützung echter Reichenauischer Diplome. Das Protokoll, mindestens das Eingangsprotokoll und die beiden Unterschriftzeilen, stammen aus echter Vorlage; diese Uebereinstimmung, das in der Erwähnung der Intervenienz Liutwards gelegene Plus gegenüber der Hauptvorlage M. 1541, sowie die Nachahmung der graphischen Merkmale und der Besiegelungsart, lassen als solche M. 1637 vermuthen. Arenga, Promulgation, Narratio, und Immunitätsformel M. $1541^{1}$ ) mit folgenden Interpolationen: 1) Liutwardus Vercellensis aecclesiae episcopus et; 2) neque dux neque comes; 3) seu ullum publicum placitum habendum; 4) et ut censiles homines sive familiae in quibuseumque locis sint constituti. pacem habeant et coram nullo comite aut bannum persolvant aut saeculare negotium habeant nisi coram abbate vel ipsius monasterii advocato. Mit ,Insuper etiam obtulerunt nobis scripta.., quod Karolus maguus imperator" wird die Bestätigung eines durch Karl d. Gr. verliehenen Zollprivilegs (deperd.) nicht sehr vertrauenerweckend eingeleitet; gegen dessen Echtheit wird man sachlich und bei der kurzen Inhaltsangabe auch formell nichts einwenden können. Die Formel ,Pso firmitatis namque studio - confirmaremus monasterio" hat echtes Gepräge ") und ist vielleicht aus dem Deperditum Karls d.Gr. entnommen. Der nächste Passus, enthaltend eive Schenkungsbestätigung königlicher Einkünfte aus Alikmannien, schreibt mit Ausnahme des wiederum ungewöhnlichen Uebergangs M. 963 (Original Ludwigs des Frommen für Reichenau) aus. Die wörtliche Uebernahme wird nur durch zwei Auslassungen, denen ebensoviele Einfügungen entsprechen, unterbrochen. Anstatt, ex ministerio Chuonradi comitis' in M. 963 hat M. 1699: (centena) Apphon; anstatt ,ministerii, quod Raban comes habet, quod pertingit finibus Alansannicis sub eva' in M. 963 hat M. 1699: quae in Albegevue itcet. Es braucht zwischen den beiderseitigen Angaben keine inhaltliche Differenz zu bestehen, die Bezeichnungen nach den Amtsbezirken der

1) M. 1541 ist eine Bestätigung von d e m selben Herrscher, von Karl III. ; M. 1699 nennt die unmittelbare Vorurkunde nicht einmal, es gibt sich als Bestätigung der Privilegien Karls d. Gr. und Ludwigs d. Fr.

2) Soviel ich weiss, ist diese Bezeichnung vor dem 10. Jahthundert nicht nachweisbar.

9) Vgl. Formulae imperiales n. 16, MG. Formulae ed. Zeumer 297. 
Grafen aus Ludwigs des Frommen Zeit können sine dolo durch Anführung der Gaunamen ersetzt worden sein.

Der Rest des Contextes ist wieder wörtlich der Hauptvorlage M. 1541 entlehnt. Die unvereinbaren Angaben der Datirung haben schon Mühlbacher bei der Einreihung in die chronologische Folge der Regesten Schwierigkeiten bereitet. Statt. 886 muss es nach dem Itinerar 887 heissen; dazu passt indictio V. Annus regni X. ist für 887 um eine Einheit zu niedrig; annus imperii VIII. ist für Karl III. überhaupt unmöglich, weil es das erste Jahr nach dessen Tode bedeutet?. Die Datirung entstammt wahrscheinlich keiner echten Vorlage, sie ist vermuthlich im Anschlusse an M. 1637, das die übrigen Protokolltheile lieferte, von dem ehemaligen Kanzleinotar selbst zusammengestellt. Das Material dazu stand ihm in der reichen Bibliothek von Reichenan zur Verfügung. Die Annales Fuldenses - noch ein Jahrhundert später von Hermann dem Lahmen benützt, vergl. MG. SS. 5, 109 - berichten ad. a. 887 1): imperator ... vergens curtem Podonam ..; transacto die sancto paschae ete.; den 0stertag, der im Jahre 887 auf den 16. April fiel, konnte er einer sicher vorhandenen Ostertafel entnehmen. Dabei hätte er sich in der Berechnung des annus regni und annus imperii je um eine Einheit geirrt; im Incarnationsjahr 886 statt 887 läge ein auch in M. 1700 übergegangener Schreibfehler vor.

Die Interpolationen weisen durch ihre Tendenz ins 10. Jahrhundert. Unter Ausschliessung aller Grafengewalt vindiciren sie die Grafenrechte über die Reichenauer Immunitätseingesessenen dem Grundherren. Speciell die Censualen, welche ja zum grossen Theile aus ursprünglich Geburtsfreien und Freigeiassenen sich recrutirten, die sich aber zur Erleichterung ihrer Lebenslage als Landbauern oder Handwerker dem Schutze des Stiftes commendirt, ihm häufig auch ihren Besitz aufgetragen hatten ${ }^{2}$ ), auch sie sollen, wo immer sie sitzen mögen, nur vor dem Abte, beziehungsweise dem Vogte ihre Rechtssachen erledigen; der Graf darf keinerlei Banngelder von ihnen fordern. Das ist der Inhalt der jüngeren Immunität, welche in echten Urkunden nicht vor dem 10. Jahrhundert nachweisbar und auch in der ersten Hälfte dieses Jahrhunderts von den Königen noch selten ertheilt worden ist ${ }^{3}$ ). Es ist ein Charakteristikon zahlreicher Fälschungen des 10. Jahrhunderts, dass sie die gräfliche Gerichtsbarkeit für den Immunitätsherrn beanspruchen. Wenn

1) Schulauggabe der MG. ed. Waitz S. 115.

2) Waitz, Verfassungegeschichte 52240 .

3) Waitz, a. a. 0. 7, 247 und 255. 
Brandi 1) M. 1699 als ein Beispiel dafür anführt, dass schon Karl III. die Ignorirung des Grafengerichtes gebilligt, so wird sein Schluss durch den Nachweis der Unechtheit dieser Urkunde hinfällig.

Bevor wir die Grenzen der Entstehungszeit von M. 1699 näher zu stecken suchen, erscheint es angezeigt, anch für M. 1700 Vorlagen und Tendenz zu bestimmen. Das ganze Protokoll ist jenem von M. 1699 gleich; nur in der Datirung lässt M. 1700 die Indiction weg. Ebenso stimmen Arenga, Promulgation und der erste Theil der Narratio wörtlieh mit M. 1699 überein, auch in der dort gegenüber der Vorlage M. 1541 vorgenommenen Interpolation ,Liutwardus Vercellensis aecclesiae episcopus et'.

Für den sachlichen Theil der Narratio ist eine noch im Originil erhaltene Reichenauer Urkunde Ludwigs des Frommen, M. 960, Vorlage; diese wird auch als Vorurkunde erwähnt. Dem Vergleichenden fallen zwei inhaltliche Differenzen gegenüber der echten Vorlage auf: 1.) In M. 960 wird von der Schenkung der Villa Dettingen ein durch Angabe der Grenzen bestimmter Waldtheil ausgenommen; diese Einschränkung ist in M. 1700 weggefallen. 2.) ist die ganze Stelle ,necnon et tributum, quod Ratpold ad supradictum fiscum persolvebat $a b$ his locis, quae Vualavuis Liutegarninga et Rorinang nominantur‘ interpolirt,

Dann folgt mit ,Pro firmitatis' anhebend und ,monasterium contalimus' schliessend ein formeller Schluss der Narratio und Beginn der Dispositio von echtem Gepräge ${ }^{2}$ ); der erste Satz hat auch in M. 1699 Aufnahme gefunden; für beide diente wohl eines jener zwei in M. 1699 erwähnten Deperdita Karls des Grossen als Quelle. Der Rest des Contextes ist $=$ M. $1699=$ M. 1541.

Zur Charakteristik der beiden sachlichen Differenzen, welche den Zweck der Fälschung bilden, genügt der Hinweis, dass die durch sie angeblich verliehenen Besitzrechte noch in der zweiten Hälfte des 12. Jahrhunderts strittig waren und vom Custos Udalrich in erweiterter Auflage mit aller ihm zugebote stehenden Fälscherenergie vertheidigt wurden ${ }^{3}$ ).

Nun zur Entstehungszeit von M. 1699 und M. 1700. Von demselben Fälscher geschrieben und in ganz analoger Mache fabricirt, werden beide Urkunden auch ziemlich gleichzeitig verfertigt worden sein. Die Argumente für die Entstehungszeit der einen werden daher auch für die chronologische Einreihung der andern massgebend sein

1) Urkundenfälschungen 74.

2) Vgl. Form. imp. n. 16 a. a. 0.

3) Vgl. Brandi, Urkundenfälschungen n. 3, 4, 32, 44, 63 und meine Au-s führungen unten S. 77 bis S. 79 . 
dürfen. Einen terminus a quo bietet für M. 1699 das Originaldiplom Ludwigs des Kindes vom J. 909, M. 2002. Diese Bestätigung der Immunität und freien Abtwahl schreibt wörtlich M. 1541 aus; hätte M. 1699 mit seinem weitere Rechte verleihenden Inhalt damals schon bestanden, so hätte das Kloster sich damit wohl nicht begnügt: das J. 909 wird zur Zeitgrenze nach rückwärts. Die in DO. III. n. 61 erwähnten Diplome Konrads I. und Heinrichs I., welche uns nähere Haltpunkte geben könnten, sind nicht erhalten. Die älteste erhaltene Bestätigung von M. 1699 ist DO. I. n. 277 von 965 Febr. 21., mit dem als einem "Diplom zweifelhafter Geltung" uns aber nicht gedient ist. Wörtlich wiederholt wird diese angebliche Bestätigung in DO. III. n. 61 vou 990 April 31 ; also fällt M. 1699 jedenfalls vor das Jahr 990 .

Einen näheren Terminus ad quem bietet das weitere Schicksal von M. 1700; es ward schon 946 Nov. 28 von Otto I. in D0. I. n. 83 einschliesslich der Interpolationen in wörtlicher Wiederholung bestätigt. Es dürften demnach beide Fälschungen vor 946, vielleicht kurze Zeit zuvor, entstanden sein.

Schriftcharakter und Tendenz unterstützen unser Ergebnis. Noch zweimal treffen wir diese Fälscherhand in Karolingerdiplomen für Reichenau an: die von Udalrich in 12. Jahrhundert nachgezogene Datierungszeile in M. 1701 ist in Schrift und Daten gleich M. 1699 und M. $1700^{1}$ ). Allem Anschein nach hat derselbe Mann auch die Verunechtung ,solus abbas' in dem Originaldiplom König Arnolfs für Reichenau, M. 1817, auf dem Gewissen.

Bezüglich der zwei folgenden in diesen Zusammenhang gehörigen angeblichen Originale kann ich mich bei der zutreffenden Beurtheilung, die sie bisher gefunden haben, auf Ergänzungen beschränken. Zunächst wird DO. I. n. 277 fürderhin nicht mehr als ein „Diplom zweifelhafter Geltung", sonderen rundweg als Fälschung zu bezeichnen sein. Die Möglichkeit, dass es nur eine Copie in Diplomform von einer wirklich ausgegangenen Urkunde sei, wird durch den ursprïnglichen Mangel an näheren Datirungsangaben ausgeschlossen. Das von Brandi angeführte Moment, dass angesichts wörtlicher Uebernahme aus dem - von ihm für echt gehaltenen - Diplom Karls III. M. 1699 der Fälschungszweck nicht einzusehen sei, verkehrt sich durch den Nachweis der Unechtheit der Vorurkunde zu einem Verdachtsgrund. Dass eine Besiegelung wenigstens versucht worden ist, geht daraus hervor, „dass rechts unten durch das Pergament eine verblichene Seidenkordel durchgezogen $)^{2}$ " ist. Das deutet auf Bullirung. Ich erinnere daran, dass

1) Ygl. unten S. 78.

2) Brandi, Urkundenfälschungen 7 . 
M. 1699 und M. 1700 gianz ähnliche Reste ursprünglicher Bullirung aufweisen: jetzt schmutzigweisse ungedrehte Zwirnfäden sind durch zwei Einschnitte gezogen und verknüpft.

Für M. 1435 (Rheinau) sind durch Rieger ${ }^{1}$ ) die Fragen über Vorlagen, Tendenz und annähernde Entstehungszeit gelöst worden. Sickels Annahme ${ }^{2}$ ), dass Poppo C diese Fälschung erst nach seinem Austritte aus der Kanzlei, also nach 940 fabricirt hat, darf grosse Wahrscheinlichkeit beanspruchen.

Da die Herstellung von DO. I. n. 277 (Reichenau) und M. 1435 (Rheinau) durch Poppo C eine ausgemachte Sache ist, so handelt es sich jetzt darum, ob nicht vielleicht auch die Vorurkunde für seine Ottonenfälschung, nämlich M. 1699, und mit ihr M. $1700 \mathrm{ihm}$ ihre Entstehung verdanken. Auch sie sind um dieselbe Zeit, während seiner Anwesenheit in Reichenau zwischen 940 und 965, angefertigt worden. Details in der Schrift verratien trotz peinlicher Nachahmung der Vorlage, welche man fast Buchstaben für Buchstabeu verfolgen kann, einen Mann, dem die ottonische Diplomschrift geläufig war. Die bei aller Unsicherheit doch verhältnismässig gut gelungene Nachzeichnung einer Karolingerurkunde, welche seinerzeit selbst Mühlbacher über die Originalität täuschen konnte, nöthigen zur Annahme eines geschulten Urkundenschreibers. Die Zusammenstellung der Datirung weist zwar Fehler auf, verlangte aber immerhin eine ziemliche Vertrautheit mit Kanzleigebräuchen. In allen drei Fällen ist als Besiegelungsart die Bullirung gewählt.

Bei solchem Sachverhalt werden charakteristische, mit der Schrift des Poppo $\mathrm{C}^{3}$ ) übereinstimmende graphische Merkmale doppelt ins Gewicht fallen. Bemerkenswert ist, dass bei Poppo $\mathrm{C}$ anch in echten Stücken die Schäfte der verlängerten Schrift nicht gerade, sondern wie von zitternder Hand gewellt sind. Als kennzeichnend für Poppo C führt Sickel a. a. 0 . den Verbindungsbalken rom $t$ zum $i$ in, et individuae' an; M. 1699 und M. 1700 haben ihn auch. Ein aus dem Context von M. 1699 und M. 1700 gebildetes Alphabet ähnelt namentlich in den kleinen Buchstaben, ferner in $d, g, p, r$ in nicht zu ver-

1) Ueber eine Urkunde Ludwigs des Deutschen für das Kloster Rheinau in Wiener Sitzungsberichte 76, $477 \mathrm{ff}$. Was Rieger hier über die allgemeine Entwicklung des Wahlrechts vorbringt, ist allerdings nicht ganz treffend und auch vom Verfass er nur als ein vorläufiger Versuch gemeint gewesen.

2) Kaiserurk. in Abb. Text 49.

s) Vgl. hierüber Sickel in Neues Archiv 1, 454: zum Vergleich der Schrift des Poppo $\mathrm{C}$ verweise ich insbesondere auf Kaiserurk. in Abbild. III. 11; dann auf seine Kanzleiarbeiten KU. i. A. I. 23 und 28, Chronicon Gotwicense 159, welche aber viel flüchtiger sind als die notorischen Fälschungen von seiner Hand. 
kennender Weise jenem des Poppo C. Die häufige Verwendung von spitzen $\mathrm{v}$ für $\mathrm{u}$ im Inlaut gehört auch in diesen Zusammenhang. Die ständige Form des allgemeinen diplomatischen Abkürzungszeichens ist auch bei per, prae, quod sehr beliebt; die Abbreviaturen für mus, bus, que finden sich gleichfalls beiderseits. Ferner vergleiche man das, et' vor dem Recognitionszeichen. Besonders auffällig ist das h mit dem' spitz zulaufenden zweiten Halbschaft. Gravirend scheint mir auch die öfters deutlich zu erkennende Gewohnheit des Schreibers, bei Buchstaben mit einfacher Oberlänge wie $b, d, i, l$ nach dem innerhalb des Zweilinienschemas fallenden Theil abzusetzen und für den Oberschaft neu anzusetzen; das hatte zur Folge, dass die beiden Enden sich zuweilen nicht trafen. Das Fehlen anderer für den oft genannten Kanzleischreiber charakteristischer Merkmale erklärt sich durch die Anpassung an die Vorlage. Haben M. 1699 . und 1700 ausschliesslich $t$ ohne Schlinge, so herrscht in H. 1435 und DO. I. 277 jenes mit der Schlinge vor; doch finden sich daneben in der Ottonenfälschung auch schlingenlose $t$.

In Anbetracht aller Kriterien, wie sie sich aus Entstehungszeit, Herstellungsort, äusserer Technik, Composition und Tendenz ergeben, glaube ich Poppo C, der ja auch für Kheinau arbeitete, nicht Unrecht zu thun, wenn ich ihn der Autorschaft auch dieser beiden Fälschungen auf Karl III. zeihe. Die Thätigkeit, welcher er bis 940 von amtswegen oblag, setzte er nach seinem Austritte aus der Kanzlei in unbefugter Weise fort und deckte die urkundlichen Bedürfnisse von Reichenau und Rheinau.

II. Die Fälschungsgruppe aus dem Anfang des 12. Jahrhunderts.

Die Spuria, deren archivalische Ruhe die nachfolgende Untersuchung abermals zu stören gezwungen ist, sind in der diplomatischrechtsgeschichtlichen Literatur keine Neulinge. Jeder Urkundenforscher erkennt in den Fälschungen, durch welche sich die schwäbischen Klöster Buchau, Kempten, Lindau, Ottobeuren, Rheinau und Stein am Rhein unter Reichenaus Führung gegen die Uebergriffe der Vögte zu schützen suchten, alte Bekannte wieder.

Die Tendenz gegen die adrocati, die aus bestellten Beschützern zu ungerufenen Bedrückern geworden waren ${ }^{1}$ ), ist allerdings nur e in e

1) Mit kurzen, treffenden Strichen zeichnet die Grundlinien d dieser Entwicklung Dopsch in dieser Zeitschr. 17, 30 im Anschlusse an Lamprechts Deutsches Wirtschaftsleben. 
der Zielriehtungen dieser pergamentnen Waffen, wenn auch die hervorstechendste. Im Kampfe um die Echtheit oder Unechtheit mehrerer von diesen Urkunden 1) schuf sich im 17. Jahrhundert die junge Diplomatik in Deutschland ihr erstes bescheidenes Rüstzeug. Als längst die Frage, ob echt ob falsch, schon keine Frage mehr war, wurde man auf den innigen Zusammenhang dieser Stücke, den inhaltlichen wie den formellen, aufmerksam. Mïhlbacher ${ }^{2}$ ) hat darauf mit deutlichen Worten hingewiesen. Er dachte an eine gemeinsame Vorlage aller; das ist zweifellos der nächstliegende Erklärungsversuch für diese auffallende Familienähnlichkeit in Fälschungen für verschiedene Klöster. Zu den bezeichneten Abteien, die zum grösseren Theile im Konstanzer Sprengel gelegen sind, gesellt sich auch noch das Domcapitel von Strassburg. Brandi ${ }^{3}$ ) widmet der Verhältnisfrage einen eigenen Excurs; sorgfältige Textvergleichung führt ihn zur Aufstellung etwa folgender Filiationen: Von der Reichenauer Urkunde als Mutter stammen die Kemptener, Rheinauer, Buchauer und Steiner (am Rhein) Fälschungen als Töchter; in Ottobeuren und Lindau wurden Enkelkinder in die Welt gesetzt ${ }^{4}$ ).

So schien die Frage entschieden. Soviel mir bekannt, änsserte nur Dopsch ${ }^{5}$ ) gelegentlich Zweifel; ähnlich wie schon vor Brandi Mühlbacher, sah er in der Verwendung eines gemeinsamen Formulars, eines "Schimmels", die plausibelste Erklärung. Brandis Resultate über die Reichenauer Fälschungen des 12. Jahrhunderts ${ }^{6}$ ) haben eine verwundbare Stelle in der Chronologie. Die Rheinauer Urkunde angeblich Ludwigs des Deutschen (M. 1361) hat nachweislich 1125 schon bestanden ${ }^{2}$ ) und für die ursprüngliche Fassung des Ottobeurener Falsificats auf den Namen Karls d. Gr. hat Scheffer-Boichorst ${ }^{8}$ ) als späteste Zeitgrenze das Jahr 1145 festgestellt. Und doch sollen beide - das

1) Vgl. die Zusammenstellung der Streitschriften bei Baring, Clavis diplomatica 18-22.

2) Regesten $\mathbf{n}^{0} 447$ (Reichenau); dazu M. 132 (Ottobeuren), M. 154 (Strassburg), M. 157 u. M. 158 (Kempten), M. 674 (Buchau), M. 961 (Lindau), M. 1361 (Rheinat).

3) Urkundenfälschungen 107-113: Ueber die Verbreitung der Reichenaner Fälschung, die Klostervögte betreffend, und die Heimat der constitutio de expeditione Romana.

4) Brandis Ergebnis liesse sich folgendermassen veranschaulichen : M. 447

5) In dieser Zeitschr. 17, 27 f. $\overbrace{\text { M. } 158 \text { M. } 674 \text { M. } 1361 \text { St. } 1412}$

6) Vgl, sein Verzeichnis a. a. 0: 114 ff. Beweis unten S. 59 f.

8) In Neues Archiv 19, 598\%. 
Ottobeurener Stück gar erst auf dem Umwege über Kempteu - aus einer Reichenauer Fälschung auf Karls des Grossen Namen, M. 447, abgeleitet sein, die rom Custos Odalrich frühestens in den fünfziger Jahren desselben Jahrhunderts fabricirt worden sein könne ${ }^{1}$ ).

Da stimmt etwas nicht. Brandi selbst ist das nicht ganz entgangen. Aber seine scheinbar geschlossenen ${ }^{2}$ ) Resultate über Udalrichs Fälscherthätigkeit erlaubten kein Zurück: die fünfziger Jahre sind schon das äusserste Zugeständnis an Meyer v. Knonau, der das Rheinauer Chartular (mit der. Vogteiurkunde an der. Spitze) nahe zum Jahre 1126 ansetzte.

Keinem der genannten Forscher war es vergönnt gewesen, die Urschriften ${ }^{3}$ ) der in Rede stehenden Spuria zu vergleichen; auch Brandi nicht 4). In diese günstige Lage versetzten mich photographische Reproductionen ${ }^{5}$ ), als ich die einschlägigen Empfängergruppen zu bearbeiten hatte. Den Sammlungen der Mon. Germ. verdanke ich auch hier zum überwiegend grössten Theile mein Material. Da ergab sich die überraschende Beobachtung, dass alle in Urschrift überlieferten Stücke von derselben Hand sind, und dass diese selbst wieder identisch ist mit der Schrift des Fälschers von M. 1567 und M. $1766_{2}$ für Reichenau ${ }^{6}$ ).

Dies als orientirende Einleitung über den Stand der Frage und über die Veranlassung zu neuerlicher Prüfung der bisherigen Ergebnisse. In der Einzeluntersuchung wird der äusseren Mache und der formellen Composition der Fälscher ?) nachzugehen sein, wie nicht minder dem Zweck der Fabrikate. Daraus werden sich auch nähere Anhaltspunkte über die Entstehungszeit gewinnen lassen.

') Brandi, Urkundenfälschungen 72.

2) Brandis Beweis wirkte auf jeden, der die Untersuchung über sämmtliche Reichenauer Fälschungen des 12. Jahrhunderts nicht erneuern wollte und konnte, derart überzeugend, dass auch Bloch seinen Ausführungen uber Zusammenhang und Entstehung derselben durchaus beistimnte, obwohl ihm im Anschlusse an da angebliche Diplom für Stein, St. 1412, Zweifel an der Richtigkeit dieser späten Ansetzung gekommen waren. Blochs Gründe sind mir unbekannt. Vgl. Neues Arch. 22, $192^{2}$.

3) Sie sind uns erbalten von M. 157 und 158, M. 96 J, M. 1361.

4) Vgl. a. a. $0.111^{1}$ u. s.

5) In M. 157, M. 158 und M. 961 konnte ich ausserdem noch selbst Einsicht nehmen.

i) Hine genaue Untersuchung der änsseren und inneren Merkmale von M. 1567 u. M. $1766_{2}$ bestimmt mich, beide Fälschungen mit Brandi, Urkundenfälschungen 52 einem und demselben Erzeuger zuzuweisen; vgl. Dopsch in dieser Zeitschr. 14, 670.

7) Um der Beweisführung nicht vorzugreifen, halten wir vorerst noch an der Mehrzahl fest. 
Von dem Reichenauer Vogtrecht, getauft auf den Namen Karls d. Gr., M. 447, wird auszugehen sein; daran schliessen wir Untersuchungen über die concurrirenden Erzeugnisse des 12. Jahrhunderts für Kempten, Strassburg, Ottobeuren, Buchau, Rheinau, Lindau und Stein a. Rh.; die so gewonnene Einsicht in den Zusammenhang der Ableger wird uns vielleicht schärfer blicken lassen in die Fälschungsthätigkeit für Reichenau selbst.

Reichenau. M. 447. Inserirt ${ }^{1}$ ) in einem Originaldiplom Heinrichs VII. von 1312 0ct. $17^{2}$ ). Für das Protokoll ist eine Urkunde Karls III. von 887 Juli bis September verwendet ${ }^{3}$ ). Das Fehlen der Recognition und das Regierungsjahr 41 gehören aufs Conto des Kanzleibeamten unter Heinrich VII. ${ }^{4}$ ) Die Arenga erweist sich als eine Erweiterung jener von St. 2669, einer Urkunde Heinrichs IV. für Reichenau. Brandis Ansicht über die wahrscheinliche Provenienz und Wahl der Vogtnamen des Textes scheint mir sehr plausibel; so namentlich auch die Hereinziehung eines Grafen von Bregenz mit Rücksicht auf einen angesehenen Vogt aus diesem Geschlecht in des Fälschers Zeit: ein comes Rudolfus de Prigantia ist 1116-1137 nachweisbar. Gleichwie der Name Amalharus aus Herm. contr. zu stammen scheint, so dürfte auch für die Einführung des Veroneser Bischofs Egino und des Grafen Gerold ${ }^{5}$ ) die Lectüre des Herm. contr. Veranlassung und sicheren Boden abgegeben haben, wenn auch die Klostertradition sich dieser Wohlthäter noch erinnert haben mag; vgl. Herm. contr. ad ann. 799, wo beide Männer gerade in dieser Rolle unmittelbar hintereiuander auftreten. Eingehendere Studien dürfen wir dem Fälscher nicht zumuthen, zumal diese beiden Namen nur erzählendes Beiwerk sind, das er nahm, weil er's zur Hand hatte und weil es ge-

1) Um 1500 hatte Oehem noch die Urschrift vor sich. Nach einem Rückvermerk s. XVI zu schliessen, scheint sie schon im 16. Jahrh. in Reichenau verloren, gewesen zu sein. Von den drei inserirten Karolingerurkunden (M. 447, M. 465, M. 1817) sei , allain ain original und rechter hauptbrief ${ }^{\star}$, der Bestätigungsurkunde Heinrichs VII. beiliegend, vorhanden gewesen. Wir kennen M. 465 und M. 1817 in Urschrift bzw. Original.

2) XVI. kal. novembr.

3) Ich darf mich hier, soweit ich Brandi, Urkundenfälschungen $44 \mathrm{f}$. zustimme, wohl ganz kurz fassen.

4) Vgl. Brandi, Gall Oehem 44.

5) Von den ihnen zugeschriebenen Schenkungen lässt sich nur Dürmentingen als. solche des Bischofs Egino belegen, während Altheim nicht aus der Hand des Grafen Gerold, sondern aus jener Ludwigs d. Fr. in Reichenauischen Besitz übergieng. Vgl. das auf urkundlicher Grundlage beruhende, wohl um 1139 zusammengestellte Schenkungsverzeichnis bei Brandi, Gall Oehem, 16-21. 
eignet war, seinem Fabrikat echtes Gepräge zu leihen. Soll es endlich ein Zufall sein, dass der Fälscher dieses angeblich durch Hetto erlangte Privileg an dasselbe Jahr 811 anknüpft, zu welchem Hermann dieses Abtbischofs erwähnt?

Zu den vielen Eigenthümlichkeiten des Dictats gehört, um nur einzelnes hervorzuheben, die Häufung von synonymen Ausdrücken und eine besondere Vorliebe, jedes wichtigere Ereignis ,coram multis principibus' geseheben 1) zu lassen.

Die Reimprosa, wenn auch eine stilistische Mode der Zeit, darf sonst als Kriterium sicher nicht unbeachtet bleiben ${ }^{2}$ ). In unserem Falle wird bei ihrer Verwertung zur Autorsbestimmung Vorsicht geboten sein, handelt es sich doch um zwei Personen desselben Klosters und desselben Jahrhunderts (1. Viertel-3. Viertel).

Die Fälschung bezweckt, die Befugnisse und Bezüge der Vögte einschränkend zu fixiren und speciell die ordentliche Gerichtsbarkeit des Kastrogtes auf der Insel selbst ganz auszuschliessen.

Kempten. M. 158, eine Fälschung auf den Namen Karls des Grossen, ist überliefert als Urschrift des beginnenden 12. Jahrh. und als wenig späterer Nachtrag im Kemptener Chartular aus der ersten Hälfte des genannten Jahrhunderts. Die Urschrift steht auf Rasur einer Urkunde Karls III., wie das ursprüngliche et (SR) bewejst; dieses ist identisch mit dem Recognitionszeichen eines Diploms Karls III. von 887 Sept. $21^{3}$ ), (M. 1711). Dem getilgten Diplom scheint auch die um 887 Juli-September mögliche Kanzleiunterfertigung entnommen zu sein; vgl. M. 447. Die Schrift zeugt für das Bemühen des Fälschers, karolingischen Charakter zu erzielen; unwillkürlich aber schleichen sich Kennzeichen späterer Zeit ein, wie z. B. die erst seit etwa dem Ende des 10. Jahrh. ${ }^{4}$ ) in der Kaiserurkunde übliche Verschnörkelung des t-Schaftes in der verlängerten Schrift, oder die Zickzack-Schnörkel der Oberschäfte, welche in dieser Form der diplomatischen Minuskel von rund 1050-1150 eignen. Anderes wieder, z. B. die Hervorhebung des $\mathrm{S}$

1) Einmal in der Narratio, dann wieder bei der in die Dispositio eingeschalteten Erzählung von der Absetzung des bösen Vogtes. Der Ausdruck an und für sich und seine Betonung entbehrt nicht eines bestimmteren Zeitcolorits; er bezeugt den wachsenden Einfluss des Reichsfürstenthums und ist in echten Königsurkunden vor dem Ende des 11. Jahrhunderts sehr selten nachweisbar. Vgl. Ficker, Vom Reichsfürstenstande 1, $43 \mathrm{ff}$.

2) Vgl. Brandi, Urkundenfälschungen $60 \mathrm{ff}$.

8) Vgl. Kaiserurk. in Abbild. IV. 1 und 2.

4) Mein Material sind die Kaiserurk. in Abb.; auch Tangl (Sammlungen der MG.) hat auf diese Schriftmerkmale hingewiesen. 
in ,secundun quod' etc. zu Anfang eines nenen Abschnittes erinnert an die Papsturkunde derselben Zeit.

Die Invocation passt zu Karl d. Gr., auch der Titel kommt dem von 801-814 gebräuchlichen Kaisertitel sehr nahe. Der Text erweist sich - darin ist Brandi unbedingt beizustimmen - als ein den Kemptener Verhältnissen angepasster Auszug aus M. 447 für Reichenau. Von Interesse ist das hier vorhandene sachliche Plus gegenüber M. 447; an zwei Stellen: advocatos et defensores, qui nobis parati sint servire et proipso abbate in hostem nobiscum pergere, also in Form eines scheinbar harmlosen Relativsatzes eine vollständige Abwälzung der Heerfolgepflichta) vom Abt auf die Vögte; die Bestimmungen über die Rechte des Vogtes enthalten als Mehr in Rücksicht auf M. 447 die Grösse des ihm erlaubten Gefolges: 12 Mann zu Ross. Zum Verständnis der Composition sei ferner darauf hingewiesen, dass der hier genannte Audogar vou Hermannus Contractus (MG. SS. 5, 99) ad a. 752 als Gründer und erster Abt von Kempten erwähnt wird. Im Dictat ist für den Vergleich mit später zu besprechenden Fälschungen beachtenswert, dass Karl in Signumzeile wie Datirung das Attribut ,magnus' führt. Die Verlegung der Handlung nach Rom in sancto die pascae ${ }^{3}$ ) sei gleichfalls als hezeichnend notirt. Die bei M. 447 beobachtete Reimprosa drängt sich auch hier vor und zwar in den neustilisirten Theilen nicht minder als in den aus M. 447 entnommenen. Die textliche Vorlage bedingt dieselbe Tendenz: Schutz gegen den Vogt.

Eine zweite Fälschung auf den Namen Karls des Grossen für Ke mpten, M. 157, theilt mit M. 158 Ueberlieferung und Hand, beides ist gleich ${ }^{4}$ ). Das über die Schrift von M. 158 Gesagte gilt auch für diese zweite Kemptener Fälschung, welche als Palimpsest auf dem Pergament einer Urkunde aus nachkarolingischer Zeit geschrieben steht. Stärker noch als in M. 158 sind die Anklänge an die Papsturkunde: der Beginn cler Arenga und der Pön ist durch ein grosses verschlungenes

1) Urkundenfälschungen $110 \mathrm{f}$.

9) Durch M. 900 war Kempten von Ludwig d, Fr. nur theilweise Befreiung von der Heerplicht verliehen, durch M. 1407 von dessen gleichnamigen Sohne bestätigt worden.

s) Vgl. Herm. contr. ad a. 773 a. a. O. 100: Karolus ... Romam oraudi gratia adiens pascha inibi celebravit.

4) Vgl. auch Mühlbachers Neuausgabe der Regesten $n^{0}$ 162. Chrismon und Kürzungszeichen, aus verfehlter Nachahmung entstandene Formen einzelner Buch. staben (c, d, e), wie Ductus machen die Identität zweifellos, obwohl sich der Fälscher sichtlich bemüht hat, diesen Eindruck zu verwischen. 
$\mathrm{S}$ ausgezeichnet; die Formen der Buchstaben r, ri, a, s lassen curialeu: Einfluss nicht verkennen. Die Identität des Fälschers macht es höchst wahrscheinlich, dass die echten Theile des Protokolls und der Arenga demselben Diplon Karls III. entnommen sind, dessen Benützung wir ${ }^{4}$ auch bei M. 158 feststellen konnten 1). Die Namen, welche die Narratio bietet, sowie die Nachrichten über die Grïndungsgeschichte des Klosters sind chronikalischer Herkunft; mit Ausnahme der Notiz iiber Hildegardens Verdienste, die dic Kemptener Klostertradition jederzeit in übertrieben lebendiger Erinnerung behielt ${ }^{2}$ ), finden sich alle Daten bei Hermannus contr. ${ }^{3}$ ) wieder. Die Immunitätsverleihung, mit der die Dispositio anhebt, lässt sich nicht mit einiger Wahrscheinlichkeit auf erhaltene Kemptener Urkundeu ${ }^{4}$ ) zurückführen; auch die echten Formeltheile weisen auf die spätere Karolingerzeit. Die Vorlagensuche ergibt die bemeríenswerte Beobachtung, dass die Immunitäts-Bestimmungen, die auch der Zinsleute liebevoll gedenken, wörtlich gleichlauten mit denen der Reichenauer Fälschung des 10. Jahrhnnderts, M. 1699; diese Uebereinstimmung ist umso auffallender, als auch die in M. 1699 gegenüber seiner echten Vorlage M. 1541 vorgenommenen Interpolationen in dem Kemptener Spurium wiederkehren. Die Thatsache nun, dass M. 1699 auch von dem Reichenauer Fälscher des beginnenden 12. Jahrhunderts für den Abschnitt über die Aufener Klosterleute in einer angeblichen Urkunde K. Arnolfs, M. 1766 $6_{2}$ (Brandi n. 39), in gleicher Weise benützt worden ist, wie wir es bei M. 157 beobachten konnten, wird den Sachverhalt klären helfen. Ich wiederhole: Ein Kemptener Fälscher in der ersten Hälfte des 12. Jahrhunderts ist in der angenehmen Lage, auch eine passende Reichenauer Orkunde als Material heranziehen zu können; etwa zur selben Zeit thut das ein Reichenauer Arbeitsgenosse, der ibm in Schrift und Technik aufs Haar gleicht. In den beiden folgenden Theilen, enthaltend die Verleihung freier Abtwahl auch aus fremden Klöstern ${ }^{5}$ ) und die Pön, treten die stilistischen Neigungen des Verfassers

1) Der beiden Machwerken gemeinsame Lesefehler Amulbertus spricht gleichfalls deutlich für diesen Sachverhalt.

2) Vgl. Hagenmüller, Geschichte von Kempten (1840) 1, 21 und dazu L. Baumann, Zur älteren Geschichte des Stiftes Kempten in Zeitschr. für Schwaben und Neuburg 2, 230, wieder abgedruckt in Baumanns Forschungen zur schwïbischen Geschichte, Kempten 1898.

3) MG. SS. 5, 99 und 100 (ad ann. 752, 759, 765, 773, 774, 779, 781).

4) Mandium war Kempten schon durch Karl d. Gr. verliehen worden; die Bestatigung durch Ludwig d. Fr. (M. 562) erwähnt ein solches Deperditum.

5) Freiheit der Wahl von eigenen Klosterbrädern hatte bereits Ludwig d. Fr. verliehen (M. 967) und Ludwig d. D. bestätigt (M. 1407); in der 
besonders deutlich herror: Reim folgt auf Reim, die Figur des Contrastes im Einzelausdruck wechselt mit der des Parallelismus in der der Satzfügnng 1). In der Androhung irdischer und ewiger Strafen begegnen wir Formeln wieder ${ }^{2}$ ), die in der Papsturkunde heimisch sind und von dort seit der zweiten Hälfte des 11. Jahrhunderts in die Kaiserdiplome Aufnahme finden. Es ist ein eigenthümliches $\mathrm{Zu}$ sammentreffen, dass der Verfasser der falschen Reichenauer Urkunde M. $1766_{2}$ auch in der Concipirung der Pön einen bis zur Wortwahl verwandten Geschmack zeigt ${ }^{3}$ ). Datirt ist diese Fälschung gleichwie M. 158 vom 0stertag des Jahres 773 zu Rom mit der charakteristischen Situationsmalerei ,in aecclesia sancti Petri coram Adriano papa et multis aliis principibus".

Der Zweck ist ein dreifacher: 1.) Verleihung von Immunität und Königsschutz für die angeblichen Schenkungen Hildegardens an Kempten im Iller-, Alp- und Augstgau, sicut in alio brevi ${ }^{4}$ ) continetur. 2.) Freie Wahl des Abtes, im Nothfille auch aus einem fremden Kloster. Gerade zu Beginn des 12. Jahrhunderts - um dieses kann es sich nur handeln - waren dem Kloster nacheinander von Heinrich V. zwei auswärtige Mönche hirschauischer Richtung als Aebte vorgesetzt worden: Manegold aus Hirschau selbst seit ca. 1105 und Hartmann aus St. Blasien, gest. $1114^{5}$ ). Die Vermuthung liegt nahe, dass man sich gegen eine Wiederholung solcher Eingriffe seitens des Königs auch in der königlichen Abtei Kempten vorzusehen suchte ${ }^{6}$ ). 3.) Verhiuderung

Ausdehnung der Wahlfreiheit eventuell auch auf Fremde ist der springende Punkt der Fälschung zu suchen.

1) Mangels einer überlieferten Reichenauer Fälschung dieses Inhalts lässt es sich nicht feststellen, ob und wie weit hier Neustilisirung für Kempten vorliegt.

2) Z. B. nisi . resipuerit, eine Reueformel, die auch in M. 447 und dem daraus abgeleiteten M. 158 anzutreffen ist.

8) Vgl. Si quis .. hoc . . statutum transgredi ac temere infringere presumpserit . ., LX libras nostrae monetae, medietatem monasterio, fisco nostro aliam medietatem persolvat, et ante tribunal divini iudicis .. reus existat (M. 157) mit: Quisquis igitur hoc statutum aliqua temeritate transgrediens . . opprimere presumpserit, ante tribunal summi iudicis reus existat ac XXX libras, medietatem nobis nostrisque successoribus, medietatem abbati persolvat.

4) Hiemit scheint jene zweifelhafte Urkunde gemeint zu sein, auf die sich das Spurium Ottos II. s. XIII. in. (DD. O. II. 325) beruft. Der Umfang dieses aus Hildegards Erbgut stammenden Besitzes war also noch Anfang des 13. Jahrh. strittig.

5) L. Baumann, a. a. O. S. 246.

6) Bezeichnend ist, dass die allerdings jüngeren und unzuverlässigen Chroniken von Kempten die Namen dieser beiden Aebte verschweigen, vgl. Hagenmüller a. a. $0.1,75$. 
lehenrechtlicher Vergabung von Klostergut ohne Zustimmung des Abtes und der Brüder.

Eine dritte hieher gehörige Fälschung für Kempten ist Jaffé Reg. Pontif. 2. ed. n. $2406^{1}$ ). Nach Ueberlieferung, Dictat und Tendenz ist auch für diese Urkunde auf den Namen Hadrians I. einheitliche Genesis mit M. 157 und M. 158 anzunehmen. Da die Urschrift verloren ist, müssen wir uns bei der Frage nach der Herstellungsart auf die aus den inneren Merkmalen zu gewinnenden Kriterien beschränken. Das echte Gepräge grösserer Formeltheile lässt auf eine Papsturkunde als theilweise Vorlage schliessen, aber nicht aut eine solche Hadrians; Protokoll wie Text weisen vielmehr auf spätere Zeit ${ }^{2}$ ).

Angesichts der Ständigkeit des Contextformulars in der päpstlichen Kanzlei halten wir uns zunächst an das Protokoll. Die Grussformel ,salutem et apostolicam benedictionem', bereits im 9. Jahrhundert anzutreffen, hat sich seit Gregor VII. ${ }^{4}$ ) zu dieser bestimmten Gestalt verdichtet; in unserer Fälschung erscheint sie noch mit der Wendung über dauernde Geltung (in perpetuum) vereint. Bereits im 12. Jahrhundert werden die beiden Formeln nach Urkundenarten differeuzirt, und die eine für litterae, die andere für Privilegien verwendet. Einen weiteren Haltpunkt für eine annähernde Zeitbestimmung der Vorlage bietet die Scriptumzeile, welche schon unter den Päpsten des 11. Jahrhunderts ungleich behandelt, nach dem Pontificate Calixtus' II. verschwindet 5). Damit ist für die Vorlage in dem Ende des ersten Viertels des 12. Jahrhunderts ein terminus ad quem gegeben, womit uns aber nicht viel gedient ist. Die Adresse (religioso abbati venerabilis monasterii, quod vocatur $N$. et per ipsum in eodem monasterio degentibus monachis etc.), der Titel des Papstes in der Datirung (pontificatus vero domni Adriani summi pontificis et universalis pape) und die Contextformeln scheinen mir - soweit das bei Migne ge-

1) Gedruckt als Beilage.

2). Brzüglich der bisher von der Papstdiplomatik stiefmütterlich behandelten inneren Merkmale ist man darauf angewiesen, sich vielfach erst selbst mühsam einigermassen zurechtzufinden; namentlich gilt das für jene Zeit, in der der Gebrauch des Liber diurnus schon stark abnimmt, die Herrschaft der Kanzleiordnungen aber noch nicht begonnen hat. Abgesehen von Ulysse Roberts Specialarbeit über Calixtus II. wird man deshalb noch immer en Pflugk-Harttung, Die Urkunden der päpstl. Kanzlei vom 10.-13. Jahrh., greifen müssen. A. Girys Bemerkungen im Manuel de diplomatique sind für derartige Zwecke zu allgemein.

3) Die Arenga, Convenit apostolico moderamini schon im Liber diurnus ed. Sickel $59 n^{0} 64$.

4) Vgl. Pflugk-Harttung in Archiv. Zeitschrift 6, 12.

s) Pflugk-Harttung, a. a. O. 15. 
druckte Material an Papsturkunden einen Schluss erlaubt - eher für das 9. oder 10, als für das 11. oder 12. Jahrhundert zu sprechen. Am meisten Aehnlichkeit finde ich mit Privilegien Johauns VIII. (872-882), unter dem auch ein scriniarius Gregor nachweisbar ist. Da begegnet man $z$. B. in J.-E. 3053 ausser der gleichlautenden Arenga auch einer der Papsturkunde fast ganz fehlenden Publication mit wörtlicher Uebereinstimmung: Igitur omnibus sanctae dei ecclesiae fidelibus et nostris praesentibus et futuris notum fieri volumus ${ }^{1}$ ); ebenso verhält es sich mit dem formelhaften Theil der Narratio. Zur Eiuleitungr der Pön in der Kemptenerfälschung (Statuimus preterea apostolica censura sub divini iudicii obtestacione et anathematis interdictu etc.) vergleiche man beispielsweise J.-E. 3033 oder 3110. Der substantivische Beginn des positiven Theiles der Strafformel (Observatores etc.) wird im 11. Jahrhundert allmählich von dem Particip (Servantibus, conservantibus) abgelöst. In J.-E. 2406 sind demnach echter Herkunft die Arenga, zum Theile Schutz- und Pönformel mit der Verheissung ewigen Lohnes. Die Androhung irdischen Mühsals (fiat habitacio eius deserta bis contraria) als verstärkende Ergänzung der ewigen Strafen entuahm der mönchische Fälscher seinem Psalmengedächtnis ${ }^{2}$ ).

Nach Ausschälung der echten Bestandtheile tritt in Stil und Tendenz der Fälscher von M. 157 und M. 158 auch hier deutlich hervor. Die Localisirung der Handlung nach Rom in den April 773 bei Anwesenheit Karls, Hildegards und vieler Fürsten ${ }^{3}$ ) erinnert unmittelbar an die beiden auf Karls Namen getauften Urkunden. Zu der aus echter Vorlage entlehnten Schutzformel sind als eigentlicher Zweck Bestimmungen gekommen, welche 1.) den Abt gänzlich von der königlichen Heerpflicht befreien ${ }^{4}$ ), 2.) die lehenrechtliche Vergabung des Klosters oder seines Besitzes sowie alle Entfremdung von Klostergut dem Kaiser und jedem andern untersagen, welche endlich 3.) die freie Wahl eines Abtes aus der Mitte der Klosterbrüder oder auch von auswärts sichern sollen ${ }^{5}$ ). Die Thatsache, dass dem Fälscher bei seinem Werke auch eine Papsturkunde vielleicht ans dem 9. Jahrhundert vorlag, erklärt uns auch die curialen Elemente in Schrift und Dictat von M. 157 und M. 158.

1) Eine Promulgation auch in J.-E. 3033, vielleicht durch den Einfluss der fränkischen Königsurkunde zu erklären. Jobann VIII. zählte auch in der Datirung nach Kajserjahren Karls III., vgl. Bresslau, Urkundenlehre 837.

2) Vgl. Psalm 68, 26;108, 9 und 10.

3) In Narratio und Eschatokoll.

4) Vgl. M. 158 und dazu oben S. 42.

5) Vgl. M. 157 und dazu S. 44. 
Strassburg. In unverkennbarem, wenn auch noch wenig beachtetem Zusanmenhang ${ }^{1}$ ) mit den oben besprochenen Erzeugnissen stehew die beiden Spuria, die sich das Strassburger Domcapitel im 12. Jahrhundert als Schutzwehr gegenüber seinem Bischof anfertigen liess: M. 154 und J.-E. 2401. Auch hier mussten die Namen Karls d. Gr. und Hadrians I. herhalten. M. 154 kennen wir nur aus Schilters Druck der Chronik Jakobs von Königshoven; es ist daher auch nur von Seite der inneren Merkmale zu fassen. Nicht minder als das Eschatokoll vergleicht sich das Dictat des Textes mit M. 447 $=$ M. $158^{2}$ ) und M. 157, soweit die Verschiedenheit des Inhaltes es nur irgend erlaubte. Man beachte:

\section{154.}

Cam principem ac defensorem ecclesiarum nos fecit dominus, ne gratiae eius videamur esse ingrati, servitium eius augmentare, bene et oportune instituta confirmare, emendanda reformare et sedata ubique discordia pacem concordiam et tranquillitatem nos oportet restaurare.

Idcirco notum sit omnibus fidelibus nostris praesentibus scilicet et futuris, qualiter Etto venerabilis sanctae Argentinensis ecclesiae episcopus folgen die Intervenienten coram multis principibus celsitudinem nostram adiit flebiliter conquerens, suorum plerosque antecessorum episcoporum scilicet cum suis quibusdam canonicis ... ecclesiastica potestate tantum abuti, ut, cum deberent simoniacae haeresis veri exstirpatores esse, imprudenter effecti sint iniuriosi defensores.

.. placuit nostrae et astantium providentiae

.. Bertoldo .., qui advocatias .. coram multis principibus amisit.

Da uns eine Reichenauer Fälschung über freie Abtwahl, welche in demselben Verhältnis zu M. 157 stünde, wie M. 447 zu M. 158,

5) Nur Mühlbacher macht auf die Uebereinstimmung in Recognition und Datirung mit den Kemptener Fälschungen aufmerksam.

2) In den kleinen Differenzen zwischen M. 447 und M. 158 steht M. 154 auf Seite von M. 447, weshalb ich dieses als Vergleichsobject wähle. 
nicht erhalten ist ${ }^{1}$ ), können wir den Rest des Strassburger Spuriums nur dem inhaltsgleichen Passus des Kemptener Stückes (M. 157) gegenüberstellen.

M. 154: Praecipimus quoque, ne . M. 157: Quando autem presens vel defuncto priore aliunde veniens, sed post eum aliquis pater . . migraverit, de ipsius gremio, "si reperitur idoneus, non aliunde veniens ibi albas constiepiscopus eligatur: sed si nnllus ibi tuatur, sed ab ipsis monachis eiusdem dignus, quod minime eredimus, inveniatur, tune primum alter aliunde assumatur ...

Bezeichnend für das Dictat ist die hier wie dort vorkommende Bezugnahme auf eine Besitzurkunde mit: in alio brevi.

M. 154: . . res in alio brevi determinatas

Si quis autem episcopus (!) dux iudex potens vel impotens, spiritalis vel secularis hoc nostrae dispositionis et confirmationis decretum mutare et violare praesumserit et memorati episcopi possessiones minuere aut ullas violentias vel perturbationes pro his statutis nostris inchoare tentaverit, centum libras auri optimi persolvat, medietatem fisco nostro, triginta archimandritae Mloguntino, viginti Argentoratensi ecclesiae.

M. 154.
Signum domni Karoli magni et serenissimi regis Francorum.

Amalbertus cancella- Amulbertus calcella- $*$ * Amulbertus cancellarius ad vicem Liutperti rius ad vicem Liutperti rius ad vicem Luitperti archicancellarii recognovit archicancellarii recognovi archicapellani recognovi et subscripsit anno domi- et $*$ (SR). nicae incarnationis 773 , indictione 11 , anno gloriosissimi Caroli 5.

Actum Romae in sancto

\begin{tabular}{r|r} 
Actum Romae in sancto & Data anno ab incarna- \\
die paschae ipso papa & Data anno ab incarna- \\
Adriano sedente in sede) indictione XI., anno vero & tindictione XI., anno vero
\end{tabular}

\begin{tabular}{c|c} 
Actum Romae in sancto & Data anno ab incarna- \\
die paschae ipso papa & Data anno ab incarna- \\
Adriano sedente in sede) indictione XI., anno vero & indictione XI., anno vero
\end{tabular}

') Ueber die Frage, ob nicht auch eine solche gleichzeitig fabricirt worden sein dürfte, rgl. $\mathrm{S} .83 \mathrm{f}$.

M. 157: . . sicut in alio brevi continetur, donavit.

$\mathrm{Si}$ quis vero spiritualis vel secularis, potens vel impotens, magnus vel parvus hoc nostrae auctoritatis statutum transgredi ac temere infringere presumpserit et res eiusdem monasterii inutiliter distraxerit et ab usu abbatis et fratrum aliquo modo sine sua et fratrum permissione alienaverit, LX libras nostrae monetae, medietatem monasterio, fisco nostro aliam medietatem persolvat.

M. 158.

M. 157. et $(\mathrm{SR})$. * Signum domni Karoli Signum domni Karoli (M) serenissimi impera- (M) Magni, imperatoris toris augusti. augusti. 
sua;

|regni piissimi Karoli VI., |regni magni Karoli VI, imperii primo; $\quad$ inıperii primo;

in dei nomine felici- Actum Rome in sancto Actum Romae in sancto ter amen. Data Romae die puscae in aeclesia die pascae; feliciter amen. 14. kalendas maii. sancti Petri coram Adriano
papa et multis aliis prin-
cipibus; in dei nomine
feliciter amen.

Der in M. 154 auftretenden Intervenienten Lull ron Mainz und Johannes von Konstanz gedenkt auch Hermannus contr. anlässlich ihres Hinscheidens bei den Jahresnotizen von 781 und 786 . Den Reimklang wird jedermann hören, der die Urkunde laut liest.

Ich schliesse hier auch gleich meiue Beobachtungen über Composition und Dictat der Strassburger Hadrianfülschung an, um dann in einem über Zweck und Zeit beider zu hancleln.

J. -E. 2401, als Insert einer Urkunde des Bischofs Heinrich von Strassburg aus dem J. 1205 überliefert, verdaukt seine Entstehung zweifellos derselben Zeit und Fabrilk wie M. 154. Fassung und Tendenz berühren sich auf das engste. Minder handyreiflich, aber umso merkwürdiger ist das Verhältnis, in dem auch diese zweite Fülschung des Strassburger Domcapitels zu den gleichzeitigen schwäbischen, insbesondere zu den Kemptener Erzeugnissen trotz der Verschicdenheit der erstrebten Rechte steht. Mit theilweise echten Formeln am Eingang und Abschluss verbrämt, ist der Kern der Urkunde, die Narratio und Dispositio, im wesentlichen frese Fälschererfindung. Von dem mageren Protokoll erlaubt nur die arg verstïmmelte Scriptumzeile 1) einen Rückschluss auf die Zeit der Vorlage. Püpstliche Bibliothekare in der. Eigeuschaft als Kanzleileitrr sind vom Ende des 8. bis zum Ende des 11. Jahrhu derts nachzuweisen, solche des Numens Zacharias kennen die Juffé'schen Listen nur in 9. Jalırhundert.

Und nun vergleiche man J.-E. 2401 für Strassburg mit J.-E. 2406 für Kempten.

\begin{tabular}{l|l} 
J.-E. 2401. & J.-E. 2406. \\
Adrianus episcopus servus servo- & $\begin{array}{c}\text { Adrianus episcopus strvus servo- } \\
\text { rum dei folgt Adresse und Gruss. } \\
\text { Convenit apostclico morterumini pia }\end{array}$ \\
Convenit apostolico moderamini pia & $\begin{array}{l}\text { Con } \\
\text { religione pollentibus benivola com- }\end{array}$ \\
passione succurrere ac poscentium ius pollentibus benivola con- \\
passione succurrere et poscentium \\
alacri devotione impertiri assensum.
\end{tabular}

1) Da der Bibliothekar sicherlich nicht selbst als Schreiber fungirte, so haben wir in .Scriptum per manum / Zacharie sanıte Romase sedis bibliotecarij zwei an sich echte Theile in unechter Verbindung vor uns. 
Igitur omnibus sancte dei ecclesię $\left\{\begin{array}{l}\text { sensum folgt eine Fortsetzung der } \\ \text { Arenga. } \\ \text { Igitur omnibus sanctę dei ecclesię }\end{array}\right.$ fidelibus presentibus scilicet ac futu- filelibus pręsentibus scilicet et futuris notutin esse volumus, quie venerabilis frater as coepiscopus noster Argentoratensis Etho nowine coram dilectissimo filio nostro Karolo rege Francorum nostro suggessit apostolatui.

Scriptum per manum Zacharię sanctę Romanę sedis bibliotecarii; actum Rumę in 2. feria pasche an no incarnationis domini $773^{\circ} \mathrm{co-}$ ram multis principibus feliciter. ris nutum esse volumus, qualiter dilectus et spiritualis filius noster Karolus gloriosus rez et imperator et patri.ius Romanorum cum sua cara coniuge Hildegarda et aliis multis prin ipibus suggessitnostro apostolutui. Scriptum quidem est per marum Gregorii notai ii et scriniarii huius Romanę sedis et apostolice in mense aprili, indictione undecima, luna XX prima, an no ab incarnatione domini UCCLXXIII', pontificatus vero dumni Adriani summi pontifi is et universalis papę secundo, pręsente Karolo imperatore et Hillegarda imperatrice et aliis innumerabilibus feliciter amen.

Wean - was auf Grund der nachfolgenden Ausführungen möglich - für beide Hadriaufälschungen eine und dieselbe echte Papsturkunde als Vorlage gedient hat, so zwar, dass der Verfasser für das Eschatoholl dur einen den notarius et scriniarius Gregor, für jenes der anrleren den bibliothecarius Zacharias ans ihr entlehnt hätte, so würden die zwei Namen und Titel bestimmter auf eine Urkunde Johanns VIII. hinweisen. Unter dessen Pontificat fungirten nach den Jaffé'schen Listen zwei solche Männer in diesen Stellungen. Ich gebe dieser Möglichkeit mit aller Reserve Ausdruck.

Bei den Strassburger Fälschungen glaubte ich die Parallelstellen dem Streben nach Kürze nicht opfern zu dürfen. Kein Unbefangener wird die (iesammtheit der Uebeleiustimmungen mit den schwäbischen Fubrikaten einem Zufall zuschreiben wollen ${ }^{1}$ ). Die Thatsache ist da; aber die Erklärung dafür? Verhältnismässig einfach wäre diese noch, wenn sich die Coucordanzen auf die Kemptener Stücke allein bezögen. Es hat sich aber bei der Strassburger. Karlsurkunde gezejgt, dass sie in einzelnen Diverongen zwischen M. 158 und M. 447 der letz-

4) Der Zusammenhang wird besonders klar, wean man z. B. die Fälschungen für das Strassburger Kluster St. Stephan M. 1086 und M. 1369 mit denen für das Dumapitel vergleicht; obwohl in der Tendenz den schwäbischen Urkanden naher stebend (Vogtei), zeigen sie formell keine Deckungen; vgl. uber sie, die gleichfalls dem 12. Jahshundert angehören, Wiegand in Zeitschrift f. Gesch. des Oberrheins N. F. 9, $387 \mathrm{ff}$. 
teren, einem Spurium für Reichenau, näher steht. An den Kemptener Fälschungen können wir in der Schrift und in der Fassung des Protokolls das Strehen des Verf rtigers beobachten, seinen drei Machwerken bei aller Gleichheit ') den verrätherischen Stempel einheitlicher Herstellung durch Variationen in Kleinigkeiten zu nehmen. Dasselbe Trachten lassen die Eschatokolle der Strassburger Spuria unter sich und gegenüber ihren Kemptener Verwandten erkennen. Der Kemptener Mönch wie der Strussburger Canonicus wähnten Karl d. Gr. im J. 773 beim Papste zu Besuch in Rom; Hermann der Lahme konnte ihnen diesen Irrthum beigebracht haben. Auch ihren Bedarl an Personennamen für die auftretenden Intervenienten vermochten die beiden nicht miuder als ihr gleichstrebender Rtichenaner Genosse bei dem genannten Chronisten mühelos ${ }^{2}$ ) und voliständig zu decken. In der Verwendung der Reimprosa wetteifern sie alle.

Unverkeunbar ist die Tendenz, welche das Domcapitel in Strassburg mit den zwei Urkunden verlolgte: Eine Handhabe zu gewinnen gegen missbräuchliche Ausnüitzung der Machtfülle seitens des Bischofs und seiner geistlichen Beamten. Durch äie zu selbständigen Plründen gewordenen Antsstellen war ein grosser Theil der Einküufte den übrigen Canonikern entzogen worden. Um dem für die Zukuuft vorzubeugen, bestimmt M. 154: Der Eigenbesitz der Neueiutreteuden, in Ermanglung eines solchen wenigstens 7 Pfund, soll den "Brüdern" zufallen; 3 Unzen Goldes davon werden dem Bischof und Propst ververgönnt ${ }^{3}$ ). 2. Die Wahl eines Bischofs, aus der eigenen Mitte wie auch im Nothfalle von auswärts, steht unbeschadet der päpstlichen "Majestäts" - und der köuiglichen "Ehrenrechte" ausschliesslicn dem Capitel zu; zu den erforderlichen. Eigenschaften des Neugewählten gehöre auch die, dass er nicht ,patrum traditiones destruendo alicui fiat offensus vel molestus'. 3. Bischofs- und Capitelbesitz sei vollständig zu trenwen und stehe die Verfügung über letzteren nur dem Propst und den Canonikern zu.

J.-E. 2401 bestimmt die Rechte der sieben von Bischof Hetto eingesetzten Archidiuconen des Strassburger Sprengels; darunter auch ihre Unabsetzbarkeit, ausser im Falle eines nach dem ius canonicum zu ahndenden Verbrechens. Verbietet 2. jede Einmischung des Bischofs in Angelegenheiten des durch die Gütertheilung dem Kloster

1) Vgl. insbesondere die Datirung.

2) Die Notizen zu den betreffenden Jahren umfassen in der Ausgabe der Mon. Germ. nicht einıal eine ganze Seite.

3) Von rührender Naivetät ist die Begründung : ,Da sie ja doch die Herren nond Meister seien ${ }^{\alpha}$. 
zugewiesenen Besitzes. 3. Der Bischof darf dem Capitel nur einen diesem genehmen Propst vorsetzen, welchem es obliegt, die Vermögensinteressen seiner Mitcanoniker sorglich zu wahren und insbesondere alle Präbenden unter dieselben zu vertheileu ${ }^{1}$ ).

4. Anlässlich jedes Amtswechsels bei den in bischöflicher Nutzung stehenden Regalien sollen gemäss königlicher Schenkung dem Propste drei, der.Gesammtheit der Canoniker vier Pfund abgeliefert werden. Gelingt es uns, diese beiden interessanten Fälschungen zeitlich näher zu fixiren, so erhalten wir aus ihnen einen wichtigen Einblick in die innere Geschichte des Strassburger Domstiftes. Wann hatte im 12. Jahrhundert das Capitel Veranlassung, solche Cautelen gegenüber seinem Bischof anzuwenden? Unsere Quellen ${ }^{2}$ ) berichten von einem tiefgehenden Zwist mit dem Bischof Kuno (1100-1123), gegen den das Domcapitel mit scharfen Worten sogar die Hilfe des Papstes anrief: Im Jahre 1123 ward er abgesetzt und vertrieben.

Diese Ansetzung wird auch dadurch gestützt, dass die eben behandelten Strassburger Urkuıden bereits in M. 1768 für oder besser gegen Ebersheim benützt zu sein scheinen $\left.{ }^{3}\right)$. Dopsch ${ }^{4}$ ) setzt dieses angebliche Diplom König Arnulfs in die Mitte des 12. Jahrhunderts, eher früher als später. Es bedeutet die Antwort des Strassburger Bischofs auf die in M. 768 zum Ausdruck gebrachten Exemtionsbestrebungen des in seiner Diöcese gelegenen Klosters und scheint in Strassburg unmittelbar auf Veranlassung und in Kenntnis der Ebersheimer Spuria M. 135 und M. 768, welche man dem Bischof als Beweismittel vorgehalten haben mag, hergestellt worden zu sein. Be-

1) Vgl. Hinachius, Kirchenrecht 2, 91.

2) Cod. Udalrici bei Jaffé, bibl. rer. Germ. 5, 254 n. 137 (wieder abgedruckt im Strassb. Urk.-B. 1, 54); Annales Argent. ad a. 1123 in MG. SS. 17, 88; Annalista Saxo ad a. 1123 in MG. SS. 6, 759.

s) Ausser dem ausschlaggebenden Gleichlaut der Pönformel in M. 154 und 1768 vergleiche den Passus über freie Abtwahl in M. 1768 (non aliunde veniens ibi abbas constituatur, sed ab ipsis monachis eiusdem congregationis . . eligatur et abbas constituatur, nisi forte, quod absit, nullus illic idoneus inveniatur. Tunc prinum alter aliunde, non tamen sine fratrum electione assumatur) mit dem ent.sprechenden in M. 154 (ne . . aliunde veniens, sed de ipsius gremio, si reperitur idoneus, episcopus eljgatur, sed si nullus ibi dignus, quod minime credimus, inveniatur, tunc primum alter aliunde assumatur); ferner die Stelle über die Unabsetzbarkeit des Abtes in M. 1768: (sed nunquam postea deponatur, nisi forte, quod «bsit, tanto ac tali facinore innodetur, quod ... ecclesiastico ordine privetur ac degradetur) mit jener, die Archidiaconen betreffenden Be-timmung in J.E. 2401 ( . . nisi forte, qnod absit, talibus facinoribus innodarentur, quod iure canonico ab omni episcopali vicaria merito deponerentur).

$\left.{ }^{4}\right)$ In dieser Zeitschr. 19, 603, vgl. 596. 
züglich M. 1768 sei nebenher bemerkt, dass die Exemtionsfrage noch am Ende des 17. Jahrhunderts den Gegenstand einer vom Ehersheimer Abt Bernard seinem Ordinarius, dem Fürstbischof Wilhelm Egon von Strassburg (1682-1704) erstattenen ,Informatio status A primonasteriensis coenobii ..., prout eundem in suis documentis reperit', (Strassb. Bez.-Arch. G 1276) bildete. Grandidier erlaubte sich in seinem Druck willkürliche verbessernde Correcturen.

Ottoheuren. Von den ins 12. Jahrhundert gehörenden Fälschungen für dieses Kloster füllt in den Bereich unsırer Frage hauptsächlich eine angebliche Urkunde Karls d. Gr., M. 132; für die übrigen, sowie für das Verhältnis dieses Stückes zu jenen, verweise ich auf melne Bemerkungen im Excurs „Zur Kritik der älteren Geschichtsquellen von Ottobeuren" S. 96 ff. M. 132 ist eine formell und sachlich erweiterte Fassung eines älteren, vor 1145 hergestellten Spuriums ${ }^{1}$ ). Hier interessirt uns besonders der ursprüngliche Text. Ausser kleineren formellen Interpolationen halte ich die zweite Arenga (Unde quidquid pertinere confidimus), wie auch die Bestimmungen über Abtinvestitur (nobisque ac successoribus - liberrimam habere) und Zollfreiheit (Amplius presenti - transeant et pergant) für spätere (Ausgang des 12. Jahrhunderts) Zuthat. Der Rest scheint im Wesentlichen ${ }^{2}$ ) die primäre Form von M. 132, M. 132 A, zu repräsentiren. Für das Eingangsprotokoll, die (erste) Arenga, Vogteibestimmungen und Corroboratio diente zweifellos M. 158 (Kempten) als Vorlage. Aber auch die anderen einheitlichen Kemptener Fälschungen dürften dem Ottobeurener Mönche nicht ganz unbekannt geblieben sein, wenn es erlaubt ist, diesen Schluss aus dem an die Kenptener Hadrianurkunde erinnernden Nachsatz der Arenga (potestati regali convenit tuitionem inpertire) sowie aus der mit M. 157 gemeinsamen Fürbitte Hildegards zu ziehen; mit M. 157 theilt M. $132 \mathrm{~A}$ in seinem ersten Abschnitt auch die Tendenz: Schutzrerleihung und Freiheit der Abtwahl. Im übrigen ist die Formulirung unabhängig von M. 1507 und enthält echte, aber jüngere Fragmente.

In Kenıten hatte man für die beiden Hauptzwecke, Freiheit der Abtwahl und Vogtrecht, zwei gesonderte Fälschungen auf Karls d. Gr. Namen verfertigt; die Ottobeurener fassten beide in eine m gleichnamigen Stück mit theilweise gleicher Formulirùg zusammen. Den

3) Beweis dafür im Excurs.

") Mag: sein, dass auch der förmlich angeleimte Passus ,ac si alique cause adversus eum aut honines ipsius monasterii surrexerint, quas infra pagum cum fidelibus suis deffinire non potuerint, in presentiam nostram reserventur' erst nachher eingefügt worden ist. 
Ministerialen schenkte Ottobeuren grössere Aufmerksamkeit and liess für sie die nämlichen Rechte gelten, wie sie ihre Stitudesgenossen in Fulda und Reichenau hatten.

Buchau. Für M. 674, eine angebliche Urkunde Ludwigs des Frommen, hat jetzt als relativ beste Deberlieferungsform das Register Friedrichs IV. cod. P f. 244 im Wiener Haus- Hof- und Staatsarchiv zu gelten, wo die Fälschung, einer Urkunde Karls IV. inserirt, eingetragen ist. Daneben behält die Stuttgarter Copie des 17. Jahrhuuderts immer noch selbstäudigen Wert. Wir sind auch hier auf die aus den inneren Merkmalen zu gewinnenden Indicien angewiesen. Das echte Eingangsprotokoll verräth Beuützung eines Diploms Ludwigs d. Fr. und zwar - wenn wir in nos propitiante eiue Verderbung von ursprünglichem repropitiante sehen dürfeu - aus den Jahreu 834-840. Von einem solchen Diplom für Buchau mangelt jede Kunde 1). Wohl aber kann für die Beurtheilung der Composition die Thatsache von Bedeutung sein, dass Reichenau damals in M. 960 eine Originalurkunde Ludwigs aus dem Jahre 839 besass, welche ausser dem gleichen Eingangsprotokoll anch noch wörtlich dieselbe Arenga, Publication, sowie wesentliche Uebereinstimmungen in der Schenkungsformel aufweist; die Pertinenz von M. 674 ist durch sichtliche Interpolation wie terra salica verunechtet ${ }^{2}$ ).

Zwischen die in M. 674 nun folgende Verleihung von Immunität und ausschliesslicher Gerichtsbarkeit über die Zinsleute (Constituimus - possidere) und den entsprecheudeu dispositiven Theil ron M. 157 für liempten (constituentes - possidere) darf man das Gleichheitszeichen setzen. $O b$ dieser wörtliche Gleichlaut durch unmittelbare Benützung von M. $155 \mathrm{zu}$ erklären sei, oder ob nicht vielleicht beide aus einer allem Anschein nach gefertigten, aber nicht erhalteuen Reichenauer Parallelfälschung ${ }^{3}$ ) schöpiten, muss dahingestellt bleiben.

Der nächste Abschnitt, das Vogtrecht enthaltend, steht der Reichenauer Fälscliung M. 447 näher als einer auderen Urkunde derselben Tendenz, einzelne Sätze wie ,ius habeat - satisfecerit' finden wir in dieser Fassung nur dort wieder. Dass diesem Theil des Buehauer Spuriums gerade M. 447 zugrundeliegt, geht aus der in M. 447 völlig sinngemässen, in M. 674 aber überflüssigen und uypassenden Fügung

1) Ueber die wahrscheinliche Gründungszeit Buchaus vgl. Württembergische Kirchengeschichte (heraung. vom Calwer Verlagsverein, 1893) 68.

2) Dass die Concordanzen des Buchauer Spuriuras mit M. 961 für Lindall bereits auf M. 674 als Grundlage für M. 961 zurück gehen, hat schon Brandi a. a. 0. 1:2 zur Evidenz gezeigt.

э) Vgl. unten S. 83 meine Bemerkungen zu M2. 230. 
,ipse adrocatus' deutlich hervor. Danehen sind im Detail Congruenzen mit M. 158 an vou M. 447 abweicheuden Stellen (duorlecim equos; honeste procuretur) nicht zu übersehen. Von ,Quodsi ultra statutum an bis zum Schlusse der Dispositio ist das Dietat sowohl gegentiber den beiden Kemptener (M. 157, M. 158) als im Verhältnis zur Reichenaner Fülschung (M. 447) ziemlich frei. Trotzdem fusst der Verfisser auch bei diesem neustili,irten Theil neben M. 447 nameutlich auf 1. 157; in den Bestimmungen über Freiheit der Aebtissinwahl entspricht dem pater $(=A b t)$ von M. 157 eine mater in M. 674. Beiden gemeinsam ist auch die auf Beschränkung des freien Verfügungsseehtes des Abtes, bzw. der Aebtissin abzielende Tendenz bei Vergubung ron Klostergut. Dabei ist den speciellen Verhältnissen des Franenklosters Buchau Rechnung getragen: die Aebtissiuwahl steht Nonnen, Clerns und Volk za, unter den an der Erhaltung des Klosterbesitzes Interessirten wird ausser den sorores auch noch der fratres ${ }^{1)}$ gedueht. Die Corroboration kann einer echten Urkunde Ludwigs d. Fr. entnommen sein; vielleicht derselben, welche die unzweifellraft echte, ins Itinerar sich genau einfïgende Datirung (819 Juli 22 Ingulheim) lieferm musste. Die Auflösung der Bnchauer Fälschung in ihre Bestaudtheile, verbunden mit dem Versuch, deren Provenienz festzustellen, erlaubt mit grosser Wahrscheinlichkeit den Schluss, dass der Verfertiger für sein Werk folgendes Material verwendete: 1. An echten Diplomen : ein Deperditum Ludwigs d. Fr. von 819 Juli 22 unbekannten Inhalts für unbekannten Empfänger (möglicherweise für Buchau selbst 2); M. 960 für Reichenau (?) 2. Die Fälschungen M. 157 und M. 158 (Kenipten); M. 447 (Reichenau). Zur Pön vergleiche M. 1361 für Rhe nau.

Ausser der wohl echten Schenkung verfolgt M. 674 folgende Zwecke: 1. Immunität and ausschliessliche Gerichtsbarkeit der Aebtissin und des Stiftsvogtes über die Zinsleute. 2. Fixirung der Befugnisse des Vogtes und seiner Bezüge. 3. Freiheit der Aebtissiuwahl, insbesoudere gerichtet gegeu willkürliche Vorsetzung einer Fremden. 4. Verbot, Klostergüter dem klösterlichen Haushalt zu entfremden.

Der Inhalt der Fälschung wurde iu grossentheils wörtlicher Wiederholung von Otto IV. 1239 Jan. 29 (Böhmer-Ficker Reg. V. n. 264) bestïtigt:

1) Damit sind die die priesterlichen Functionen in Buchav besorgenden Cleriker gemeint.

2) Es wäre dies das älteste Zeugnis für die Existenz des Klosters Buchan; diese Urkunde hätte wahrscheinlich die Schenkung der Villa Mengen und der Kirche in der Villa Saulgan zum Gegenstande gehabt und wäre' auch für die Pertinenz benützt worden. 
Halten wir kurze Rückschau. Aus der textlichen Beschaffenheit der Fälschungen' liess sich zunächst die zeitliche Folge ihrer Herste!lung nit ziemlicher Sicherheit erschliessen. Reichenau führt mit M. 447 den Reigen. Für Kempten ist dieses Reichenauer Fabricat, sowie ein solches des 10. Jahrhunderts, gleichfalls aus Reichenau, schon benützt. Dem Strassburger Fülscher haben entweder das Reichenauer Vogtrecht und die Kemptener Stücke (M. 157 und J.-E. 2406) vorgelegen oder - was auch möglich wäre - es existirten ausser M. 447 noch je eive Reichenauer Parallelfälschung zu M. 157 und J.-E. 2406, die ihm zur Hand waren. Für Ottobeuren erlaubt der überarbeitete Zustand, in dem das Spurium M. 132 jetzt vorliegt, keinen, haltbaren Schluss. Der Verfasser der Buchauer Crkunde war in der Lage, nicht nur die zweckdienlichen Reichenauer und Kemptener Falsificate zu verwenden, er zählte auch zwei echte Diplome Ludwigs d. Fr., darunter ẹines wahrscheinlich für Reichenau, zu seinem Materiale. Eklektisch vorgehend legte er seine Wünsche in einem Stück nieder.

Die Thatsache, duss die späteren Fälschungen. Bekauntschaft mit der Melirzahl ihrer Vorgängerinnen zeigen, sowie die Vieiheit der Tendenzen schliesst die Erklärung der Uebereinstinımungen mittels einer allen gemeinsamen, aher in ungleicher Auswahl verwerteten Musterrorlage aus; es hätten fast ebensoviele solcher. „Schimmel ${ }^{\text {a }}$ von Kloster zu Kloster wandern müssen, als Tendenzen in den Fälschungen vertreten sind. Auch die formelle Behandlung in Stil und Gestaltung des Gesammtprotokolls zeigt trotz der Verschiedenheit der Bedürfnisse eine beachtenswerte Gleichförmigkeit. Ohne der schliesslichen. Erklärung, für die es zuvor noch der Beiziehung der weiteren, willkommener Weise in Urschrift überlieferten Spuria bedarf, vorzugreifen, steht schon jetzt fest, dass mehrere schwäbische Klöster und ein elsäs:isches Domcapitel unter gegeuseitigem Mitwissen durch Fülschungen thatsächlich besessene Vorrechte zu sichern, neue zu erreichen suchten und wenigstens zum Theil auch zu erreichen wussten. Das urkundenreichere Institut stellte den ärmeren seine Schätze zur Verfügung.

Bisher fehlte uns die Möglichkeit, auch die äussere Technik, namentlich die Schrift der Erzeugnisse für verschiedene Empfänger, zn vergleichen. Die Urschriften für Rheinau, Lindau und Stein werden in ihren äusseren Merkmalen handgreifliche Kriterien liefern und hoffentlich die Frage entscheiden.

Rheinau. M. 1361, ein Spurium Ludwigs des Deutschen, ist eine Urschrift des 12. Juhrhunderts, geschirieben auf ein radirtes echtes Diplom Ludwigs d. Fr. von 814-832, wie sich aus Resten des Re- 
cognitionszeichens von Durandus entnehmen lässt 1); ursprünglich von dem belassenen Siegel bedeckt, wurdeu sie clurch dessen Abfall sichtbar. Der erste Blick auf die Schrift lehrt Identität mit der Fälscherhand von M. $157=$ M. 158 für Kempten. Bei dem uuzeitgemässen, durch Nachahmung älterer diplomatischer Formen gekünstelten Charakter verscheucht die Gleichheit in Zug, Ligaturen, Einzelbuchstaben und Kürzungszeichen jeden Zweifel. Beschreibungen köùnen von paläographischen Dingen nie überzeugen; sie wollen gesehen werden. Ich beschränke mich daher hier auf einige Hinweise. Die Buchstabenformen von $a, c, d, e, f, g, q, r, s, t$ sind neben den charakteristischen Kürzuurgsceichen beiden Schreibern geläufig. Das sog. erste Recognitionszeichen ${ }^{2}$ ) ist nichts anderes als ein verschnörkeltes et:

Die radirte Urkunde Ludwigs $d$. Fr. lieferte Invocation und Titel. Die nur 856-857 mögliche Recognition ist einem Diplom Ludwigs d. D. entnommen. Dieselbe Recognition findet sich unter den erhaltenen echten Urkunden für die in Betracht kommenden sehwäbischen Klöster nur in M. 1383 (orig.) für Reichenau, mit dem das Rheinauer Spurium auch graphisch Verwandtschaft zeigt ${ }^{3}$ ). Der Fälscher sucht augenscheinlich seine Schrift einer echten Vorlage anzupassen; das Diplom Ludwigs d. Fr. konnte, weil zuvor ausradirt, als solche uicht mehr dienen. Von einem Diplom für Rheinan mit diesen Merkmalen wissen wir nichts; überhaupt werden innerhalb der zwei möglichen Jahre für unsere Klöster nicht viele solcher Urkunden ausgestellt worlen seim. Reichenau stellte auch sonst seinen Urkundenvorrath befreundeten Abteien zur Verfügung. Alle diese Umstände, wie anch die Thatsache, dass der Hauptstock von M. 1361 gleichfalls aus der Reichenauer Fälschung M. 447 stammt, dass höchstwalırscheïnlich Hermannus Contractus für die Intervenienten und die Datirung das Material bot: legen die Annahme einer Mitbenützung von M. $1383^{4}$ ) bei Herstellung von M. 1361 nahe. Derselbe Mann fälschte auch im Reichenauer Interesse M. 1567 und M. $1766^{5}$ ).

') Sickel im Anzeiger f. schweiz. Geschichte 2, (1874) $39 \mathrm{ft}$.

2) Vgl. Meyer v. Knonau in Quellen z. Schweiz. Gesch. 3, Rheinauer Chartular 5 .

s) Von demselben Schreiber rührt das in den Kaiserurk. VII. 7 abgebildete Diplom M. 1387 her; vgl. dort unter anderem das Kürzungszeichen.

4) Hier wird auch Abt Folchwin von Reichenau genannt, der in $\mathbf{M} .1361$ als Intervenient zu Rbeinaus Gunsten auftritt; echte Urkunden bieten kein Analogon, Kheinau und Reichenau verbindet kein Rechtsverbältnis, das eine solche lîrsprache begründen könnte, vgl. Brandi a. a. 0. 109-110.

5) Vgl. unten S. $69 \mathrm{ff}$. 
Arenga, Publication und Vogteibestimmungen lauten fast wörtlich gleich mit M. 447. Die die Narratio zierenden Fürsprechernamen Raban von Mainz, Salomon von Konstanz und Folcwin von Reichenan finden wir bezeichnenderweise sämmtlich gerade an der Stelle bei dem Rëichenaner Chronisten Heriman ${ }^{1)}$ wieder, wo dieser im Auschlusse an die Fulder Annalen von der Mainzer Reichsversammlung im J. 852 berichtet. Auf Grund der so gewonnenen Kenutnisse ward auch die Datirung: 852 Mainz coram multis principibus in generali concilio geschmiedet; Monats- and Tagesdaten gibt Heriman nicht, sie fehlen auch der Rheimauer Fälschung.

Für die Daten über die Gründung durch Wolvenes Stiftung diente wahrscheinlich das Rheinauer Diplom Ludwigs d. D., M. 1391, als Quelle; der dort fehlende Name des ersten Abtes Gozpert konute wenn nöthig - dem Fälscher aus einer Rheinaner Privaturkunde ${ }^{2}$ ) bekanot werden, nach welcher im J. 853 ein Gozbertus comes atque abba an einem Tauschgeschäft theiluimmt. Die Stelle äber die l'flichten des Abtes lässt DO. I. $418(972)=$ D0. II. 45 (973) als Vorlage vermathen.

Die Formulirung der Wahlfreiheit steht unter den zum Vergleiche vorhaudenen Fälschungen M. 157 am nächsten. In denı aus M. 447 entnommenen Abschnitt über die Vogtei sind nur die speciell für Reichenan berechneten Bestimmungen und die drei Vogteide weggelassen worden. Als positive Vergünstigung fügt die Rheinauer Urkunde hinzu: Cuiuscumque autem fidei abbas eiusdem cenobii adrocaciam nou timet committere, eidem nos et successores nostri bannum regale (!) debemus contradere. Sogar scheinbare Differenzen in Einzelheiten, wie die Einschaltungen , $\mathrm{a}$.piam' und ,eum omnibus commodis finden in M. 447 an anderer Stelle ihre Parillelen. Neu ist die am Bnde der Salierzeit aus der Papsturkunde in die Kaiserdiplome übernommene Formel: semel secundo et tercio commonitus, si non emendaverit. Die Pönformel ist in Anlehnung an M. 157 frei stilisirt.

Als Behelfe hat der Fälscher von M. 1361 also verwendet: Je ein echtes Diplom Ludwigs d. Fr. (814-832) und Ludwigs d. D. von 856-857 (vielleicht identisch mit M. 1383 für Reichenau); an Rheinauer Urkunden wahrscheiulich M. 1391 und DO. I 418 (oder DO. II. 45). Von Fülschungen benützte er M. 447 für Reichenau und ein Spurium über Wahlfreiheit mit der M. 157 eigesthümlichen Fassung;

1) Ad ann. 849-852 und MG. SS. 5, 105 .

2) Meyer v. Knonau a. a. O., Rheinauer Chart. 7 n. 3, vgl. auch Rheinauer Chart. 19 n. 4. 
M. 157 selbst scheint ihm nicht unbekannt gewesen zu sein. Bei Heriman dem Lahmen mochte er sich betreffs einer passenden Datirung Raths erholt haben.

Rheinau hat nie ein Diplom Karls d. Gr. und wohl auch keines von Ludwig d. Fr. besessen, da es allem Anschein nach erst unter Ludwig d. D. als Abtei begründet worden ist 1).

Das Interesse der Fälschung ist gerichtet:

1. auf die Wahlfreiheit. Der Abt darf von niemandem abgesetat werden, ausser er lässt sich Verbrechen zu Schulden kommen, die mit Deposition belegt sind. Die Entscheidung hierüber steht einem allgemeinen" Concil zu Konstanz oder Mainz zu. Aufdrängung eines Fremden als Abt ist verboten. Die Einschärfung der Unabsetzbarkeit des Abtes geht jedenfalls auf ein momentanes Bedürfnis oder jüngst gemachte Erfahrung der Rheinauer zurück. Es mag sich ein ähnlicher Vorfall ereignet haben wie im J. 1067, von welchem das Diplom Heinrichs IV., St. $2705^{2}$ ), berichtet: Ein Rheinaus Rechte gefährdender Eingriff des Kaisers zu Gunsten des Diöcesanbischof s. Bezieht sich vielleicht der undatirte Brief Heinrichs V. (?) ${ }^{3}$ ) auf dieses Vorkommnis?

2. auf die Vogtei. Ueber die Vogteiverhältnisse geben die im Chartular gesammelten Urkunden des 12. Jahrhunderts deutlichere Auskunft. Schon am Beginn seiner Regierung befiehlt Heinrich $V$. dem Vogte Rückerstattung des dem Kloster in der Kriegszeit entrissenen Besitzes und warnt ihn vor Ueberschreitung seiner Vogteibefugnisse. Um 1125 nahm der Streit zwischen Rheinau und seinen Vogte, dem Grafen Rudolf von Lenzburg, besonders heftige Formen an. Der Papst und sein Legat mahnten den feindseligen Grafen ${ }^{4}$ ); der Bischof von Konstanz ward von Honorius II. beauftragt, das Seine zu thun ${ }^{5}$ ). Königliche und päpstliche Privilegien ${ }^{6}$ ) bestätigten dem Kloster dessen Freiheit in der Wahl des Vogtes und Abtes.

1) Vgl. Meyer v. Knonau a. a. 0. 86 und derselbe in Neues Archiv 10, 375: ein altes Urkundenverzeichnis von Rheinan tührt als erste Privılegien solche eines. Königs Ludwig an (Anzeiger f. schweiz. Gesch. 1, 156).

2) Meyer v. Knonau, Rhein. Chart. 47 n. 32: concessimus, ut ex hac die et deinceps neque epis copus neque ulla alia persona eundem abbatem eiusque successores seu fratres inibi degentes andeat inquietare, ut liberi et quieti etc.

3) Rheinauer Chart. 55 n. 40 : Mit der Bitte um Vergebung geschehenen. Un. rechts sichert der Kaiser dem Kloster den Genuss seiner Freiheit zu.

4) Rhein. Chart. no 37, 39.

5) Ebenda no 36.

7) Ebenda 9ls n. 34 das Diplom Lothars III. 1125 Nov. 3. vgk. dazu n. 38; als n. 35 die Urkunde Honorius' II. 1126 (so wahrscheinlicher als 1125) Febr. $24=$ J.-L. 7186. 
Dieser Streit war es, der die Herstellung unserer Fälschung und die Anlegung des Chartulars veranlasste ${ }^{1}$ ): M. 1361 eröffuet die Reihe der eingetragenen Stücke. Durch die Privilegienbe.tätigungen Lothars IIL und Honorius' II. war die Rechtsfrage zu Gunsten des Klosters entschieden: die beiden Urkunden bedeuteu die Erreichung des in der Fälschung angestrebten Zieles ${ }^{2}$ ). Das Spuriuin auf Ludwigs d. D. Namen mag kurz vorher entstanden $\operatorname{sein}^{3}$ ).

Liudau. M. 961, Ludwig dem Frommen unterschoben und urschriftlich erhalten, steht vollständig auf Rasur einer nicht mit Sicherheit näher bestimmbaren 4) Urkunde. Der Fälscher zeichnete ein von Hirminmar (816-839 als Recognoscent nachweisbar) ge-

1) Aus der Einleitung des Chartulars erhellt diese T'endenz zur Genüge (vgl. namentlich a. a. O. S. 81).

2) Lothar III. bestimmt (a. a. O. S. 49): . monachi . . liberam facultatem habeant secundum deuro abbatem eligendi absque ullius terrore sive contradictione, quem etiam, si inter se non habuerint; de alio religioso eligant monasterio, qui videlicet electus nullius dicioni subiaceat, nullius superioris aut inferioris persone difficultate turbetur aut cuiuscumque districtionis sive preceptionis molestiam patiatur; folgt die Stelle auf die Pflichten des Abtes aus DO. I. 418 oder DO. II. 45 : . advocatum qurm voluerit consilio fratrum eligat ac ponat, qui nullum sibi substituat, sed ita se agat, ut si abbati displicuerit, loco cedat et alius qui melior ei visus fuerit succedat. Vgl. dazu die gegenüber M. 447 neu hinzugekommene positiv ausgesprochene Vergünstigung. Honorius II. bestimmt (a. a. 0 . S. 51): Nullus advocatus constituatur nec aliquis quolibet ingenio se ingerat vel intromittat, nisi quem abbas elegerit. Qui si in aliquo restiterit, concessa potestate careat et alium auctoritate apostolica abbas constituat. Obeunte te nunc eiusdem loci abbate vel quolibet tuo successore nullus ibi qualibet astutia vel violentia praeponatur, nisi quem fratres communi consensu vel pars consilii sanioris elegerint. gelangt.

9) Zu demselben Resultat ist auch Dopsch (Sammlungen der Mon. Germ.)

4) Denn die Echtheit des Siegels ist zweitelhaft. In einen talgartigen Klumpen, der vorne und rückwärts mit Pergament überklebt ist, ward der ron einem echten-Siegd abgelöste Siegelabdruck eingefügt. Und doch war es jedenfalls früher als die ihm ausweichende Contextschrift am Platz; Reste eines ursprünglichen Recognitionszeichens, ein noch wahrnehmbares Ludwigsmonogramm rechts neben dem jetzigen, sowie innere Gründe sprechen ebenso dafür, dass eine Urkunde Ludwige d. Fr. hatte weichen müssen. Wann das echte Siegel beschädigt und in der vorliegenden Wejse wiederhergestellt worden ist, ob in der Zwischenzeit bis zur Fälschung, ob gelegentlich der Fälschung beim Abschaben des Pergaments, ob später, darüber lässt sich nicht einmal eine Vermuthung aussprechen. Vgl. Mühlbacher, Reg. 2. Aufl. no 992, dem das Vorbandensein des ursprünglichen Monogranms entgangen zu sein scheint. Diese Frage ist deshalb von Bedeutung, weil es sich um das alteste Zeugnis für Lindaus Bestand handelt. Vgl: Hauck, Kirchengesch. 2, 550. 
schripbenes Diplom Ludwigs d. Fr. nach ${ }^{1}$ ): In Chrismon und Recognitionszeichen, wie nicht minder in der verlängerten und Contextschrift macht sich dieser Einfluss mit sprecheuder Deutlichkeit geltend. Dabei ist es ihm doch nicht gelungen, den inclividuellen Charakter seiner eigenen Schrift zu verwischen. Die meisten der dem Schreiber von M. 1361 und M. 157 eigenthümlichen Buchstabeuformen präsentiren sich auch hier dem Auge des erstaunten Betrachters. Reformirungen in hirminmarischem Sinne mussten sich vou besonders charakteristischen Zeichen gefalleu lassen die Buchstaben: f, g, r, s; neben seinem specifischen e schreibt der Mann auf gut hirninmarisch auch ein solches mit langem Anfsatz. Beim s passirte ihm manchmal ein Rückfall in alte Gewohnheiten. In Lirraturen von re, et und st, folgt er seinem Vorbild. Für die zahlreichen Kürzungen gebraucht er regelmässig seine zwei nebeneinandergestellten Haken, die aber wahrscheinlich auch auf das Vorbild Hirminmars oder späterer Kanzleischreiber zurückgrehen dürften. Gleichwie in M. 1361 schliesst er den Context mit einem weitausgezogenen $\mathrm{S}$.

Die Compositionsarbeit des Fälschers war folgende. Eingangsprotokoll uud Arenga $=$ M. 960 (orig. für Reichenau) $=$ M. 674 (spur. für Buchau); Corroloration (mit Weglassung der Handmalankündigung) und Eschatokoll (Incarnationsjahr interpolirt) $=$ M. 960. Alle diese mit M. 960 übereinstimmenden Formeln könnten möglicherweise auf ein verlorenes echtes Diplom für Lindau gleichen Datums wie M. 960 zurü lkgehen, das behufs Herstellung von M. 961 abgeschabt worden ist. Die Benützung eines solchen wird auch durch zahlreiche, in M. 960 nicht vorfindliche, echte Formeltheile *) wahrscheinlich. Gleichwohl musste der Fülscher ausser diesem eventuellen Deperditum für Lindau noch eine von Hirminmar geschriebene Urkunde als graphisches Muster herangezogen haben, weil er ja das Lindauer Diplom zuvor ausradirt haben musste: Bei seinen engen Beziehungen zu Reichenau ist am ehesten an M. $960 \mathrm{zu}$ denkeu.

Die Anwesenheit ron nonuulli principes sowie die Intervention Rabans von Maiuz und Salomons von Konstauz hat das Lindauer mit dem Rheinauer Spurium (M. 1361) gemeinsum. Eine Untersuchung

1) Vgl. sickel, Reg. 418 .

2) Das gilt für die Promulgation und den ersten bis ,Statuimus' reichenden Theil, sowie für den auf die Vogteibestimmingen folgenden Schluss des Contextes. Von ,Statuimus quoque - in perpetuum careat ist M. 674 zweifellose Vorlage. Nach den anderweitig nicht ableitbaren echten Formeltheilen zu schliessen, hätte dieses Deperditum Verleihung von Immuntät und freier Aebtıssinwahl zum Inhalt gebabt. 
der Verfüguugen über Immunität, Zinsleute, Vogtei, Pön (Statuimus careat) ergibt, dass die Buchauer Fälschung (M. 674) ausgeschrieben ist 1); die für das Frauenkloster Buchau geschaffene Compilation aus M. 447, M. 157, M. 158 wurde auch für das Nonnenstift Lindau braucbbar befunden. Dabei zeigt sich doch in dem Eiuschub gegenüber M. 674 ,sine abbatissae permissione` Benützung oder wenigstens Erinnerung an M. 447. Vielleicht ist auch diss Wiederauftauchen des Conditionalsatzes ,nisi sane resipuerit, der in M. 674 fehlt, mit M. 447 in Zusammenhang zu bringen.

So konnten wir auch in der Werkstätte des Fälschers für Lindau mit verschiedener Deutlichkeit wahrnehmen: 1. zwei echte Diplome Ludwigs, das eine für die formelle, das andere für die graphische Nachahmung bestimmt; 2. an gefälschten Urkunden: M. 674 (Buchau), M. 1361 (Rheinau), M. 447 (Reichenau). Sickels 2) Altersbestimmung der Schrift (s. XI./XII.) passt schlecht zu Brandis später Ausetzung (Sechzigerjahre des 12. Jahrhunderts ${ }^{3}$ ). Auf Grund der Identität des Fälschers mit dem des Rheinauer Spuriums M. 1361, das im Jahre 1125 bereits bestanden haben muss, weise ich M. 961 etwa den Zwanzigerjahren, jedenfalls aber der ersten Hälfte des 12. Jahrhunderts za; Sickels meisterhaft geschultes Auge hat dis Richtige getroffen. Die Urkunde trägt "spätestens dem 12. Jahrhunderte angehörende* Dorsualien.

Die Fälschung verfolgt den Zweck: 1. dem Kloster die Freiheit von Fiscalabgaben zu sichern. 2. die zinspflichtigen Leute, welche nur der Gerichtsharkeit der Aebtissin und des Vogtes unterstehen sollen, vor jedem Eingriff des Grafen zu schützen. 3. durch Regelung des Vogtrechtes, dessen Uebertretung den Verlust der Vugtei für immer nach sich ,zieht, auch gegen den eigenen Advocatus eine Waffe zu bieten. 4. die Freiheit der Aebtissiuwahl auch für den Fall der

1) Dieses Verhältnis ist erkennbar aus kleinen Aenderungen, die in M.674 gegenüber seinen Quellen vorgenommen sind; sie sind auch in M. 961 ibergegangen: ecclesias (M. 674, M. 961): villas (M. 157); sine iusta sociorum \& u 0 rum deliberacione (M. 674, M. 961): sine justa sociorum deliberacione (M. 158); mansiones seu pernoctationes (M. 674, M. 961): ac mansiones et pernoctationes (M. 447); cum ceteris commodis (M. 674, M. 961): cun omnibus commodis (M. 447). Den Ausschlag gibt die von den anderen Fälschungen abweichende Fassung des Satzes: quicquid placitanclo adquisierit, due inde partes erunt albatisse, tercia advocati, welche in M. 674 und M. 961 wörtlich gleich lautet.

2) Reg. 418.

8) A. a. 0. 112-113. 
Nothwendigkeit auswärtiger Berufung zu wahren. 5. die lehenrechtliche Vergabung von Stiftsgütern zu verhindern; die Einkünfte sollen der Aebtissin, den Schwestern und den Canonikern zukommen. Ueberhaupt soll Lindau gleiche Freiheiten und Gerechtsame besitzen wie die Kirche ron Konstanz.

Stein am Rhein. Zwei angebliche Diplome Heinrichs II. verlangen auch für dieses Kloster einen Platz in dem Rahmen unserer Untersuchung: St. 1412 und St. 1485. Beide sind Urschriften des 12. Jahrhunderts von einander gleichsehenden Hünden ${ }^{1}$ ). Der Schriftvergleich mit den gleichartigen früher besprochenen Fälschungen wird dadurch ungemein erschwert, dass der Verfertiger hier seine Normalschrift nur wenig zu verstellen brauchte, während sie in den übrigen Spuria der Karolingerzeit angepasst werden musste. Immerhin gemahnt z. B. die in den beiden Heinrichsdiplomen zu beobachtende Vorliebe für die us-Ligatur neben jener für das bedeutungsgleiche Specialzeichen und die häufige Verwendung von $v$ für $u$ an M. 961. Das in St. 1485 gebranchte Kürzungszeichen deckt sich mit jenem, das dem Fälscher von M. 1567 geläufig ist, währeud ihm dort das vermeintlich karolingiscle Zeichen trotz mehrnaligem Versuche nicht recht gelingen will. Dass hier wie in den Kemptener Stücken und in M. 1567 das t der verlängerten Schrift die üblichen Zickzackschnörkel trägt, kann wenig besagen. Ein Urtheil für oder wider die Identität der Hand mit jener der anderen Fälschungen erlauben somit die Schriftzüge nicht. Auffallend ist ein ganz vereinzeltes offenes $\omega$-ähnliches a in St. 1485 .

Vielleicht geben die inneren Merkmale deutlicheren Aufschluss über die Art des Zusammenhanges.

St. 1412 hat ein für Heinrich 1I. passendes Eingangsprotokoll; die einzige nnverdächtige Urkunde dieses Herrschers für Stein ist St. 1462, mit der unsere Fälschung des 12. Jahrhunderts Fügungen wie ,castrum Babinberch dictum. . molimur in sedem episcopatus sublimare ${ }^{2}$ ) oder per successuras etates sowie einzelne nicht ganz gewöhnliche Ausdrücke gemein hat. Sonst ist von Benützung einer echten Vorlage ujehts zu spüren ${ }^{3}$ ); desto mehr aber von Fälschungen

1) Ausser einer Photographie von St. 1412 liegen mir von Herra Professor Bresslau gütigst zur Verfügung gestellte Facsimileproben beider Urkunden vor.

2) St. 1462: intendentes . . locum Babenberc dictum in sedem et episcopatus sublimare; tain praesens etas quam et successura posteritas.

3) Ueter den Wert der Nachrichten aus der Klostergeschichte sowie über die gerade für Heinrich II. recht unwahrecheinliche reiche Dotation vgl. Bloch a. a. $0.193^{2}$ und Vetter, das Georgakloster zu Stein in Schriften d. Vereins zur Gesch. des Bodensees 13, 278. 
derselben Zeit und Tendenz. Arenga und Vogteibestimmungen lauten wörtlich gleich M. 447 für Reichenau; die Uebereinstimmungen mit M. 447 übertreffen sugar jene mit der Rheinaner Urkunde M. 1361, an die wir aber doch bei der Furnulirung der Abtsobliegenheiten, ad bene vivendum ac regulariter suos regendum ac provide omnia disponendum ${ }^{1}$ ) erinnert werden. Das dem Abte eingeschärfte Verbot, res ecclesie sue dissipare vel liberis aut quibuslibet alienis homiuibus beneficia . . imprudenter concedere, haben wir anch in M. 157, M. 674 , M. 961 angetroffen. Ueber seine intimen Beziehungen zu Reichenau klärt uns der Fälscher selbst bereitwillig bei Anführung der Iutervenienten auf: fidelium nostrorum episcoporum videlicet et abbatum favore, sed precipue Augieusi abbate Warinherio etc.; Stein war niemals in einem rechtlichen Verhältnis zu Reichenau gestanden ${ }^{2}$ ).

Das Schlussprotokoll ist erfunden. Das unmögliche ${ }^{3}$ ) Datum 1005 Oct. $1 \mathrm{Ulm}$ ist wohl gewählt, un damit anzudeuten, dass St. Georgen in Stein bereits zwei Jahre früher als das ihm vorgesetzte Bisthum Bamberg feierlich neu gestiftet worden sei ${ }^{4}$ ). Verleihung freier Abtwahl seben gleichzeitiger Unterordnung unter den Bischof hätte sich doch nicht gut ausgenommen.

A usser der ansehnlichen Güterschenkung richtet das Spurium seine Spitze in schlecht verhüllter Weise: 1. gegen den Bischof, dem Leistungsforderungen an das Kloster verboten, Einsetzung des von den Mönchen frei gewählten Abtes geboten wird. 2. gegen das Verfügungsrecht des Abtes ijber den Klosterbesitz, der nicht entfremdet werden dürfe. 3. gegen die Vö̈rte, deren Bestellung dem Abte unter Ausschluss der Erblichkeit zu.teht. 4. trifft es fumilienrechtliche Verordnungen betreffs der Steiner Ministerialen, denen erlaubt wird, Wechselheiraten mit den bambergischen einzugehen.

Bezüglıch St. 1485, das uns in einer Nachzeichnung ${ }^{5}$ ) von der

1) M. 1361: monachos suos regulariter regat, ... res monasterii intus et foris bene ordinet, omnia juxta sapientis architecti disposicitionem (!) decenter congrue ac utiliter gubernet.

2) Brandi a. a. O. 110.

3) Vgl. Pabst in Hirschs Jahrb. unter Heinrich II. 2, 45. Zwei Kanzler mit den Namen Sigefridus und Bruno finde ich nebeneinander, zudem mit Rollenwechsel, nur unter dem Gegenkönig Herinann, Stumpf Reg. S. 251.

4) Vetter a. a $0.30^{20}$. Der officielle Grüurlungstag ist höchstwabrscheinlich der Tag der Einverleibung ins Bamberger Bisthum, der 1. Novemler 1007.

. 3) Die untere rechte Ecke der Urkunde und damit die Siegelstelle ist weggeschnitten. 
Hand des Fälschers von St. 1412 überliefert ist, ist Bloch 1) zum Schlusse gekommen, dass sich einerseits „mit Sicherheit nur das Wort ,ecclesiis' als gefälscht bezeichnen lasse", dass aber andrerseits vom Inhalt doch nur soviel gewiss sei, „dass Heinrich dem Kloster eine Schenkung gemacht hat" ; sehr wahrscheinlich sei, dass diese Schenkung eine Besitzung zu Kirchen betroffen habe. Bloch erkannte die Verdachtsmomente, welche in dem graphischen Zusammenhang mit dem Spurium St. 1412, in der Stellung und Fassıng der Pön, in dem Fehlen des Ausstellortes, in der Zulassung des Zeugenbeweises und dem gerichtlichen Entscheid des Jahres 1169, in der Scheukung des ganzen locus Chilicheim gegen die Echtheit der Urkunde vom 1. Nov. 1007 vorliegen; weil er aber in den von den Bamberger Gründungsurkunden abweicheudeu Theilen den Stil des - allerdings erst seit 1013 als Kanzleibeamten nachweisbaren ${ }^{2}$ ) - Notars GB zu erkennen glaubt, erklïrt er, dass die „Fa-sung im grossen und ganzen als zuverlässig betrachtet werden" könne. Ohue die vou Blnch constatirten Uebereinstimmungen zu übersthen, suchen wir, die durch die Schriftverwandtschaft gebutene Spur verfolgend, Näheres über die Verfasser von St. 1412 und St. 1485 auszuforschen. Wie gieng der eine, wie der andere zu Werke? Zeigen sie in Stil und Mache Beziehungen zu einaudt.r oder zu bekannten Concipisten? Als echte Vorlage wurde auch bei St. 1485 die einzige echte Urkunde Heinrichs II. für Stein, St. 1462, herangezogen; sie lieferte das Gesammtprotokoll und den Anfang des Coutextes bis ,sublimando proveximus'. Auch soust konnte sie Dienste leisten, so klingt namentlich die Pön in den Worten ,si quis, quod absit . . inextiuguibili' deutlich an das Muster an. Wenn der Verfusser statt des in St. 1462 vorfiudlichen Ausdrucks, queudam nostre paterne hereditatis' zweckentsprechend deu allgemeineren ,quendam nostri iuris ac proprietatis' gei raucht, so dürfte diese Freilheit bei einem einigermassen conceptgewaudteu Dictator noch nicht zur Annahme mehrerer weiterer Vorlagen nöthigen, etwa der Bamberger Gründungsurkunden, von denen überdies die eiue nur, nostri iuris', eine andere nur, nostr.ue proprietatis' hist.

St. 1485 hat mit St. 1412, abweichend von St. 1462, Wendungen gemeinsan wie:

$$
\text { St. } 1485
$$

\begin{tabular}{c|c} 
St. 1485 & St. 1412 \\
praediisque et variis & rerum
\end{tabular} praediorum donationibus

1) A. a. O. 198.

) Bressliu, Erläuterungen zu den Diplomen Heinrichs II. in Neues Archiv 2:, 158. 
donationibus magnifice sublimavimus.

monasteriorum, inter quae unum quoddam in Alemannia iuxta ripam Rheni situm Steine vocitatum nostra dispositione constructum.

eius commendationi volumus esse subiectum.

huius . monasterii procuratores et praelati.

serenitatis nostrae praesentiam adiere.

fidelium nostrorum episcoporum videlicet et abbatum, ducum et comitum favor.

et rerum copiis undecunque provenientibus ditando amplificare.

constructionem non ignobilis monasterii in istis Alemannie partibus iuxta ripam Rheni loco Steine dicto disposuimus fieri. weiter unten per nostram dispositonem.

subicere volumus und weiter unten cura monasterii commendetur.

eius [loci] abbatibus vel procuratoribus.

placuit serenitati nostre.

fidelium nostrorum episcoporum videlicet et abbatum favore, sed ... duce Herimanno adnitente aliisque Suevie principibus vgl. dazu St. 1462: omnium nostrì fidelium tam archiepiscoporum quam episcoporum abbatumque necnon ducum et comitum consultu.

Auch die Pertinenzformel von St. 1485 scheint eine Art CompiJation aus St. 1412 und St. 1462 zu sein; St. 1485 wie St. 1412 sprechen von ,ecclesiis, villis, hominibus, censualibus, terris‘ als Zubehör.

\section{St. 1485.}

nec ipsi [abbati] liceat cu iqua m libero homini potenti aliquam exinde partem pro beneficioconcedere.
St. 1412.

[abbas] metum habeat, ne .. liberis aut quibuslibet alienis hominibus beneficia ex possessionibus inprudenter concedere presumat.

Weist somit nicht nur die nahe Verwandtschaft der Schrift, sondern auch die Uebereinstimmung im Dictat, wie endlich die Benützung derselben echten Urkunde auf eine Fälscherhand in beiden Steiner Spuria hin, so darf es uus von dem Munne, der bei St. 1412 gleichwertige Erzeugnisse für Reichenau und Rheinau zu seinem Material zählte, nicht wundern, dass er sich auch in St. 1485 vielfach eines uns nicht mehr unbekannten Wortschatzes bedient. Der beliebte Ausdruck, disponere, dispositio' ist uns schon in M. 154 (zweimal) M. 961, M. 1361 begegnet. Weiters vergleiche man:

St. 1485.

M. $154=$ M. 447 : . . celsitudiserenitatis nostrae praesentiam nem nostram adiit flebiliter adiere et . conquerentes ali- conquerens. 
quod sublementum et auctionem praediorum illuc concedi et superaddi suppliciter postulavere.
Ipsorum obnixae petitioni . . nos vota illorum benigne suscepimus et petitioni eorum ob divinae mercedis augmentum adimpleri decrevimus.
M. 157: ob .. supplicem rogatum.

M. 961: . nostram adien s celsitudinem und dignitatem nostram - postularit.

M. 1361: .. celsitudinem nostram adierunt . . humiliter deprecantes und nobis flebilitersunt conquesti.

M. 37 (zwei Fälschungen Ddalrichs unter wahrscheinlicher Benützung einer Fälschung seines Vorgängers in Reichenau):

.. ad eorum subplementum.. per nostrum incrementum ac supplementum.

M. 1567: fratrum votis ac piis postulationibus satisfacientes . . fratris donationem libenti animo accepimus et ..decernimus.

J.-E. 2406: ad mercedis nostre augmentum.

M. 37: ut . . immorentur obnixius.

Wie in St. 1485 wird auch in M. 961 für Lindau der Schiffszoll als Pertinenz zur Schenkung verliehen.

\section{St. 1485 :}

cum tributis et teloneis de navibus per Rhenum discurrentibus vel undecumque noster fiscus circumquaque illic aliquod ius exigere aut sperare deberet.

\section{St. 1485}

ad idem monasterium contradimus et transfundimus, ut . . absque contradictione habeat.
M. 961 : quicquid ex libera hereditate... fiscus noster sperare debeat in tributis, in monetis, in teloneis et navigationibus.

M. 157: illuc tradidit ac in proprium ius eiusdem monasterii transfudit.

J.-E. 2406: consistat sine cuiuslibet contradictione.

M. 154 : sine omni futura contradictione.

M. 961: quietus sine cuiuslibet contradictione.

M. 1361: bannum debemus contradere.

M. 1567 : donavit; tradidit et transfudit. 
Für das in den meisten besprochenen Fälschungen enthaltene Verbot der Entfremdung von Klostergut beguüge ich mich mit der Anführung einer Parallelstelle.

St. 1485: nec ipsi [abbati] liceat M. 674: interdicimus, ne aliquas cuiquam libero homini putenti ali- res praefati monasterii criquam in quan exinde partem pro beneficio beneficium concedat vel aliquo modo concedere vel ullo modo ab usu fra- ab usu sorornm vel fratrum deo ibi trum deo illic servientium alienare. tamulantium alienare praesumat.

Vergleichsstellen für die Corroboration anzuführen unterlasse ich, weil sie bei einer so ständigen und häufigen Formel vichts beweisen, und mache zum Schlusse nur noch auf den ganzen Tenor der Pön sowie auf einzelne bemerkenswerte Ausdrücke in derselhen (vgl. contrarius extiterit . . nisi resipuerit z. B. mit M. 157: nisi in hac vita resipurrit, reus existat) aufmerksam. Wendungen wie ,iustus existat, balmunt existat (M. 158), alienus existat (J.-E. 2406), extorris existat (M. 37) und ähnliche sind bei ihrer Häufigkeit für das Dictat dieser zusammenhängenden Spuria wohl auch beachtenswcrt; sie verrathen Einfluss curialeu Stils. Gleichwie verwandte Schriftzüge in Fälschungen wegen der nothwendigen Verkünstelung für die Frage nach der Identität der Hände schwerer wiegen, als in echten Urkunden, bei denen schon das ihnen anhaftende Zeitcolorit Aehnlichkeiten bedingt, so scheinen mir die oben constatirten Uebereinstimmungen von St. 1485 mit dem Stil der schwäbisch-elsässischen Falsificate für die Eruirung des Verfassers und die davon ahbangende Beurtheilung des Heinrichdiploms ausschlaggebender zu sein als die Bloch aufgefallenen Concordanzrn mit dem Dictat des Notars GB. Nimmt mau dazu, dass dieser Privatschreiber des Hildesheimer Bischofs erst sechs Jahre später als Miturlied der Kanzlei auftritt, so verliert Blochs Ansicht den Boden der Wahrscheinlichkeit ${ }^{1}$ ). Die eingangs verzeichneten Verdachtsgründe, darunter namentlich auch die Identitït der Hände, beansprucheu erhöhte Beachtung und drängen zur Annithme gleichzeitiger, einheitlicher Entstrhung von St. 1412 und St. 1485. Von dem Inhalt des letzteren ist nichts mehr mit Sicherheit als echt zu retten. So wird auch der Hergang des Processes von 1169, in welchem der Herzog Bertold als Vogt des Klosters und Vorsitzender des Gerichtes zugleich fungirte, erklärlich; so auch der sonst unbegreitliche, weil rechtswidrige Versuch des Herzogs, den Zeugenbeweis nicht zuzulassen ${ }^{2}$ ). Es war

1) Bei dem von Bischof Bernward für Steterburg erwirkten Diplom von 1007, St. 1438, liegt der Fall doch weit anders; wenn Bresslau (Neues Archiv 22, 158) dieses dem GB zuschreibt, so ist das eben Herstellung durch den Empfänger. Was gieng aber den Hildeshejmer Bıschof die Abtei Stein an?

;) Seriem igitur rei, prout dixerant, septem idoneis testibus licet me renitente comprobabant sagt der herzogliche Urtheilsbrief bei Vetter a. a. 0. 69. 
vermuthlich von den Kirchenern die Echtheit der vom Abte vorgelegten Schenkungsurkunde 1) mit Erfolg bestritten worden; den Gedanken, dass hiemit möglicherweise die Ausschneidung der Siegelstelle zusammenhängt, hat schon Bloch ausgesprochen. Das Patronatsrecht über die betreffenden drei Kırchen mag wohl schon längere Zeit von den Freien gegen die Ansprüche Steins ausgeübt worden sein ${ }^{2}$ ) und einige Jahrzehnte vor dem Processe die Veranlassung abgegeben haben, gelegentlich der Anfertigung von St. 1412 auch diese Ansprüche urkun llich sicherstellen zu lassen.

Gegen Entstehung aus Anlass des $1169 \mathrm{er}$ Rechtsstreites und für eine frühere Herstellungszeit spricht auch die übliche Fälscherpraxis: War die Urkunde unmittelbar dazu bestimmt, im Processe über das Gründungsrecht der Kirchen zu Kirchen, Eimeldingen und Märkt als Beweismittel producirt zu werden, so ist die Zurückhaltung des Verfertigers bewunderungswert. Ohne die strittigen Objecte auch nur zu nennen, bescheidet er sich, sie implicite mit dem Worte ,cum ecclesiis' als Klosterbesitz hinzustellen.

Ausser dem Eigentlum srecht über den ganzen „Ort" Kirchen beausprucht das Kloster mit St. 1485 auch den als Pertinenz angeführten Rheinzoll daselbst.

Mit Stein hat die Reihe der mitbetheiligten Klöster ihr Ende. Wir kehren von unserer Wanderung, die sechs Abteien und einem Domcapitel galt, zum Ausgangsorte zurück, zu Reichenau. Unsere Eiudrücke und Erfahrungen verdichten sich zu einem bestimmten Urtheil. Bevor wir es aussprechen, lenkt das schon von Brandi als zusammengehörig constatirte Urkundenpaar, M. 1567 und M. 1766 durch seine bekannten Schriftzüge die Aufmerksamkeit auf sich und veranlasst uns, dem Vorgänger Udalrichs auf dem Felde Reichenauischer Fälschungsthätigkeit näher zu treten.

M. 1567, ein angebliches Diplom Karls III., ist Palimpsest; die ursprüngliche Urkunde ist nicht mehr zu bestimmen wegen der Anlechtbarkeit des Siegels ${ }^{3}$ ). Der Schreiber zeigt sich in der

1) Auf diese scheinen sich der Vogtherzog und der Abt bei der Behauptung, dass das Kloster die strittigen drei ecclesiae, tenore antiquitalis .. ditioni suae cum dominio fundatorio subegisse ', berufen zu haben. Dass in dem kurzen, parteiisch gehaltenen Ürtheilsbrief die miseliche Diplomgeschichte verschwiegen wird, ist nicht verwunderlich.

2) Quod ius fundationis trium ecclesiarum . . suo mancipassent dominio.

3) Der Fall erinnert an das Lindauer Spurium: hier wie dort ist das Material, ein mit porösen Stoffen stark versetztes Wachs, ungewöhnlich; auch hier deckt ein Pergamentblatt den Siegelrand. Der Abdruck dagegen gibt zu kei- 
Nachahmung diplomatischer Schrift noch sehr unbeholfen; auch häufige Nachtragungen einzelner Buchstaben und ganzer Wörter deuten auf geringe Uebung. Die st und ct Ligaturen bereiten ihm grosse Schwierigkeiten und nehmen unter seiner Hand verschiedene Formen an. Und doch findet sich die Mehrzahl der in den oben besprochenen Urschriften verwendeten charakteristischen Buchstabenformen schon hier; ich nenne a, c, d, e, g, p, ri, q, s. Verräth die äussere Mache dieselbe Hand, die uns schon wiederholt untergekommen, so kanu Composition und Dictat die Richtigkeit unserer Beobachtung nur festigen. Das Protokoll stammt mit Ausnahme der unmöglichen Datirungsformel aus einer echten Urkunde Karls III.; die Recognition weist auf die Zeit von 878-887. Diese Frist wird auf 878-881 Febr. eingeschränkt, wenn wir Eingangs- und Schlussprotokoll auf dieselbe Vorlage zurückführen dürfen. Ebenso gehen Areuga 1), Publication und Corroboration auf eine, vielleicht die nämliche, echte Urkunde zurück. Dem Diplom Karlmanns ist wahrscheinlich der echte sachliche Theil mit der italienischen Pertinenz entlehnt. Wenu wir in der Dispositio einen Satz lesen wie: Nos vero humili rogatu sanctissimi patris nostri Johannis papae et instinctu dilectae coniugis nostrae Richgardae et multorum principum consilio venerabiliun fratrum votis ac piis postulationibus satisfacientes etc. und aut eine Datirung ,881 actum Romae coram domino papa Johanne et multis principibus: stossen, so sind wir bei dem dargelegten Schriftbefund auch über den Verfasser zur Genüge unterrichtet. Es überrascht uns nun nicht mehr, dass die in dem freien Fälscherdictat enthaltenen historischen Daten „anch" von Herimannus Augiensis ad. a. 881 berichtet werden ${ }^{2}$ ). Wie in der Rheinauer Urkunde ist auch hier in der Datirung darauf verzichtet, den chronologischen Angaben Hermanns ein Tages-'und Monatsdatum hinzuzuerfinden. Zweck der Fälschung ist, für die Besitzansprüche auf Turdela, Castanado und Sandrobium eine rechtliche Basis zu gewinnen; die Schenkung von Grabedona ist echt ${ }^{3}$ ).

nerlei Verdächtigungen Anlass, er stimmt genau mit dem bei Mühlbacher als n० 4 verzeichneten Siegel Karls III. vgl. Dopsch in dieser Zeitschr. 14, 668.

1) $=$ M. $1543=$ M. 1546, beide von Inquirin recognoscirt. Weil sich die Arenga in von Inquirin verfassten Urkunden gerade dieser Jahre (878-879) nachweisen lässt, möchte ich diese Formeln lieber einem Karlsdiplom denn der Karlmannechen Vorurkunde zuweisen. Vgl. Brandi a. a. 0. 36.

2) MG. SS. 5, 108: Eodem anno Ka rolus rex, frater Ludowici, Italiam petens Romamque veniens una cum regina Richgarda imperiali unctione a Johanne papa coronantur.

3) Brandi a. a. 0.36 . 
M. $1766_{2}=$ Brundi $\mathrm{n}^{0} 39$ ist gleichfalls eine Urschrift aus dem Anfang des 12. Jhts., aber nicht Palimpsest. Die geringen Siegelreste erlauben keine sichere Entscheidung daräber, ob ein echtes Siegel verwendet worden ist. Ich halte mit Brandi den Schreiber dieser Reichenauer Fälschung für identisch mit jenem der eben besprochenen. Um nur Einzelnes hervorzuheben, verweise ich den Vergleichenden auf das ,et' der verlängerten Schrift, die schiefe Ansetzung der Oberlängen bei $f$ und $s$, und auf das Signum recognitionis. Formen, die ihm in M. 1567 nur selten gelungen sind, wie die Ligaturen von st, ct und das charakteristische Kürzungszeichen, hat er sich bereits angeeignet; er ist geübter geworden. Ausser Reminiscenzen an sein erstes Erzeugnis ist die graphische Nachahmung seiner textlichen Vorlage M. 1766 deutlich genug wahrnehmbar, insbesondere in der verlängerten Schrift, aber auch im Context bei den nicht eingekerbten, nur mit einer Zunge versehenen e, der Ligatur et und anderem.

Die Composition ist durchsichtig. Hauptvorlage bildete M. 17661); für die Interpolation, welche den Gerichtsstand der Aufener Zinsleute regelt, - hierin liegt der wesentliche Zweek der Fälschung ${ }^{2}$ ) - ist M. 1699, ein Spurium des 10. Jh. für Reichenau benützt, das der Verfasser wohl für echt gehalten haben mag. Auf die gleichfalls interpolirte Titulatur Hattos als ,archiepiscopus et compater noster' konnte der mit dem urkundlichen Bestande seines Klosters vertraute Mann durch das Diplom Ludwigs d. Kindes, M. 2002, aufmerksam geworden sein. In der Art und Weise, wie der Fälscher seine Vorlagen benützt, in dem, was er ihnen hinzufügt, offenburt sich seine Eigenart. Der Passus über die Aufener Klosterleute und die neustilisirte Pön sind ein schlagendes Seitenstūck zu den eutsprechenden Theilen von M. 157 für Kempten ${ }^{3}$ ). Wenn wir ferner sehen, dass er in die echte Datirung ,coram multis principibus' einschaltet, dass er sein rhythmisches Gefühl durch Reimung befriedigt, so werden wir die frappante Schriftähnlichkeit z. B. mit M. 157 nicht mehr anders erklären dürfen, als durch -.. Identität der Person des Fälschers für mehrere Klöster.

Wir können jetzt auf Grund der äusseren, namentlich graphischen Merkmale der Urschriften mit einer Sicherheit, wie sie historischer Forschung sonst versagt ist, und der Exactheit naturwissenschaftlicher

1) Die Texte sind nebeneinander gestellt im Fürstenberg. U. B. 5, 26.

2) War der Fälscher vielleicht selbst der censualis magister, dem allein unter Ausschluss von Abt, Propst und Vogt die Leitung des Genossenschaftsgerichtes zustehen soll?

s) Vgl. oben S. 43 . 
Beohachtung nahe kommt, die Behauptung aufstellen, dass folgende Urkunden ihr Dasein einer und derselbeu Fälscherfeder verdaıken: M. 1567 und M. 1766 für Reichenau, M. 157 und M. 158 für Kempten, M. 1361 für Rheinau, M. 961 für Lindau. Je ein echtes - soweit constatirhar, jedesmal ein anderes, ihm passend erscheinendes - Diplom nachzeichnend, verwenılet der vielseitige Macher radirte Originaldiplome des jeweiligen Klosters als Beschreibestoff. Nur für M. 1766 macht er mit dem glatten weissen Pergament eine Ausnahme. Bei M. 1567 noch unbeholfen und eckig, schafft er sich nach und nach aus seiner Praxis einen bestimmten Vorrath vou vermeintlich karolingischen Buchstaben und eiguet sich zusehends immer mehr die runden Formen und eleganten Ligaturen der diplomatischen Cursive an. Das Lindauer Spurium zeugt bereits von einer Gewandtheit, die bei mittelalterlichen Fälschern, falls sie ihre Erzeugnisse so fern abliegenden Zeiten unterschoben wie der unsere, selten anzutreffen ist. Da wir die Normalschrift des Mannes ${ }^{1}$ ) nicht kennen, lässt die äussere Beschaffenheit von St. 1412 und St. 1485, die bereits dem 11. Jahrhundert angehören wollen, unsere Frage unbeantwortet. Angesichts der inneren Merkmale, die in den verwendeten Material, in der Fassung und in der Tendenz zum Ausdracke kommen, dürfen wir die gleiche Persönlichkeit ohne Bedenkeu auch für M. 447 (Reichenau), M. 674 (Buchau), J.-E. 2406 (Kempten) verantwortlich machen. Dass M. 154 und J.-E. 2401 für Strassburg mit den bisher genannten Stücken den Orheber theilen, darf bei ihrer Composition der ganzes Sachlage nach als wahrscheinlich hingestellt werden. Es ist hier auch der Ort daran zu erinnern, dass das Reichenauer Immunitätsprivileg M. 581 bereits im 12. Jahrhundert in Strassburg lag, wie eine Dorsualnotiz erkennen lässt 2). Bezüglich St. 1412 und St. 1485 für Stein wage ich in der Autorfrage über ein „Vielleicht" doch nicht hiuauszugehen. Zweifelhaft bleibt, ob M. 132 A für Ottobeuren, das uns nicht mehr in der ursprünglichen Fassung vorliegt, auch dieser einheitlichen Gruppe zuzuweisen ist. Dass der Verfasser dieser einheitlichen Gruppe in Reichenau zu suchen ist, kann in Ansehung der vielfachen Benützung echter und falscher, aber für echt gehaltener Reichenauer Diplome,

1) Es wäre das Chirograph Brandi n. 97 vom Jahre 1123 zum Vergleich heranzuziehen. Es ist leicht möglich, dass die über ein Tauschgeschäft zwischen dem Abt von St. Georgen im Schwarzwalde und zwischen Reichenau handelnde Urkunde von einem Reichenauer Schreiber hergestellt ist. $\mathrm{Zu}$ beachten ist in der Datirung der Zusatz: in magno conventu.

2) Vgl. Brandi 3, n. 12. Vielleicht hängt dieser Lagerort mit dem gegenseitigen Verkehr zusammen, den die Bestellung der Fälschungen mit sich brachte. 
bei der Vorliebe für Interventionen durch Reichenauer Aebte, bei der wiederholten Heranziehung des Chronisten Herimann von vornherein als wahrscheinlich gelten; das Prioritätsverhältnis seiner für Reichenan hergestellten Fabricate verleiht dieser Annahme den Stempel der Unanfechtbarkeit. Was die Herstellungsfolge anlaugt, so hat meine Untersuchung des textlichen Verhältnisses, der graphische Kenuzeichen subsidiär an die Seite treten, Brandis Ergebnis im wesentlichen bestätigt, abgesehen daron dass intimere Beschäftiguug mit der Frage mich den Zusammenhang unter anderem Gesichtswinkel betrachten liess.

An den Anfang der Fälscherthätigkeit sind M. 1567 und M. $1766_{2}$ zu setzen. Noch schüchtern, beguügt er sich unter weitgehender Benützung echter Vorlagen mit Interpolationen. In M. $1766_{2}$ tritt er schon mit einer Tendenz (Gerichtsstand der Klosterleute) hervor, die in späteren Werken wiederkehrt ${ }^{1}$ ). In M. 447 handhabt er das Concept bereits souverän und gedenkt bei der Regelung der Vogirechte auch wieder der bedrängten famiłia. $\mathrm{Ob}$ er seiı Können nicht auch in den Dienst anderer Reichenauischer Bedürfnisse stellte, sowie er solche bei fremden Klöstern befriedigte, wissen wir noch nicht, da Brandi alle übrigen Fälschungen des 12. Jahrhunderts als Fabricate Udalrichs bezeichnet. Sie werden jedenfalls einer Ueberprüfung bedürfen, nachdem wir Brandis Annahme bereits bei M. 447 als nicht zutreffend erkannt haben. Nach Reichenau kam Kempten mit zwei Diplomen auf Karl d. Gr. und einem Privileg uuf Hadrian I. an die Reihe. Die beiden Strassburger Spuria, je eiues gleichfalls Karl d. G. und Hadrian I. zugeschrieben, scheinen den Kempteuern erst nachgefolgt zu sein. Wurden die grösseren Institute mit mehreren Urkunden bedacht, so mussten sich die miniler bedeutenden Klöster mit je einem Document über ihre Rechte und Freiheiten begnügen. Die Auswahl, die der Reichenauer Privilegienertheiler traf, wird keine willkürliche gewesen sein; er mag wohl den besonderen Wünschen der Empfänger Rechnung getragen haben. In der Reihenfolye scheint Rheinau mit M. 1361 den beiden Frauenklöstern Buchau und Lindau vorangegangen zu sein. Die einheitliche Entstehung aller dieser Fälschungen bedingt ziemliche Gleichzeitigkeit; wo immer zeitliche Kriterien zu gewinnen waren, wiesen sie uns übereinstimmend in das erste Viertel des 12. Jahrhunderts, wir dürfen

1) Vgl. Brandi 69: ,Nach dieser ähnlichen Tendenz und der immerhin verwandten Schrift mögen beide Urkunden den zusammenhängenden Fälschungen des 12. Jahrh. sehr nahe stehen, diese aber stammen einheitlich von demselben Verfasser, dem Custos und Scholasticus Odalriche. 
vielleicht sagen in die $\mathrm{Zwanzigerjahre.} \mathrm{Schon} \mathrm{die} \mathrm{paläographischen}$ Merkmale wollen zur zweiten Hälfte des 12. Jahrh., für die Brandi eintrat, nicht mehr recht stimmen. Dass auch die Tendenzen für die Zeit Heinrichs V. sprechen, werde ich unten nachzuweisen versuchen.

Deberblickt man die ganze Liste der vorbesprochenen Fälschungen des Reichenauer Bruders, so tritt der vielseitige übereinstimmende Inhalt derse'ben erst recht klar vor Augen. Die nachfolgende Tabelle, in die ich auch M. $132 \mathrm{~A}$ aufnehme, aber zum Zeichen der unsicheren Antorschaft einklammere, soll dieses Verhältnis veranschaulichen:

\begin{tabular}{|c|c|c|c|c|c|}
\hline 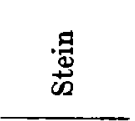 & \begin{tabular}{l}
$\frac{1}{4}$ \\
\hdashline \\
$\dot{0}$
\end{tabular} & 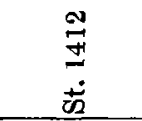 & 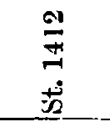 & 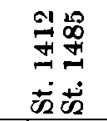 & \\
\hline 胥 & $\overline{8}$ & $\overline{8}$ & $\overline{9}$ & $\overline{8}$ & \\
\hline 品 & $\dot{\Sigma}$ & $\Sigma$ & $\dot{\nu}$ & $\Sigma$ & \\
\hline 㯊 & 葛 & $\frac{\pi}{60}$ & $\frac{\mathbb{N}}{6}$ & $\frac{10}{0}$ & \\
\hline פ & i & $\dot{\Sigma}$ & $\dot{z}$ & $\dot{\Sigma}$ & \\
\hline 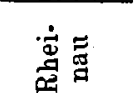 & $\begin{array}{l}\overline{8} \\
0 \\
\end{array}$ & & $\overrightarrow{0}$ & & \\
\hline 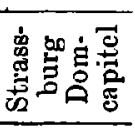 & 4 & & 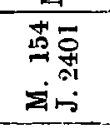 & 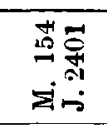 & \\
\hline 总莺焉 & 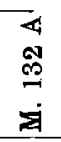 & $\begin{array}{l}\overrightarrow{4} \\
\stackrel{i}{\Sigma} \\
\dot{\Sigma}\end{array}$ & 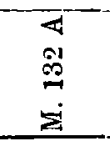 & & \\
\hline 䓌 & $\begin{array}{l}\frac{x}{10} \\
\dot{z} \\
\end{array}$ & 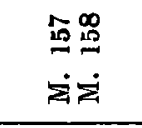 & 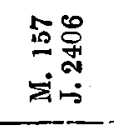 & 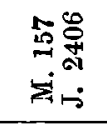 & 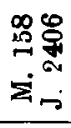 \\
\hline 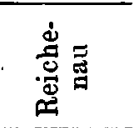 & $\begin{array}{l}5 \\
y \\
\dot{z}\end{array}$ & 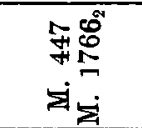 & 1 & 1 & $\vdots$ \\
\hline & 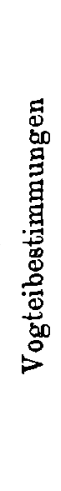 & 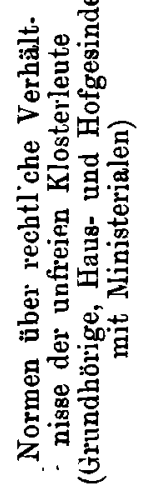 & 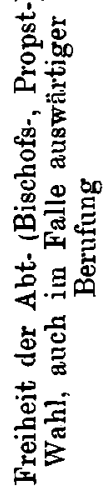 & 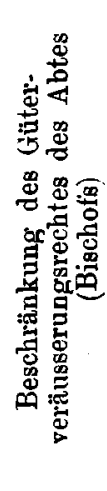 & 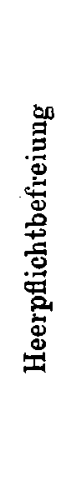 \\
\hline
\end{tabular}


Vereiuzelte andere Tendenzen, wie die Verleihung des Genusses gewisser Regalien in M. 961 und St. 1485, uud angebliche Güterschenkungen (M. 157, M. 1567, St. 1412, St. 148 ) kummen Specialbedürfnissen der betreffenden Klöster entgegen. Bei der in fast allen oben behandelten Fälschungen zu beobachterden Spitze gegen die Machtfülle des Abtes und der Hervorhebung des Einflusses der Brüder ist anzunehmen, dass die Fabrication seitens der Convente angeregt wurde.

III. Die dem Custos Udalrich zugeschriebenen Reichenauer Urkundenfälschungen des 12. Jahrhunderts.

Eine Betrachtung vorstehender Tabelle zeigt die immerhin auffällige Erscheinung, dass der Reichenauer Fälscher des beginnenden 12. Jahrhunderts fremde Klöster, insbesondere Kempten, mit so wichtigen stiatsrechtlichen Privilegien, wie es z. B. die volle Unabhängigkeit der Abtwahl und die Befreiung von der Heerpflicht sind, ausstaftete, während er dabei sein eigenes Kloster vergass. Nun existiren falsche Reichenauer Diplome mit diesen und ähnlichen Tendenzen aus dem 12. Jahrhundert, die aber erst der Custos Udalrich fabricirt haben soll. Suchen wir hierüber ius Klare zu kommen.

Es wird sich zu diesem Zwecke empfehlen, aus der grossen Gruppe der Reichenauer Falsa jene herauszuheben, bei denen der "unwürdige" Custos, wie er sich selbst in conventioneller Bescheidenheit nennt, seine Hund sicher im Spiele hat, nämlich die von ihm geschriebeuen. Aus ihnen werden die Kriterien formeller und inhaltlicher Art zu gewinnen sein, um die nur abschriftlich erhaltenen Fälschungen zu beurtheilen. Von der Entscheidung, ob Ddalrich, ob sein Vorgänger, hängt die Beantwortung der Frage ab: wann nahm Reichenau Veranlassung, sich Urkunden mit bedeut samen staatsrechtlichen Vorrechten zu verschaffen, uuter dem Salier Heinrich V. gleichzeitig mit manchem andern ihm nahestehenden Kloster Schwabens, dem die grosse Abtei hiezu literarisch geschulte Kräfte lieh, oder erst in den Sechzigerjahren, als der Staufer Friedrich die deutsche Krone trug. Udalrichs Handschrift zeigen: Zwei Diplome

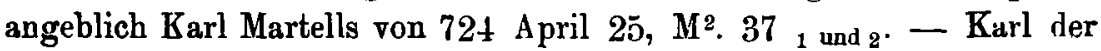
Grosse von 780 Nov. 17, M. 1701 2 (erwähnt) $=M^{2}$. 231. Derselbe von 813, M. 465. - Karl III. von 887 April 16, M. 1701. - Arnolf von 896 April 27, M. 1867. - Otto III. von 998 April 22, D0. III. n. 437. - Heinrich II. von 1016 Aug. 29, St. 1675. - Endlich die angebliche Urkunde Abt Walahfrids von 843 , Brandi, Urkundenfälschungen n. 92. 
$M^{2} .37_{1}$ u. ${ }_{2}$ sind zwei auf Karl Martells Namen lautende Machwerke, die - wie schon Brandi cunstatirt - auf einem gemeinsanen Mundbrief des Hausmeiers beruhen. Die Tendenz des ersten Stückes hat Brandi wohl nicht scharf genug gekennzeichnet. Nicht um ein altehrwürdiges Immunitätsprivileg als solches handelt es sich Odalrich; sein Interesse gilt speciell den Knechten und Handwerkern auf der Insel, auf fünf aus dem Fiscus Bodmann stammenden Gütern und besonders auf der thurgauischen Villa Ermatingen jenseits des Rheines. Zweimal, gerade an bedeutsamen Stellen, hebt er die „Bäcker, Fischer, Winzer, Walker und übrigen Diener" hervor. Ebenso köstlich als aufklärend wird die Art, wie er seinem Hauptzweck zu liebe echte Immunitätsformeln interpolirt 1). Nur diese unfreien, nützlichen Knechte dürfen ausser den Mönchen auf dem Klosterbesitz wohnen. Niemand anderer soll Gewalt über sie haben, Abt und Brüder allein. Dem klösterlichen Haụshạlt treu zu dienen, sei ibre Bestimmung. Jenen von Ermatingen werden ibre Vorfahren vorgezählt, 24 Leute, die Karl Martell an Reichenau geschenkt hat ,cum tributis suis .. et cum sua successione'. Auch die Freien, welche sich freiwillig dort niedergelassen, soll die Reichenauer Immunitätsherrlichkeit unfassen.

Widmet der Fälscher den Klosterleuten von Ermatingen schon in $M^{2} .37_{1}$ nähere Aufmerksamkeit, so ist $M^{2} .37_{2}$ augenscheinlich nur ihretwegen fabricirt. Er sagt uns auch in seiner Schwatzhaftigkeit gleich eingangs, warum sie ihm so am Herzen liegen: vinum ad sacram eucharistiam praeparandam, qua divinus sanguis conficitur, ex eadem villa singulis annis accipiatur. Das ist der Grund für die wiederholt bekräftigte Schenkung der, villa egregia atque regalis" Ermatingen und für die Fixirung des Hofrechtes der dortigen Hintersassen. Die am Schluss nachhinkenden Privilegien über Wahl und Investitur des Aìtes, über bedingte Freiheit von Heer- uud Hoffahrt lassen ihn kalt: wieder kommt er auf die ,praenominata loca et homines praenominatos' zurück. Brandi hatte den gleichen Eindruck. Die grossen staatsrechtlichen Vorrechte sind nur einkleidendes Beiwerk

1) M. $37_{1}$, Brandi S. 90 : .. sed liceat cunctis prefati monasterii abbatibus cum monachis suis sub dominicae immunitatis tuicione <pistores piscatores vinitores fullones ac ceteros servitores suos, qui soli in eadem insula ad eorum subplementum ac necessitatem habitare et commanere debent, regere, distringere ac $>$ per omnia quieto ordine possidere; weiter unten: sed .. abbates ac monachi eiusdem sedis firmissimam licentiam babeant <super suos pistores cocos piscatores winitores fullones et super omnes servitores suos ratam potestatem regendi etc.; qui soli servitores tantummodo prenominati eandem insulam ibıdem cum regulariter subsistentibns monachis caste vivendo et fideliter serviendo sunt inhabitaturi>. 
und sind gleith der Pön einer gefälschten Vorlage entuommen; die Bestimmungen über Hof- und Heerfahrt lauten wörtlich gleich wie iu Braudi n. $58{ }^{1}$ ), bei dem mir Udalrichs Autorschaft höchst zweifelhuft erscheint. Die Pön, welche dem Inhalt der Urkunde angepasst wurde, findet in der von Udalrichs Vorgänger verfertigten Hadrianfälschung für Kempten, J.-E. 2406, ein merkwürdiges Seitenstiick ${ }^{2}$ ).

Mit einem Privileg über freie Abtwahl hat sich Udalrich sonst nie befasst ${ }^{3}$ ); jetzt erinnern wir uns seines geschickteren älteren Genossen, der in dieser Branche Fachmann war. Ich vermuthe, dass wir in den oben bezeichneten heterogenen Theilen die Reste einer - von Udalrich benützten - Urkunde aus der Feder des Reichenauer Fülschers vom Anfaug des 12. Jahrhunderts vor uns haben, der seinerseits den echten Mundbrief Karl Martells zur Grundlage genommen hatte. Udulrich mochte sich genöthigt gesehen haben, aus der einen Urkuude zwei zu machen, weun er neben deu vorgefundenen grossen Privilegien seine Wünsche unterbringen wollte.

M. 1701. $=2$. Aufl. $231=$ Brandi n. 3 ist ein Fabrikat Odalrichscher Marke nach Schrift, Fassung der interpolirten Theile und Tendenz; verfertigt, um die in M. 1701 ausgesprochene, Karl III. in den Mund gelegte Behituptung: Insuper repertum est .., quod .. Karolus Magnus . . Rornang .. ad Augiensium frutrum kameram tradiderat zu belegen. Ausser M. 1701 ist M. 1699 (eher als das gleichfalls in 10. Jahrh. entstandene M. 1700) und M. $15+1$ verwendet. In den so herausgeschïlten eigenen Zuthaten offenbart sich Udulrichs Interessenkreis. Das Ertrïguis der Villa Rörnang soll zur Ernährung der Schuster, Gerber, Walker und übrigen Diener verwendet werden, während diese mit der Herstellung der Kleidung für die Brüder beschäftigt sind. Eine Parzelle des Bodmannschen Wa'des soll das Holz für die warmen Bäder des klösterlichen Krankenhauses liefern; die Herbeischaffung des Brennholzes obliegt der Rörnanger Familia.

In Anschlusse an diese Fälschıng Udulrichs betrachten wir kurz gleich auch die ïbrigen, welche dersilben Sache dienen, der Revindication von Rörnang und der Waldparzelle Azzenhus zu Gunsten des Reichenauischen Haushaltes.

1) Gedruckt Brandi, Gall Oehem 77. Vgl. unten S. 87.

2) Die psalmistische Drohung ,fint fili eius orfani et uxor eius vidua' ergab sich dort als Interpolation in eine echte piipstliche Straffornel; in M. 961 verheisst derselbe Mann dem Urkundenübertreter: nomen et memoriale illius de libro vitae subtractum maneat in aeternum maledictum.

3) Vgl. Brandi, Urkundenfälschungen 41. 
M. 1701 gibt sich als Bestätigung von $\mathrm{Ni}^{2} .231$ aus. Die vermeiutlich echte Grundlage bot M. 1700, ein Stïck, das mit M. 1699 ein zusammengehöriges Fälschungeupaar des 10. Jahrhunderts bildet. Der Passus ,preter unum mansum quem Wenehardo venatorib ete. ist durch M. 1867 veranlasst, das von Udalrich verunechtet wurde. Die Datirung lautet ad verbum gleich jener von M. 1699 und stammt auch von derselben Hand, die M. 1699 geschrieben. Da das Recognitiunszeichen mit dem vorausgehenden ,et $t^{6}$ jenes des Comeatus (843858) und der Siegelrest zweifellos echt sind ${ }^{1}$ ), haben wir, wie schon Mühlbacher MG. ausgesprochen, drei zeitlich weit auseinandcrliegende Stadien vor uns: 1. das ursprüngliche Recognitionszeichen und das echte Siegel. 2. Die ans dem 10. Jahrhundert stammende Datirungszeile. 3. Die Fälschung Udalrichs. Die Erklärung für diesen seltenen Sachverhalt ergiht sich aus der Thatsache, dass M. 1699 und M. 1700 unecht sind. Entweder war das Pergannent so stark, um eine zweimalige Rasur $\%$ vertragen oder -- was wahrscheinlicher - der Fälscher des 10. Jahrhunderts hatte dieses Pergament für M. 1699 verwenden wollen, hatte zu diesem Zwecke die echte Dutirungszeile bereits abgeschnitten ${ }^{2}$ ) und über derselben eine neue geschrieben, stand aber von diesem Vorhaben ab und nahm ein frisches Pergamentblatt, das er - wie an M. 1699 zu erkennen - selbst bullirte.

In diesem Zustand fand Udalrich die Urkunde vor, verwendete sie für seinen Zweck und zog die beibehaltenen älteren Theile, Recognitionszeichen uud Datirung, zur Verwischung des Unterschiedes nach.

Die angebliche Urkuude Arnolfs, M. 1867, steht mit den eben besprochenen Fälschungen in planvollem Zusammenhange. Hatte der Custos bisher von der Schenkung Röruangs mit Rücksicht auf die M. 1867 zugrundeliegende Urkunde und wohl nicht minder auf die thatsächlichen Verhältuisse beidemale eine einem Jäger gehörige Hufe ausgenommen, so galt es, die Schenkung durch Einbezug auch dieses mansus abzurunden. Der in Bodman residirende Graf habe dem Jäger - so erzählt uns der findige Mann - seinen Besitz unrechtmässig entrissen, König Arnolf habe ihm denselben restituirt; der Jäger habe dann seine wiedererlangte Hufe mit königlicher Zustimmung dem Badehaus der Brïder geschenkt und sei in deren Dienst getreten. Gerade bei dieser ehemals einer Jägerfamilie als freies Eigen gehörigen Hufe scheint das Reichenauische Besitzrecht besonders bestritten worden

1) = Mühlbacher Reg. LXXXIII Ludwig d. D. n. 2.

2) Zwei Reste von Oberschäften noch sichtbar. 
zu sein. Muthmasslich war das Gut durch lehenrechtliche Vergabung den Kloster entfremdet worden ${ }^{1}$ ).

Auch St. $167 \bar{j}$ befasst sich ausschliesslich mit der RörnangAzzenhus-Angelegenheit. Udalrichs Feder ist nicht zu verkeunen.

Wie schlimm es um ausreichende Rechtstitel für den Anspruch iuf Rörnang stand, zeigt die Thatsache, dass man sich in Reichenau schon im 10. Jahrh. durch Urkundeninterpolationen den von dieser Villa an den königlichen Fiscus zu zahlenden Zins zu verschaffen suchte ${ }^{2}$, wie auch der Umstand, dass Rörnang nicht einmai in dem uns durch Oehem überlieferten Güterverzeichnis ${ }^{3}$ ) des 12 . Jahrhunderts aufgeführt ist.

Dasselbe Interesse für den internen klösterlichen Haushalt spricht aus DO. III. 437 und der dem berühnnten Abte Walahfrid unterschobenen Urkunde; hier ist es neben Feststellung der Einkünfte für den gemeinsameu Keller vornehmlich die Fischergenossenschaft, deren Dienstleistungen genau bestimmt werden, dort ergeht an den Abt die Mahnung, bescheiden zu sein und sich die Sorge für Kleidung und Speisung der Mönche, namentlich das Badhaus der Kranken angelegen sein zu lassen.

Linen interessanten diplomatischen Fall bietet M. 465, geschrieben von Udalrich auf dem Pergament einer Urkunde Ludwigs d. D.; die ganze Urkunde ist auf Rasur mit Ausnahme jener Stellen, wo das noch urspüngliche Recognitionszeichen und das Siegel ${ }^{4}$ ) stehen, und zweier Drittelzeilen darüber. Aeussere und innere Gründe bestimınen mich zur Innuhme, dass wir in M. 465 eine interpolirte Neuausfertigung einer Fälschung aus dem Aufang des 12. Jahrhunderts (deperd.) vor uns haben. Aeussere: das Pergament, auf dem ein um mehr als die Hälfte kürzeres Diplom Ludwigs d. D. gestanden war, ist infolge Rasur zum grösseren Theil ausserordentlich dünn geworden; die nicht rescribirteu Stellen zeigen ein starkes Pergament. Die Rasur erstreckt sich auch über Theile, die in der ursprünglichen Urkunde sicher keine Schrift trugen. Besonders deutlich wird das bei der jetzigen Signumuud Recognitionszeile, die auf starker Rasur stehen, während der Zwischenraum nur wenig mit dem Bimsstein überfuhren scheint, um den Contrast zu mildern. Es war also hier an einer Stelle, wo das echte Ludwigsdiplom bestimmt schriftfrei war, vor den Udalrichschen

1) Vgl. den Schluss des Contextes.

9) Varauf geht M. 1700 unter anderen aus. Vgl. oben S. $34 \mathrm{f}$.

s) Brandi, Gall Oehem 17.

4) Der Siegelabdruck stimut genau mit M. n. 1 unter Ludwigs d. D. Siegeln, nur die Masse scheint mir ungewöhnlich. 
Duterschriftzeilen bereits eine Schrift in etwa gleicher Höhe (verlängerte Schrift?) und Lünge vorhanden.

Noch deutlicher weisen die inneren Merkmale auf einen solchen Sachverhalt hin. Die Urkunde zerfällt nach Inhalt und - wenn ich nicht irre - auch nach dem Stil in zwei Theile: 1. Schenkung der villa regalis Ulm cum omnibus appendiciss suis et locis adiacencibus. 2. Regelung der Vogtei daselbst. Der erste Theil zeigt die Blüte Udalrichscher Phraseologie: ne labantur, sustentamus sustentando ditamus, fratres ibidem regulariter subsistentes et divino operi die nocteque insudantes etc. Dass wir es hier blows mit einem stilistischen Uebergang zu thun haben, will mich nicht dünken ${ }^{1}$ ); allerdıngs eine materielle Fälschung muss auch nicht unbedingt vorliegen in Aubetracht dessen, dass Reichenau nebeu der königlichen Pfalı bedeutende Besitzungen in Ulın besass. Es wäre dann der Ausdruck ungenau.

Ebenso verhält es sich ja auch mit der, villa egregin atque regalis Ermatingen in $M^{2} .37_{2}$; auch sie war alter Besitz der Abtei uud doch widmet der Fülscher der Schenkung einen ganzen Absatz. Er mochte eben ausser der Betheiligung an den Vogteierträgnissen anch die anderen Eiukünfte aus Ulm durch einen kıäftigen Besitztitel auf diese Villa sichergestellt wissen wollen. Zu einer detaillirten Ausführung aber mangelte lier der Raum.

Ausschlaggebend aber scheint mir bei dieser Sachlage der Umstand zu sein, dass in dem zweiten Theil ausser den Uebereinstimmungen mit M. 447, das wir bereits als eine Fälschung des beginnenden 19. Jahrl, erkannt haben, auch noch unzweideutige Congruenzen mit M. 674 für Buchau und M. 1361 für Rheinau zutage treten. Die Begründung für die Erlassung des Vogtrechtes lautet in:

M. 465: quia, quales futuri sint M. 674: quos nescimus, quales sint homines, ignoramus. quandoque intrare.

Geringeres Gewicht lege ich auf:

M. 465 : decenter et honeste ex- M. 674: decenter, quod opportet hibeat. sibi, exhibeatur.

Dagegen wird man wieder stutzig, wenn man die Datirungen von M. 465 und M. 1361 gegenüberstellt.

M. 465: actum Magontię in con- 1 M. 1361: actum Minontie coram cilio magno coram multis principibus $\mid$ multis principibus in generali concilio

1) Wenn Brandi $45 \mathrm{es}$ als, eine allgemeine Unsitte des Mittelalters c bezeichnet, , bei Schenkuıgen schlechthin den Ort zu nennen und die Eiazelheiten als bekannt vorauszusetzen ", so trifft das bei summarischen Güterverzeichnissen gewiss meist zu, für Urkunden gilt der Satz aber doch lange nicht so allgemein. 
tam spiritualibus quam sęcularibus|(vgl. über die wahrscheinliehe Quelle (vgl. Herimannus ad 813, MG. SS. 5, für diese Angabe S. 58). 102).

Beidemale diente eine Notiz Hermanns zur Schmiedung des Datnms, beidemal in analoger Weise. Bei keiner einzigeu Fälschung Udalrichs liess sich bi.sher Benützung des Chronisten nachweisen. Desto häufiger und intensiver bei seinem Vorgänger. Mit M. 961 (Lindail) hat M. 465 das Auftreten eines Adelbert, hier als ,cognatus' des Kaisers, dort als ,fidelis vassallus et sacri palatii comes" eingeführt, gemeinsam.

Nimmt man dazu, dass Udalrich in den sicher als sein Werk zu erkennenden Fälschungen für Vogteiverhältnisse kein lnteresse gezeigt, so wird man seine geistige Autorsch „ft bei diesem zweiten Theile von M. 465 - abgesehen vielleicht von guringen formellen Aenderungen, z. B. das ,Ego' der Recognition - bezweifeln dürfen. Für seine interpolirte Neuausfertigung ist kein anderer Grund ersichtlich, als.die Sicherung der gesammten Einkïnfte aus Ulm - nicht nur der vom Vogte abzuliefernden Theile - für den Lebensunterhalt der Brüder, damit sie „ein von materiellen Sorgen freies Leben " führen können, dum a nostris sumptibus alacriter procurantur.

Auch der auscheinend ältere, nicht von Udalrich geschribbene Rückvermerk des 12. Jah hunderts nennt als Inlualt.nur: de advucatia Dlme, worauf freilich nicht besonderer Wert gelegt wirden durf.

Eine kleine Auslese aus Udalrichs Erzeugnissen wird hiureichen, seine Eigeuart auch nach der formellen Seite hin aufzudecken. Sie wird uns nehen der Tendenz ein zweites Mittel in die Hand geben, auch die nur abschriftlich erhalteuen Reichenauer Fälschungeu des 12. Jahrhunderts nach Autor uud Entstehuugszeit zu beurtlieilen. Ich glaube, nienand wird sich dem Eindrucke verschliessen könuev, dass Udalrichs Stil durch Pathos und Plirasenreichthum sich greifbar von dem seiues Vorläufers abhebt, welcher der kühlen Urkundensprache doch bedeutend näher steht.

Einzelne für seinen älteren Genossen wegen ihrer Hü̈nfigkeit charakteristische Wendungen, wie, coram multis principibus (aber nur im Text), nostre serenititis culmen adit, conquestus est nobis, treffen wir auch bei Udalrich an. Gleicbwie in der Schrift - ich erinnere nur an das $\mathrm{f}^{1}$ ) - macht sich der Einfluss jenes, der ja möglicherweise Udulrichs Lelırer war, auch im Wortschatz geltend. U,r Reimprosa verhilft er zu womöglich noch gesteigerter Verwendung.

1) Vgl. Brandi $52 \mathrm{ft}$.

Jittheilungen XXI. 
Hier eine kleine Auslese seiner Stilblüten:

M. $37_{1}$ : ut, dum ipsi peregrini monachi et posteri eorum a nostris sumptibus alacrius recreentur, deum pro nobis et pro stabilitate nostri regni frequentius et devotius deprecentur, ut per eorum sanctam doctrinam fiat ipsa provintia inluminata et exemplum bonorum operum in posteros fiat propagatum.

M. $37_{2}$ : Sed quia mundus in maligno positus de die in diem ad perniciosam nequiciam et ad damnosam ruinam atque calumniose in $\mathrm{de}$ teriorem partem assidua protervitate vergitur et bomines semper proni ad omne malnm exercendum, pigri autem aliquid boni vel honesti agendum deinceps nascent, regali nostro imperio sancimus et confirmamus, confirmando roboramus, ut hec villa ... perpetualiter inhereat, inlibata perduret, inconvulsa permaneat, incorrupta et indivisa persistat.

M. $1701_{2}=M^{2} .231$ : . . si antecessorum : normam sequentes antiqua . . cenobia olim in sanctae regule conversatione et in dé servitio spiritaliter ferventia, nune autem in aliquibus pedetemtim ad defectum migrantia..s sulamine, ne in precipicium labantur, roboramus, etc.

. fratrum turma .. pariter a nobis exigerunt, ut aliquod adminiculum nostre largitatis eidem cennobio inpenderemus etc.

M. 465: Si 'sanctorum monasteriorum loca, ne labantur, frequenter sustentamus, sustentando ditamus, etc.; fratres ibidem regulariter subsistentes et divino operi die nocteque iugiter insudantes, dum a nostris sumptibus alacriter procurantur, etc.;

ab exterioribus curis remotus dẹi servitio liberius atque securius insistere.

DO. III. 437: Sunt nonnulli cenobite, qui infra claustri sui ambitum celibem vitam agentes magna devotione degentes plurima diligentia ab omni pravo opere se custodiunt; hi si forte aliquando altiore gradu fultiuntur, ipsi tam pastores quam oves periclitantur et de meliore statu ad dederiorem labantes quasi morbidum pecus ex ignara pestilentia fascinantur.

Ubi pastor per devia vadit, grex in precipicium cadit.

St. 1675 : fratres in eadem insula celibem vitam ducentes etc.

Nos vero . ; concessionem .. sagaci animo .... indugavimus, post investigationem sollerter discussimus, post discussionem . . ex integro, sicut decebat, restituimus.

Mău sieht, hinter solchem Wortschwall bleibt der ältere Reichenauer Fälscher des beginnenden 12. Jahrhunderts weit zurück.

Noch zwei formelle Unterschiede seien hier besonders hervorgehoben, welche nicht so sthr ein Ausdruck indicidueller Neigungen der Verfasser sind als vielmehr mit der zeitlichen Differenz derselben zusammenhängen. Während der uubenannte ältere Fälscher in seinen zahlreichen "Urkunden, in deneu er" sich gegen lehenrechtliche Vergabungen ausspricht, stets noch den Ausdruck beneficium gebraucht, bedient sich Udalrich ebenso constunt des - aus Südfrankreich über Westleutschland langsam und allmälich eindringenden, in der zweiten 
Hälfte des 12. Jahrhunderts auch in den östlicheren Gegenden überwiegenden 1) - Wortes feodum (infeodare); selbst dann, wenn er in seiner echten. Vorlage an jener Stelle den Ausdruck beneficium antraf, vertauscht er ihn mit dem ihm allein geläufigen feodum.

Diunn das Pronomen ,ego' in der Recognition, das in der Kaiserurkunde seit Lothar III. das Bürgerrecht besitzt. Der älteren Kategorie von Fälschungen fehlt es gänzlich. Udalrich gebraucht es in den acht oben erörterten Machwerken viermal, in drei von den restirenden Fällen konute er die Recognition unverändert echten Urkunden entnehmen:

Nach solcher Vorbereitung können wir uns der Aufgabe usterziehen, die übrigen Reichenauer Falsificate, als deren Autor Uditlrich bezeichnet wird, zu überpriufen:

Karl der Grosse von 780 Nov. [14], M. 2. Aufl. 230 (Brandi Urkundenfälschungeu n. 4). - derselbe von 790 Juni 6, M. 297. Aruolf ron 888 Jan. 3, M. 1722. - Otto Ill. von 997 April 22; Brandi n. 58.

Dass auch für $M^{2}$. 230 (Brandi n. 4) Udalrich rerantwortlich ist, unterliegt keinem Zweifel. Es zerfällt inhaltlich in zwei, auch vach dem Ort der Handlung geschiedene Theile: 1. Schenkungsbestätigung von sechs genannten Villen, deren Bewohner den Brüdern als Schuster, Walker, Krämer, Bäcker, Köche und Fischer dienen $\left(=\mathbf{M} . \mathbf{3 7}_{1}\right)$, Neuschenkung von Rörnang, das den Unterhalt für die genannten Handwerker abwerfen soll, und der Waldparzelle Azzenhus für das Badhaus (=: M. 1701 1 und M. 1701 $1_{2}$ ). 2. Exemtion des Klosters vom Bisthum Konstanz und Verleihung freier Abtwahl, gegebenen Falls auch bei Berufung eines Auswärtigen ( $\mathrm{vgl}$. M. 157 für Kempten und M. 372). Die Handlung ist hier von Reichenau nach Konstanz verlegt, und dem entspricht auch die Ortsangabe der Datirung. Diese darf unsere Aufmerksamkeit beanspruchen. Zeigt schon der Wortlaut des Wahlprivilegs nahe Verwandtschaft mit M. 157 für Kempten, so haben wir hier eine'Datirung vor Augen, deren Absonderlichkeiten eine merkwürdige Geschmacksgleichheit des Verfassers mit dem der Kemptener und anderer Fälschungen voraussetzt ${ }^{2}$ ). Diazu kommt, dass ein Aufenthalt Karls d. Gr. in Konstanz in November 780 völlig uuverbürgt

1) Waitz-Seeliger, Verfassungsgesch. 6, 131.

2) Brandi n. 4 : $\therefore$ acta sunt haec Constantiae praesen te Karolo i mperatore et regina Hilthegarda, Johanne episcopo per omnia confirmante. J.-E. 2406: . pontificatus vero domni Adriani .. pręsente Karolo imperatore et Hildegarda imperatrice et aliis innumerabilibus feli. citer amen. Vgl, auch J.-E. 2401, M. 154, M. 157, M. 1361, M. 1567, M. 1766. 
ist und nur von Ratpert in einer durchaus unglaubwürdigen Erzählung erwähnt wird 1 ).

Deberhanpt scheint das citirte Kapitel bei Ratpert die Grundlage für diesen Theil der Fälschung abgegeben zu haben; er erzählt von Verleihung der Reichsunmittelbarkeit und freier Abtwahl durch Karl d. Gr. an St. Gallen und Reichenan. Bei ihm finden wir auch die in vorliegender Orkunde auftretenden Intervenienten, die Kaiserin Hildegard, den Grafen Gerold und den Abtbischof Johann in diesem Znsammenhang genannt. Von einer Anwesenheit des Königs in Reichenau berichtet Ratpert nicht, auch das $\mathbf{J a h r}$ des Ereignisses verschweigt er. ,Carolus rex cum Hildigarda coniuge sua Roman profecturus Constantiam adrenit' sind seine Worte. Das Jahr 780 konnte der Fälscher von Hermann d. Lahmen erfahren haben. Aber noch mehr. Die historischen Details der Narratio machen den Eindruck einer einfachen Paraphrase zu Hermanns Notiz ad 780 und 781: Karolus habito in Saxunia conventu et dispositis tam Saxonum quam Sclavorum rebus ipse Romam orandi gratia adiit. Pipinus, filius Karoli, Romae ab Adriano papa baptizatus est etc.

Die bei Udulrich sonst nicht nachweisbare Benützung chronikalischer Quellen, die Eigenart der Datirung, die unter Udalrichs Fälschungen allein stehende Tendenz ${ }^{2}$ ) und endlich die zurückgesetzte Stellung dieses Abschnittes lassen vermuthen, dass er hier wie wahrscheinlich auch bei M. $37_{2}$ und M. 465 ein Fabricat seines Vorgüngers gleichsam als Rahmen benütat habe, um in demselben sein eigenes Machwerk unterzubringen.

Er hätte also in die Narratio einer uns verlorenen Fälschung , Quındo apud Saxones et inter nos omnia in pace et concordia composita sunt, Romam ire propositum est, filium nostrum Pipinum ab Adriano papa baptizari decrevimus . . Constantiam orandi gratia intravimus etc. ${ }^{3}$ ) einen Aufenthalt des Königs in Reichenau eingefügt und an diesen die Gewährung seiner haushälterischen Wünsche geknüpft. Eine kürzende Ueberarbeitung der Vorlage war geboten, um die Urkunde nicht all/zu lang werden zu lassen. Wir haben in diesem zweiten Theil von $M^{2}$. 230 vielleicht die Ueberbleibsel einer dem Kemptener Stück M. 157 entsprechenden Urkunde für Reichenau aus der Feder des älteren Fälschers vor uns. War doch derselbe Mann

1) Katpert, Casus 8. Galli c. 3 in MG. SS. 2, 63; vgl. dazu Meyer v. Knonau in St. Galle' Mitthesl. 13, 12.

*) Vgl. Brandi 46.

3) Damit soll natürlich nicht eine Reconstruction dieses muthmasslichen Deperditums versucht sein, sondern nur Udalrichs Mache erklärt werden. 
gerade in dieser Richtung sogar für fremde kirchliche Genossenschaften thätig. Anlass zur Verfertigung einer Exemtionsverleihung hatte man zu Anfang des 12. Jahrhunderts in Reichenau jedenfalls. Erst kurz vorher, in J. 1095, war Abt Ulrich mit seinen hierauf gerichteten Bestrebungen hart zurückgewiesen worden ${ }^{1}$ ). Sehr wohl möglich, dass die angebliche Gerichtsurkunde ${ }^{2}$ ) Papst Leos IX. (J.-L. $4156=$-Brandi 11. 77) auch in diesen Zusammenhang gehört ${ }^{3}$ ).

M. 297 ist die unter dern Namen der Constitutio de expeditione Romana bekannte Fälschung, zu der unsere hervorrageudsten kritischen Geister von Eichhorn bis auf Scheffer-Boichorst das Wort ergriffen haben. Für sicheres Ergebnis der bisherigen Forschung halte ich Entstehung in Reichenau im 12. Jahrhundert; dass ich's gleich hinzufüge, auch Udalrichs Verfasserschaft scheint mir unbestreitbar. Scheffer ${ }^{4}$ ) hat genügend Vergleichsstellen für dessen Wortschatz verzeichnet; verlieren einzelne darunter durch meine Beweisführung ihren Halt, so liessen sie sich durch andere uicht minder charakteristische ersetzen. Wir haben den ordunngsliebenden Custos und Schulneister vor uns, der die Pflichten der Dienstmannen und Leistungen der unfreien Bauern bei einem Zug über Berg ebenso genau festgesetzt wissen will, wie etwa jene der Zinsleute in Ermatingen und Rörnang für den Haushalt. Schon für die Ermatinger freien und unfreien Leute hat er Bestimmungen im Falle einer Heerfahrt getroffen, hat verordnet, wer dem Rufe des Abtes zu folgen, wer zu Hause zu bleiben und sich hier dem Kloster nützlich zu nuachen habe ${ }^{5}$ ). Wenn ich meine, dass auch hier eine ältere Fälschung, vielleicht über theilweise Befreiung von der Heerpflicht, benützt ist, so würde diese Annahme auch zu dem sonstigen Bilde über Udalrichs Mache stimmen. Für solchen Einfluss scheineu mir fulgende Stellen zu sprechen: In der Narratio: cum multis principibus annum Wormatie transegimus (Herm. contr. ad 790: Hunc annum Karolus sine bello Wormatie quietus transegit); in der Dispositio: cum consensu omnium tam spiritualium quam secularium principum ibidem nobiscum assidentium (M. 465 Datirung: in concilio magno coram multis principıbus tam spiritalibus quam secularibus; vgl. auch M. 1361); si autem forte, quod absit, sonst bei Udalrich nicht gebräuchlich, gehört zum For-

1) Bernoldi chron. MG. SS. 5, 163 Z. 5-10: domnus papa illum missis literis ab huiusmodi praesumptione iterum compescuit.

2) Brandi, Gall Oehem 92.

3) Vgl. auch das Fragment Brandi n. 65.

4) Zur Gesch. des 12. u, 13. Jahrh., diplomatische Forschungen 15.

j) M. 37 . 
mular seines. älteren Genóssén; principum clientela, qui 'eottidie ad serviendum parati esse debent (M. 158: advocatos ., qui nobis parati sint servire et pro ipso abbate in hostem nobiscum pergere); endlich insbesondere die Datirung: Data VIII. idus iunii anno incarnationis domini etc.; actum Wormatie, feliciter amen. (M. 447: Data VIII. i d u s aprilis anno incarnationis domini etc.; a ctu $\mathbf{m}$ Wormatie, in dei nomine feliciter amen); dazu kommt der parallele Gebrauch von beneficium und feodum und die Wahrscheinlichkeit, dass der ältere Fälscher sich mit der Frage der Heerpflicht bei einer expeditio Romana befasst habe 1).

Wir kommen zu M. 1722, das uns nur in deutscher Uebersetzung bei. Oehem ${ }^{2}$ ) erhalten ist. Diese Orkuude steht in engster Beziehung zu M. 447, als dessen Bestätigung sie sicb gibt. Dieses Verhältnis legt den Gedanken an gleichzeitige, einheitliche Entstehung mit M. 447 nahe. Bezüglich der Composition stimme ich Brandi ${ }^{3}$ ) bei, abgesehen von seiner Erklärung der Congruenzen mit $\mathrm{M}^{2} .231$ (Arẹnga) uncl M. 1817 (Dispositio). Mir scheint im ersteren Falle M. 1722 die Quelle für die Arenga von $\mathrm{M}^{2} .231$ zu sein und nicht ungekehrt; Beweis dafür: die für Udalrich charakteristischen Ausdrücke ,pedetemptim und ,ne in precipicium labantur, wie sie $\mathrm{I}^{2} .231$ hat, finden sich in M. 1722 nicht, sind also wahrscheinlich Udalrichs Zuthat zu der aus der Vorlage genommenen Arenga. Die sachlich wichtigen Erweiterungen gegenüber M. 447: Tettingen <mit den höchern, und edlerı gotzhuslütten〉 (Z. 26); Oberndorf <mit den mindern und schlechten gotzhuslütten> (Z. 31) zeigen dieselbe Tendenz, welche; sich in der am Beginn des 12. Jahrhunderts vorgenommenen 4). Verunechtuug ,homines' (statt tributarii) des dreifach interpolirten ${ }^{5}$ ) Originals. M. 1817 ausspricht. Nun ist gerade M. 1817 in dieser interpolirten Form für den unmittelbar folgenden Passus von M. 1722 benützt 6).. Das. Verbot an den Abt, Klosterbesitz als Lehen auszuthun, passt zu dem älteren

1) $\nabla g l$, den von Udalrich nur übernommenen Theil von M. 37, und Brandi $n^{0}$ 58, wo eịn solches Privileg. Karls d. Gr. ausdrücklich erwähnt wird.

2) Brandis Ausgaje 63-65.

3) Fälschungen 44, Oehem 63-65 Noten.

*) Vgl. M. 1567 und M. 1766 , thind oben S. 35 .

5) Vgl. Brandis Gegenüberstellung in Fälschungen 44.

5) Nach Schrift und:Tendenz glaube ich: die von drei zeitlich verschiedenen Händen rorgenommenen Verunechtungen unter die auch sonst bekannten Reichenauer Fälscher folgendermassen mit Wahrscheinjichkeit: vertheilen zú können: 1. ,solus abbas' (statt eines ursprünglichen advocatus) dem Fälscher des 10. Jh. (Poppo 6), 2. ,homines" (statt tributarii) jenem aus dem Anfang des 12. Jḥ. 3. , in villis ibidem' dem Custos Udalrich in der zweiten Hälfte des 12. Jh. 
wie dem: jüırgeren Fälscher; doch findet es sich bèi Udalrich seltèner, eben $*$ wie die Versicherungen der Närratio „mit vili fürsten“, ., nff empfangnen "rautt wyser personen". Ob. Udalrich auch an dieses Werk seines Vorö̈ingers Hand angelegt, worauf die die Stelle éiner, Corroboratio einnehmendeu Schlusszeilen des Contextes ,besunider. das sy den mönchen . . in sicherhieit frides und rỉwes gewertig dienend, als dann sölliches ire alten fryhaitzbrieff bezügend deüten könnten wir wissen es nicht.

Die in engstem Anschlusse an das echte Diplom Ottos III (D0. III. 279) gefertigte Fälschung Brandi n. 58 i), soll dem Kloster die wichtigsten staats- und kirchenrechtlichen Privilegien verleihie:! Sie ist uns auch nur bei Oehem erhalten. Ihre Tendenz "ergibt sich unmittelbar aus den Interpolationen gegenüber der Vorlage 2).. Die Abtei beansprucht: 1. Freiheit von der Heerpflicht, ausser bei einer Romfahrt $\left(=\right.$ M. $37_{2}$ ). 2. Freileit yon jedem ausserordentlichen Servitium an den König ausserhalb. des Inselbereiches; nur wenn das Reichsoberhaupt von Ulm nach Zürich zieht, darf es in dem Reichenauischen Mindersdorf "Lieferung und Dienst" verlangen. . 3. Freibeit vom Besuch der königlichen Hoftage ausser bei den wichtigaten Reichsangelegenheiten, zu denen alle Fürsten ohne Ausnahme entboten werden $\left(=\right.$ M. $\left.37_{2}\right)$. 4. Ausschluss jeder weltlichen Gewalt auf der Insel (jüngere Immunität), hier offenbar gegen den Vogt gerichtet, vgl. M. $447^{3}$ ). 5. Der Abt darf nur in Gegenwart des Papstes - im Falle eines Verbrechens - seiner Würde entsetzt werden 4); zielt in erster Linie gegen den Diöcesanbischof, Zu: allen diesen Privilegien habe der Papst seine Zustimmung ertheilt, sie stehen unter seinem Schutze, vgl. M. 1567.

Und zu diesen Interpolationen soll sich ein Mann veranlasst gesehen haben, der - wie Braudi 77 ganz richtig bemerkt:- , sich thatsächlich nicht näher mit dem Verhältnis des Klosters zum Reich beschäftigte ". Alle diese Vorrechte soll das Kloster bereits unter den salischen Kaisern erhalten haben; die Ausnahmebestimmungen sollen so drückend, die in den Vergünstigungen gelegenen Vortheile so wenig

1) Mit Unrecht ist dieses interessante Stück nicht in die Diplomata aufgenommen worden.

2) Ueber dje Composition Brandi, Urkundenfälsch. $37 \mathrm{ff}$, Oehem 77 Noten.

3) Nec aliquis post eum adrocatus infra Augiensem insulam jus habeat placitandi vel aliquam indiciariam $p$ itestatem exercendi, nisi forte ab abbate vocatus adveniret et tunc voluntati sive petitioni ipsius satisfaceret.

4) Vgl. M. 1361 für Rheinau, das den kleineren Verhälțissen dieser Abtei angepasst ist. 
greifbar gewesen sein, dass ein Fälscher sich mit ihnen nicht abgegeben hätte. Nein, noch im 12. Jahrhundert hat es in Deutschland keine; Reichenau an Grösse und Reichthum einigernassen vergleichbare Abtei gegeben, die vou Rechtswegen so wenig Reichslasten zu tragen gehabt hätte, als es der Fälscher hier für sein Kloster beansprucht.

Einzelne ärmere Reichsabteien, wie Werden, Tegernsee, Niederaltaich, Benediktbeuren geuossen allendings volle Befreiung von der Heerpflicht, andere wenige hatten diese Last auf die mit Klostergütern belehnten Vögte abzuwälzen gewusst. Solche Exentionen wurden unter den salischen und staufischen Kuisern eher beschränkt als $t r$ weitert; Neuverleihungen fanden höchst selten, und nur bei besonderer Nothlage der Klöster, statt. Wer hätte die schweren Kriegslasten eher zu tragen vermocht als die unter den Ottonen so reich ausgentatteten Stifter? Zudem galt ja der Besitz der Klöster und Propsteien als unmittelbares Reichsgut ${ }^{1}$ ). Wenn der Fälscher für den Römerzug die Heerpflicht bestehen lässt, so trägt er zwingenden Verhältnissen Rechnung. Sein Kloster lag an der Hauptstrasse nach Italien ${ }^{2}$ ); an eine Befreiung von der Fahrt über Berg war gar nicht zu denken.

Wie mit der Heerptlicht, so steht die Sache auch bezüglich der Hoffahrt. Ein solches Privileg war keineswegs so nichtssagend, als Brandi infolge einer missverständlichen ${ }^{3}$ ) Auffassung der Stelle meint. Es würde zu den seltenen Ausnahmen zählen, welche die Kaiser im 12. Jahrhundert von der allgemeinen Verpflichtung der Reichsfürsten zum Besuch der Reichstage gewährten, wie z. B. an den österreichischen Herzog im Jahre $1156^{4}$ ). Dadurch, dass Dispensationen von Fall zu Full oft genug ertheilt wurden, wird die principielle Frage nicht berührt. Heinrich V., in dessen Zeit ich aus anderen Gründen 'ie Fälschung zu setzen geneigt bin, äussert sich einmal in einem Schreiben an den Abt von Tegernsee scharf dahin, „dass keinem Fürsten die

1) Vgl. über die Heerpflicht Weiland, Die Reichsheerfahrt von Heinrich V. bis auf Heinrich VI., Forschungen 7, 138-140, Waitz, Verfassungsgeschichte 8 , 148-155, Schröder, Lehrbuch der deutschen Rechtsgeschichte 3. Aufl. 511, 515 und die andere dort citirte literatur.

2) Vgl. Wattenbach, Geschichtsquellen 1, 396.

3) Nicht um die Erlangung einer unter den Salieru überhaupt üblichen besonderen Einladung handelt es sich, sondern um die Beschränkung der Besuchsplicht auf Tage von solcher Bedeutung, dass kein Fürst fernbleiben dürfe.

4) Gleichzeitig erbielt Heinrich von Oesterreich auch theilweise Befreiung von der Heerpflicht; Oesterreich war eben eine Mark, und die erste Aufgabe der Marken war der Schutz ihrer Grenze. 
Pfficht zum Besuche der Reichsversammlung erlassen sei ${ }^{\text {1 }}$ ). Dass St. Maximin ${ }^{2}$ ) und Ottobeuren ${ }^{3}$ ) in der ersten Hälfte des 12. Jahrhunderts zu Fälschungen greifen mussten, um den Anspruch auf Vorrechte gegenüber der allgemeinen Verpflichtung zur Heer- und Hoffahrt zu begründen, ist bezeichuend genug. Dass man allem Anschein nach damals mit diesen Dokumenten nicht durchgedrungen, nicht miuder.

Soviel wird man mindestens sagen können, dass derartige Privilegien jedenfalls die Mühe der Fälschung lohnten ${ }^{4}$ ), zumal um dieselbe Zeit in Reichenau auch eine Urkunde auf Karl d. Gr. fabricirt wurde, die theilweise Freiung von der Pflicht, die Hoftage zu besuchen, verliebeu wissen will: Brandi n. 6. Die Zugeständnisse an den König, auch in der Servitiumfrage, scheinen mir nur das Minimum an Leistungen für das Reich zu sein, welche der Fälscher gelten lassen musste, wollte er sich nicht von vornherein jeglicher Aussicht auf Erfolg begeben. Nichts nöthigt uns, Brandi n. 58 Udalrich zuzuweisen. Solche Tendenzen verfolgt sein höherstrebender Vorgänger; das Bestreben, die kaiserliche Gewährung auch noch durch püpstliche lestätigung zu bekräftigen, hat ein sprechendes tualogou in M. 1567 : Hier wie dort macht der Fälscher in vordringlicher Weise in Narratio und Datirung auf die Gegenwart des Papstes bei dem Bewilligungsact aufmerksam. hier ist diese Stelle sogar in die echte Datirung iuterpolirt.

Treffen unsere Beobachtungen zu, so hat der geschickte Reichenauer Mönch am Beginn des 12. Jahrhunderts sein eigenes Kloster den benachbarten Schwesterklösteru nicht hintangesetzt. Er hat es vielmehr mit allem Wünschenswerten ausgestiattet. Ausser den uns bereits früher bekannten Privilegien hat er für dasselbe angestrebt: Völlig unabhängige Abtwahl uud Exention von Konstanz mit directer Unterstellung unter den römischen Stuhl; theilweise Befreiung von

†) $M G$. Constitutiones 1,125 n. 73, vgl. Waitz-Seeliger, Verfassungsgesch. 6, 452. Wacker, Reichstag unter den Hohenstaufen 23-26.

9) Bresslau in Westdeutsche Zeitsch. 5, $46 \mathrm{f}$.

3) Excurs S. 97; die Ottobeurener Falsificate DO. I. 453 und DO. I. 423* (Nachtrag) lehren, dass selbst ein Fälscher die Gewährung solcher Privilegien obne entsprechenden Ersatz an das Reich bei einer begüterten Abtei für unmöglich hiclt.

4) Schon Dopsch in Mitth. d. Inst. 14,667 kamen Brandis diesbezügliche Ausführungen wenig überzeugend vor. Uebrigens dürfte Brandi selbst heute anders darüber urtheilen. Rechtshistorische Specialuntersuchungen über die Verpflichtung der Reichsabteien zu den Reichsleistungen während des Mittelalters wären nothwendige und lohnende Arbeiten, die z. Th. noch ausstehen. 
der Pflicht der Heer- und Hoffahrt nebst Beschränkuıg des an Kaiser und Reich zu leistenden Servitiums. Diesen Spuren folgte ein Menschenalter später der Custos und Scholasticus Udalrich; in der. Techuik dem Lehrer verwandt, nur minder geschickt, im Stil schwülstiger. In der Tendeuz dagegen ungleich; hatte jever Reichenuus Stellung nach Aussen, die Befugnisse der die Vogteien invehabenden weltlichen Nachbarherren 1), dus Verhältnis zum Bisthum Constanz, zu Reich und Rom, ins Auge gefasst, so widmete Udalrich sein Interesse den inneren Zuständen, den Leistungen der Klosterleute an den Haushalt, den Verpflichtungen der Ministerialen. Ihm lag vornehmlich das physische Wohl seiner Klosterbrüder am Herzen, ihre Verpflegung uud Bekleidung, ihr Kranken- und Badhaus. Gegenüber selbstsüchtigen Bestrebungen les Fürstabtes bestimmte er die zur Deckung dieser Bedürfnisse erforderlichen Güter. Zuweilen benützte er Erzeugnisse seines Vorgängers als verbrämendes Beiwerk.

IV. Die Fälschungen im Lichte ihrer Zeit.

Zweimal im 12. Jahrhundert haben wir Reichenauer Mönche zu umfassenden Fälschungen schreiten sehen, jedesmal von verschiedenen Absichten und Bestrebungen geleitet. Unsere Betrachtung fasst die bedeutsamere ältere Gruppe ins Auge, welche im ersten Viertel : des genannten Jalrhunderts, in der Zeit Heinrichs V., entstanden ist, Ihre Anlage ist so systematisch, die Durchführung so geschickt, dass diese Urkundenherstellung geradezu ein hervorragender Zweig literarischer Bethätigung genannt werden muss. Herrscher grauer Vorzeit, die ältesten, zu denen die betheiligten Abteien überhaupt in Beziehung getreten waren, wurden als Aussteller gewählt. Bleibt es zweifelhaft, ob der Mann für Reichenau auch eine Fälschung auf Karl Martell verfasste, so lockte ihn, wie andere die durch Geschichte und Sage verherrlichte Gestalt Karls des Grossen, gerade an diesen Namen die Verleihung der wichtigsten staatsrechtlichen Privilegien zu knüpfen. Bestätigungen durch spätere Könige sollten von der Continuität im Genusse der Vorrechte Zeugnis geben. 'Bei den Fälschungen für fremde Abteien griff er gleichfalls in die Anfünge ibres Daseins zurück: Bei Kempten auf Karl d. Gr., bei Linclau und Buchau auf Ludwig d. Fr., bei Rheinau auf Ludwig d. D. Für Papsturkunden bot sich in Hadrian I. ein passender Gönner ${ }^{2}$ ). Bewusst oder unbewusst

1) Vgl. Brandi 87.

2) Wenn unser Fälscher mit Vorliebe Karl d. Gr. und Hadrian I. Bestimmungen gegen Simonie treffen lässt, so hat er sich damit recht geeignete Per- 
liegt dieser Wahl der Aussteller das im älteren deutschen Recht geltende Princip zugrunde, dass beim Conflıt 2weier Königsurkunden der älteren der Vorzug gebühre. Bis ins 12. Jahrhundert ist bei gerichtlichen Entscheidungen in der Regel darnach verfahren worden 1). Bresslau führt unter anderen Belegstellen auch ein Beispiel aus dem J. 1125 an, das unseren Verhältnissen zeitlich, örtlich und sachlich nahe steht. Vor dem Hofgericht Heinrichs V. beriefen sich das Bisthum Basel und das Kloster St. Blasien in einem Streit wegen der Vogtseinsetzung beide auf königliche Diplome. Recht erhielt dis Kloster, welches ein privilegium antiquius et veracius produciren konnte; St. Blasien hatte zuvor aus dem vorgelegten echten Präcept Ottos II. durch Verunechtung der Daten ein solches Ottos 1. gemacht.

Wollen wir die Reichenauer Massenfälschung an Begiun des 12. Jahrhunderts recht verstehen, so müssen wir sie im Lichte ihrer Zeit betrachten. Ein Grund für das zahlreiche Auftreten von Urkundenfälschungen im 12. Jahrhundert liegt zweifellos in der Wiederbelebung des Urkundenbeweises in Deutschland überhaupt. Insbesondere die Kirche hatte allen Grund, diese Entwicklung za fördern und ibrep Interessen nutzbar zu machen ${ }^{2}$ ).

Die Zeit des Investiturstreits ist ein treffendes Beispiel, wie politisch-religiöse Kämpfe auch rein verfassungsrechtliche Zustände beeinflussen und mitbestimmen. Als Gregor VII. die idealistischen Bestrebungen der Cluniacensi-chen Mönche nach Reinheit der Kirche, nach Beseitigung der alten mit Simonie und Nikolaitismus bezeichneten Schäden zu seinem politischen Prugramm erhoben, als er sich die Befreiung der Kirche von jeder weltlichen Macht zur Aufgabe gestellt hatte, war das deutsche Königthum in seinen Grundfesten angegriffen. In Wort und Schrift haben der Papst und seine Anhänger den Gedanken vertreten, dass die Abhängigkeit der Kirchenämter und ibrer Inhaber von den weltlichen Gewalten eine unrechtmässige, eine usurpirte sei. Die agitatorische Verbreitung dieser Ideen in Deutschland übernahmen die Hirschauer. Besonders in Schwaben erzielten die begeisterten. Prediger überwältigende Erfolge ${ }^{3}$ ). Dass sie ihre Theorieen auch zur That amzusetzen wussten, lehren

sönlichkeiten ausgesucht. Vgl. MG. Epistolae 4, 13 ż und Mühlbacher Reg. 320 mit Nachtrag:

1) Bresslau in Forschungen $26,18 \mathrm{ff}$.

2) Vgl. Dopsch in dieser Zeitschr. 14, 25 und 19,610.

8) Vgl. P. Giseke, Die Hirschauer während des Investitnrstreites und das ausgezeschnete Buch Haucks, Die Kirche Deutschland unter den sächsischen und salischen Kaisern. 
die Gründungsurkunden der Reformklöster und die kaiserlichen Bestätigungen derselben. Aus den einzeluen Bestimmungen kann man ersehen, welche Forderungen sie im concreten Fall mit Rücksicht auf die Freiheit eines Klosters stellten. Mit Recht lat Naudé ${ }^{1}$ ) in den Hirschaner Kaiserurkunden eine formell und inhaltlich von den andern gleichzeitigen Diplomen abwe.chende Gruppe gesehen.

Die Urkunde des Mutterklosters vom Jahre 1075 (St. 2785) bildete sichtlich das Muster für jene anderer Hirschauer Gründungen. Man wird Empfängerecncept annehmen müssen. Dreierlei Bestimmungen, in allen diesen Diplomen witderkehrend, seien hier hervorgehoben: 1. Freie Wahl des Abtes, wenn nöthig, auch von auswärts. 2. Wenn der Abt sich eiı Vergehen gegen den gemeinsamen Nutzen der Brüder, z. B. Verschleuderung oder beneficiarische Vergabung von Klostergnt an Fremde zu Schulden kommen lässt, kann er nach Anklage und Ueberführung seitens der Brüder abgesetzt werden. 3. Nicht um irdischen, sondern ewigen Lohnes willen soll der Vogt die Rechte und Freiheiten des Klosters schützen; sonst durf der Abt ihn ohne weiteres absetzen und einen anderen ervennen. Die Befugnisse des Vogtes werden genau fixirt, ebenso seine Einkünfte in Naturalien bis auf die einzelnen Masse. Untervögte zu bestellen, ist deu Vogt unter:agt. Der Papst habe die Freiheiten des Klosters garantirt ${ }^{2}$ ). Deren Uebertretung wird mit zeitlichen und ewigen Strafen belegt.

Solche und ähuliche Urkunden erhielten von Heinrich V. eime Reihe von Hirschauer Reformklöstern; ich nenne Usenhoven (1107), St. Georgen (1108), Gottesau (1110), Muri (1114), Paulinzelle (1114), Odenheim (1123), Alpirsbach (1123), Scheiern (1124), St. Blasien $\left.(1125)^{3}\right)$. Wenn wir noch einer Bestätigungsurkunde des Mainzer Erzbischofs Ruthard vom Jahre $1090^{4}$ ) für Komburg gedenken wollen, durch welche dem Kloster Freiheit der Abtwahl, Absetzbarkeit des Vogtes, Befreiung vom Kriegsdienst und dem Besuch der erzbischöflichen Hoftage gewährleistet, sowie die Erlaubnis ertheilt wird, gegen Uebergriffe des Erzbischofs in Kom Schutz zu suchen, so haben wir den Begriff Klosterfreiheit, wie ihn die Hirschauer fassten, zerlegt.

1) Albert Naudé, Die Fälschung der ältesten Reinhardsbrunner Urkunde $89 \mathrm{ff}$.

2) Päpstliche Schutzprivilegien haben während des Investiturstreites fast nur reformirte Klöster oder solche, die wenigstens gregorianisch gesinnt waren, bekommen. Vgl. Hauck a. a. 0. $865 \%$.

3) Es sind bei Stumpf n. 3012, 3026, 3041, 3106, 3115, 3186, 3189, 3197, 3204. Vgl. Naude a. a. O. 102.

4) Wirteml. Urk.-B. 1, 286. 
Nur andeuten, nicht im einzelnen ausführen wollte ich mit Obigem den Inh.lt der Privilegien. Die Zusammenstellung wird genügen, um zu zeigen, dass Hirschauer Klöster geraıle jene Privilegien von Kaiser Heinrich V. thatsächlich erhalten haben, welche die alten Benedictinerklöster durch Fälschungen zu erreichen suchten. Wo wohl der Grund liegt, dass dıs, was für die einen recht, nicht auch für die anderen billig war? Ich meine hauptsächlich darin, dass erstere meist Neugrüudungen ${ }^{1}$ ) aus der Salierzeit waren, dass die Könige sie fast gar nicht durch Schenkungen begünstigt hatten. Bei den alten Reichsabteien ${ }^{2}$ ) waren mit den Fragen über Freihest der Abtwahl, Absetzbarkeit des Vogtes bereits soviele Interessen des Königs und der Fürsten tangirt, dass m.t der Verleihung solcher Privilegien eine jahrhundertelange Entwickluug hätte rückgängig gemacht werden müssen Begab sich der Kö̈uig seines Einflusses bei der Bestellung des Vorstandes der Abteien, dann verzichtete er auf die reichen Mittel des Kirchengutes, die lange Zeit den Herrschern die wichtigsten Hilfsquellen gewesen waren. Den Fürsten wäre der Besitz einträglicher Vogteien, Kirchenlehen und Zehuten genommen worden ${ }^{3}$ ).

Andrerseits. Die Rücksichtslosigkeit, mit der Heinrich V. vor und nach dem Wormser Concondat Kirchentürsten einsetzte ${ }^{4}$ ), die Ausbeutung, welche der Laienadel auf Grund der Vogteigewalt trieb, und endlich die Entfremdung zahlreicher Besitzungen iu der uuruhigen Zeit der inveren Kämpfe lässt eine Gegenwehr seitens der hurtbetroffenen Klöster hegreiflich erscheinen.

Wie weit die Bestimmungın der Spuria den thatsächlichen Verhältnissen der einzelnen Abteien entsprachen, lässt sich mit unsern Mitteln nicht mehr controliren. Eine so weitgehende Wahlfreiheit haben die deutschen Könige - von vereinzeltneu Fällen abgesehen den Stiltern weder in der salischen woch in der ottonischen Periode eingeräumt ${ }^{5}$ ); auch Lothar und dıe Staufer nicht. Dass die Ausätze der Vogteinkünfte, wie sie unsere Fälschungen für Reichenau statuiren, höher sind als jene in ungelähr gleichzeitigen echten Urkunden für andere Klöster Süddeutschlands ${ }^{6}$ ), darf uns nicht wundern, wenn wir das Grössenverhältnis berücksichtigen. Das Wahrscheinlichste ist, dass

1) Vgl. Bruno Albers, Hirsau und seine Gründungen rom J. 1073 an, in der Fentschrif zun 1100jährigen Jubilänm des deutschen Campo Santo in Rom.

2) Vgl. Ficker, Vom Reichsfürntenstiınde 1, 3:9 ff.

s) Waitz, Verfassungageschichte 8, 442.

4) Waitz, Verfissungsgeschichte 7, 268, 297.

5) Vgl. Waitz, Verfassungsgeschichte $7,265 \mathrm{ff}$.

") Vgl. Brandi 88. 
bestinmte Normen für unsere Klöster lange Zeit überhaupt nicht bestandej; und dass man sich zu einer genauen Fixirung erst genöthigt sah, als wiederholte Uebergriffe eine solche dringeud erforderten. Dàs häufig wiederkehrende Verbot, Klostergüter ,in beneficium concedere', 'bedeutet eiue Reaction' gegen die Schmälerung des geistlichen Grundbesitzes, wie sie durch die Vererblichung der Lehen eingetreten war. Insbesonclere seit dem 12. Jahrhundert ist ein starkes Zurückgehen des kirchlichen Grundbesitzes gegenüber einem Anwachsen des weltlichen zu constatiren ${ }^{1}$ ).

Das vereinte Auftreten solcher Tendenzen in solcher Verbreitung scheint mir nicht ohne Beziehung zu den während des Investiturstreites aufgeworfenen Fragen; auch von dieser Seite betrachtet, passen diese Fälschungen an besten in das erste Viertel des 12. Jahrhunderts. So gewinnen sie einen bedeutsamen Hintergrund und fügen sich in ihre aufgeregte Zeit ein. Fragen wir nach dem Band, das diese Klöster umschloss, als sie die gemeinsame grosse Fälschungsaction vornahmen, so möchte ich auf Confraternitäten kein allzu grosses Gewicht legen; unit einer grossen Auzahl kirchlicher Genossenschaften eingegangen, auch mit solchen in Frankreich und Italien, mussten sie nicht gerade engere Beziehungen zu Folge haben. Ausserdem konnte ich sie für unsere Zeit nicht im einzelnen nachweisen, obwohl sie wahrscheinlich bestanden halsen ${ }^{2}$ ). Die örtliche Nähe und die Gleichheit der Bedürfnisse, verbunden mit der geringen Aussicht auf rechtliche Befriedigung, wird sie zusammengefülırt haben. Reichenau, Kempten, Buchau, Liudau, Rheinau, sie alle liegen im Constanzer Sprengel; bei den gleichfalls benachbarten Abteien Ottobeuren und Stein, das eine zur Diöcese Augsburg gehörig, das andere Bamberg incorporirt, ist die unmittelbare Betheiligung nach der Beschaffenheit ihrer Urkunden zweifelhaft, gleichwie beim Domstift Strassburg. Von Reichenau wissen wir, dass es wenigstens in den letzten Jahrzehnten des 11. Jahrhunderts zur römisehen Partei zählte ${ }^{3}$ ); Kempten standen am Anfang des 12. Jahr1) จ. Inama-Sternegg, Deutsche Wirtschaftsgeschichte 2, $121 \mathrm{ff}$.

iv) V.gl. z. B. die Uebersicht der St. Galler Fraternität, MG. Confraternitates 144, welche alle uns angehénden Instiute unfasste und die Confraternitates Augiensis \&. IX ebendort $145 \mathrm{ff}$. In diesem Zusammenhange sei auch erwähnt, dass ein Reichenauer Necrolog im 10. Jahrhundert nach Rheinau kam, dass es dort abgeschrieben und fortgesetzt wurde, MG. Necrologia 1, 271. 'Um 830 schou bestand eine Societät zwischen Rèichenau und : trassburger Kanoniliern (Grandidier, Histoire de l'église dè Strasbourg 2b n. 176). Nähere Beziehungen zwischen Reichenau und Buchau vermuthet ftar das 11. Jahrhundert aus anderen Gründen Dieterich, Die Geschichtsquellen des Klosters Reichenau bis zur Mitte des 11. Jabrhunderts, S. 243 .

s) Giseke a. a. O. 20,84. 
hunderts nacheinander zwei Hirschauer Aebte vor 1), Rheinau war un 1090 von Petershausen aus reformirt worden ${ }^{2}$ ), Ottobeuren $\left.{ }^{3}\right) 1102$ voǹ St. Georgen. Eine königliche Bestätigung der in den Fälschungen angestrebten Privilegien hat nach unserer Kunde nur Rheinau i. J. 1125 erreicht. Besonders festen Fuss scheinen die Hirschaner Gewohnheiten in unseren Klöstern nicht gefasst $\mathrm{zu}$ haben; schon in einem um das Jahr 1140 in Salzburg angefertigten Verzeichnis ${ }^{4}$ ) verbrüderter Klöster, ,welches gleichsam eine Musterungsliste über den Heerbann der Reformpartei, vornehmlich in Oesterreich, Baiern und Alemannien darstellt ${ }^{* 5}$ ), fehlen sie alle.

Eine so umfassende, geradezu gewerbsmässige Urkundenfälschung für das eigene und auch für benachbarte fremde Klöster, wie sie in den ersten Jahrzehnten des 12. Jahrhunderts in Reicheuau ins Werk gesetzt wurde, hat - soviel bisher hekannt - in den zahlreichen Gruppen unechter Documente des Mittelalters nicht ihr Seitenstüek; sic steht einzig da. Eine Parallele, aber viel kleineren Massstabes nach Anzahl der Urkunden und Theilnehmer hat sie in der Thätigkeit des Poppo C. der nach seinem im Jahre 940 erfolgten Austritt aus der Kanzlei M. 1699, M. 1700, DO. I. n. 277 für Reichenau, M. 1435 für Rheinau fabricirt hat.

Ist das Echte vom Unechten mit dem uns zugebote 'stehenden Mittel der Vergleichung reinlich geschieden, die Entstehungszeit nach Thunlichkeit festgestellt, so werden die Fälschungen nach zwei Seiten historisch verwertbar. Die echten Bestandtheile stellen die kümmerlichen Reste der ältesten Königsurkunden für die betheiligten Abteien dar, vı,n den Empfängern selbst zur Herstellung von Falsificaten geopfert; sie sind bei den meisten hier behandelten Klöstern für uns das trüheste Zeugnis ihres Bestandes. Die unechten Zuthaten werfen ein grelles Streiflicht auf die rechtlichen und wirtschaftlichen Zustände and Strömungen der Abfassungszeit und gliedern sich unserer ans andern Quellen gewonuenen Kenntnis an.

Die Thatsache gemeinschaftlichen Vorgehens belehrt uns über die intimen klösterlichen beziehungen in Alemannien. Sie wird fǘr die fälschungenreichsten Zeiten des Mittelalters, das 10., 11. und 12. Jahrhundert. nur erklärlich aus einer ganz anders gearteten Stellung der

1) Vgl. oben S. 44.

?) Hanck, a. a. O. $863^{2}$.

3) Giseke, a. a. 0.161 .

4) MG. Necrologia 2, pars 1, 52 Spalte 25, 53, Spalte 34. Froundlicher Hinweis Prof. Herzberg.Fränkels.

5) Herzberg-Fränkel in Neues Archiv 13, 275: 
öffentlichen Meinung zu Wahrheit und Betrug, als wir sie heute einnehmen; es liegt eine wesentlich verschiedene Auffassung zugrunde ${ }^{1}$ ). Insbesondere in der zweiten Hälfte des 11. und am Beginn des 12. Jahrhunderts hatte der zwischen den beiden höchsten Autoritäten, dem Kaiserthum und dem Papstthum, erbittert tobende Kampf, der zur Lösung heiliger Eide getührt, eine arge Verwirruug der sittlichen Principien zur Folge gehabt ${ }^{2}$ ). Die weuig ausgebildete Fühigkeit zur Kritık leistete Urkundenfülschungen erheblichen Vorschub ${ }^{3}$ ).

\section{Exeurs.}

Zur Kritik der älteren Geschichtsquellen von Ottobeuren.

An Königsurkunden bis zum Ende des 12. Jahrhunderts sind auf uns gekommen :

M. 132, angeliliches Diplom Karls d. Gr.; chronicon Ottenburanum f. $3^{\prime}$ aus dem Ende des 12. Jh.

M. 447, nngebliche Urkunde Karls d. Gr. mit gleicher Ueberlieferangsform.

M. 1799, 'Tauschbestätigung Arnolfs; Freisinger Chartular des 12. Jh.

DO. I. 453 spur., Urschrift aus der ersten Hälfte des 12. Jh.

DO. I. $42: 3^{\mathrm{a}}$ spur.; Chronicon Ottenburanum.

Stumpf 3362, angebliche; Diplom Lothars III., theilweise erhalten als Insert in iler nachbezeichneten Urkunde Friedrichs I.

Stumpf 4124, Original Friedrichs I. Ausserdem in einem Originaltranssumpt Friedrichs II. von 1220 Jan. 4 und im chronicon Ottenburanum,

Die Mehrzabl der aufgezählten Stücke sind Fälschungen des 12. Jahrhunderts. Um sie als schätzenswerte Erkenntnisquelle für die Zeit ihrer Entstehung nutzbar zu machen, müs-en wir in unserem Fulle zunächst ihr gegenseitiges Verhältnis zu ergründen suchen.

Wir beginnen mit der Vergleichung der zwei Spuria auf den Namen Ottos I., weil hier wenigstens das eine Stück in der Urschrift erhalten ist. Foltz ${ }^{4}$ ) sah in den beiden Urkunden zwei inhaltl ch übereinstimmenile, wahrschrinlich gleichzeitig entstanılene Formen derselben Fälschung. Scheffer-Boichorst ${ }^{5}$ ) hat aus der Stellung, welche die genannten Stücke in

1) Vgl. hierüber das lehrreiche Verzeichnis zahlreicher Fälle von G. Ellinger, Das Verhältns der öffentlichen Meinung zu Wahrheit und Lüge im 10, 11. und 12. Jahrhunilert. Berl. Diss. 1884 .

2) Dieser Zeit (1084-1087) verdanken auch die falschen Privilegien Hadrians 1. und Leos VIII. (MG. Coustitutiones I n. 446, n. 448-450) ibre Entstehung. Sie wurden als Waffen der kiniserlichen Partei geschmiedet.

3) Vgl. Bressliu, Urkundenlehre $17 \mathrm{f}$.

4) Vorbemerkungen zu DO. I. 423a unter den Nachträgen.

5) Neues Archiv 19, $598^{2}$. 
der Gebührenfrage an die Personen des königlichen Hofes einnebmen, erkannt. dass weder der Inbalt völlig übereinstimmt, noch die Gleichzeitigkeit wuhrscheinlich sei. Führen wir die formelle wie sachlich Vergleichung durch.

Im Protokoll von DO. I. $423^{2}$ ist der Titel erweitert durch ,Romanorum et semper ; diese Titelform ,imperutor Romanorum et semper augirstus ${ }^{6}$ wird, zuerst in der allerletzten Zeit Konrauls IJI. auftretend, unter Heinrich VI. zur Regel. Hinzugekommen sind auch ilie für Otto I. durchaus echten Formeln der Arenga, Pullication und Corroboration 1). Die Signumzeile ist durch Weglassung von ,magni imperatoris‘ gekürzt und an ihren richtigen ort vor der Datirung gesetzt, die Rrcugnition durıb , et subscripsi' bereichert worden. In der Narralio wurde der Titel des Bi-chufs Odulrich durch ,et abbas Ŏttenburensis evclesie‘ erweitert (vol. vita Ouilalrici MG. SS. 4, 409). Fine Aenderung liegt - um nur die charakteristischen Differenzen anzuführen — auch vor in ,a curiuli remota itineratione' gegenüber ,a curiali itineratione'. Die nähere Angabe der von den schwälischen Herzogen zu übernehmenılen Pflichtr.n, , hostes rei publice nostre deliellare et quociens fit, expedicionem noliscum movere *, ist gleich-

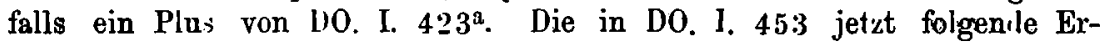
wähnung eines Privilegs Karls d. Gr. über die Vogtei hat der Umarbeiter an den Schluss des Contextes gesetzt und geschickt an die von ihm nen hinzugefügte Bestätigung aller früheren Privilegien angeschlossen: auch ein solches für die negociatores ist darunter. Von ferneren Erweiterungen, die uns in DO. I. $423^{\mathrm{a}}$ begegnen, seien ange'ührt: non muneris quippiam vel curialis exactionis. - item in predictis civitutibus curiam nostrum generalem acturi cum principibus, ex precepto idem abbas conveniat; de ceteris omnino, ut attentius leo famuletur, liber + t securus permaneut. item ${ }^{2}$ ) investituram ecclesiarum Stainhaim et Kyrvbtorf insuper. - de quibuscumque debitis a Cyrchtorf usque in Musebrunge. Erwähneuswert ist vielleicht auch noch die Vorliebe des Ueberarheiters für coordinirende Verbindıngswürter wie tandem, item, insuper, nihilominus.

Diese Zusammenstellung gestattet uns Ein-icht in die Art der Ueberarbeitung. In formeller Beziehung wird, sogar mit Heranziehung eines echten Diploms Ottos I., möglichste Correctheit er-trelt, in sucblicher Hinsicht ist eine Steigerung, mitunter wenigstens eine genauere Formulirung, unverkennbar.

Für die andere in diesem Theile des Chronikons enthaltene Königsurkuncle, tür M. 13ㄹ, fehlt solche; Controlmaterial. Finigen Er-atz scheint mir die Kemptener Fälscbung M. 158 zu bieten, welche ich mit Mühlbacher und Brandi für die Vorlage des Ottobeurener Falsiticuts halte.

1) Vgl. die Vorbemerkung'n a. a. O. Hipr wird auch treft.nd bemirkt, dass lie Dalirung von DU. 1. +53 "nil DO. I. 42 a pinen Leitpuukt br'zulbne, ,in dem die Eitheilung eines D ploms für Ottobeuren yn.h ans anclern c,rünilen al. walurscheinlich gelten kannc. Aus Hermannus contractus ad 973 (.VIG. S.. 17, 116), nowie aus dir vita Oulalrici (.IG. SS 4, 410) erfahren wir dirnt. dass damills 197:/973) Bischof Cdinlich von Augsburg vum Kuiser ein Freibeitsprivilug für die Al, ei erwirkt hat.

2) Iı der Aufzïhluı,g dieser dem Kloster entirmileten, nun nber den Herzogen von Alemannien übrrla-senen Einküıfte Uerühıt sich DU. 1. 4.32 eines Theils mit St. $336 \%$, anderes Thejls mit N. 477.

Jittheiluugen XXI. 
Die Uebereinstimmung im Eingangsprotokoll wird durch zweimaliges Plus bei M. 132 unterbrochen, dei omnipotentis' in der Invocation, ,rex Francorum' im Titel 1). Die Recognition ist durch Weglassung des Kanzlernamens gekürzt, durch Vorsetzung eines seit Lothar III. gebräuchlichen ,Ego“ vor den Namen des „Erzcapellans* erweitert. Die Datirung erlaubt schwer einen Vergleich, weil sie an einen anderen Zeitpunkt anknüpft; an chronologischen Daten ist sie ärmer als die von M. 158. Ausser der fast wörtlich mit M. 158 gleichlautenden Arenga schliesst sich in M. 132 noch eine zweite an, die sicher einer echten Vorlage aus späterer Karolingerzeit entstammt. Die Verleibungen königlichen Schutzes, freier Abtwahl ${ }^{2}$ ), unentgeltlicher Investitur und gänzlicher Zollbefreiung finden in M. 158 keine Parallele. Die Formeln für Mundium und zum Theil die für freie Abtwahl sind wie die zweite Arenga echt, aber jünger. Die Bestimmungen über unentgeltliche Investitur und Zollfreiheit harmoniren, zum Theil sogar im Wortlaut, vollständig aber im Inbalt, gerarle mit jenen Theilen von DO. I. $423^{2}$, die sich als Interpolationen gegenüber DO. I. 453 erwiesen huben ${ }^{3}$ ).

Beim Vogtrecht treten die Concordanzen mit M. 158 wieder zutage; nur die Reihenfolge der Einzelbestimmungen ist mehrmals geändert. Umso beachtenswerter dürften folgende Differenzen sein: Die Bestimmung der Kemptener Vogtfälschung, welche die Heerfolgepflicht des Abtes auf die Vögte abwälzen will 4), ist in M. 132 weggefallen und ebenso mechanisch wie radical ersetzt durch: si opus habuerint; sin vero, nos nostrosque successores iustissimos et certissimos deffensores habeant. Der Satz nos - habeant findet sich auch in den beiden Fassungen der Ottonenfülschung. Ein Plus gegenüber M. 158 ist ferner der glossenartige Passus: id est in iniuria pannorum vel satisfactione temeritatum; desgleichen die den cellaerarii zugesellten villici, welche beide von jeder Leistung an den Vogt frei sein sollen. Sachlich erwähnenswert ist endlich folgende Diver-

1) Die Zuthaten im Protokoll könnten einer Urkunde Ludwigs d. D. von 830 -833 entnommen sein.

2) Diese beiden Vorrechte hat man in Kempten einer zweiten Fälschung M. 157 reservirt.

3) Man vergleiche:
M. 132.
DO. I. $423^{\mathrm{a}}$.

liberum hunc ab omni exacione curiali vel munere permittimus abire.

M. 132 .

Amplius, presenti sane a b bati eiusque successoribus monachis et hominibus ac negociatoribu 8 pretati loci...

<n on muneris quippiaun vel curialis exactionis $>$ ab eo exigatur.

DO. I. $423^{\mathrm{a}}$.

Preterea . . inbemus, ut omnia precepta, libertates, dignitates privilegiaque a predecessoribus nostris regibus vel imperatoribus prenominato monasterio abbati monachis bominibus tam ingenuis quam servientibus a c negociat oribus quoquomodo concessa sunt.

4) Hiefür war in Ottobeuren anderweitig in analoger Weise vorgesorgt: DO. I. n. 453 lässt den Kaiser Utto I. verfügen, dass die Herzoge von Alemannien gegen Ueberlassung gewisser - zur Zeit der Verfertigung der Fälschung offenbar bereits in deren Besitz befindlucher - Ottobeurener Lehen alle Verptlichtungen dee Abtes gegen Kaiser und Reich übernetmen sollen. liese Fälschung auf den Namen Ottos I. spricht bereits von einer die Vogteiverhältnisse regelnden Urkunde Karls d. Gr.: 
genz ${ }^{1)}$ gegenüber der Kemptener Urkunde: nullum de 〈militari〉 familia sine iusta sociorum 〈suorum> deliberatione dampnet vel <aliqua iniuria〉 coherceat <offendat. Qui militares vel aljo nomine ministeriales optimo iure perfruantur, quo Fvldenses vel Avgienses pociuntur $\rangle$. Während M. 158 allgemein von der familia, der Hofgenossenschaft, spricht, hebt M. 132 eine bestimmte Classe, die Ministerialen, heraus. Die Gleichartigkeit des Verhältnisses, in dem DO. I. $423^{\mathrm{a}}$ zu DO. I. 453 einerseits, M. $132 \mathrm{zu}$ M. 158 andrerseits steht, ist handgreiflich: In beiden Fällen wird der Titel des Ausstellers pomphaft erweitert, andere Protokolltheile vermeintlich rectificirt. Der Context erfährt einen Zuwachs an echten Formeln (Arenga, Publication, Corroboration) aus echten Vorlagen. Die sachlichen Zutbaten berühren sich beiderseits auf das engste. M. 132 kann nicht die ursprüngliche Fassung der Ottobeurener Vogtfälschung sein; derselbe Mann, der aus einem DO. I. 453 ein DO. I. $423^{\mathrm{a}}$ schuf, hat auch hier seine Hand im Spiele. Es liesse sich etwa folgende Proportion aufstellen: D0. I. 453 verhält sich zu DO. I. $423^{\mathrm{a}}$ wie M. $158 \pm \mathrm{x} \mathrm{zu}$ M. 132. Wenn ich die primäre Fassung der Fälschung auf Karl den Gr. mit M. $158 \pm \mathrm{x}$ veranschauliche, so möge man daraus ersehen, dass ich für dieselbe natürlich nicht völligen Gleichlaut mit der Kemptener Vorlage annehme; dieses $x$ ist eine Grösse, die sich im Einzelnen unserer Kenntnis entzieht. Soviel scheint mir sicher, dass die Bestimmungen über Investitur und Zoll, also der Absatz von ,Investitus siquidem - securi transeant et pergant" eine Frucht der Ueberarbeitung sind. Für die Beantwortung der Frage, welche von den Erweiterungen, die M. 132 gegenüber M. 158 zeigt, gleichfalls eine Folge der Umreduction seien, können vielleicht die Glossen des Chronisten zu einem Theile derselben einen Fingerzeig geben, der derselben nach Zeit und Tendenz sehr nahe steht. Mit der Constatiruug eines Vorläufers von M. 132 bin ich zu einem Ergebnis gelangt, zu dem schon Scheffer-Boichorst ${ }^{2}$ ) in Uebereinstimmung mit einer privaten Mittheilung Bresslaus auf ganz anderem Wege, durch rein inhaltlicbe Ueberlegung, gefübrt wurde. Scheffer beantwortet uns auch die Frage nach der Entstehungszeit von DO. I. 453: Vor 1145; später hätte man die Erfahrungen Abt Isingrims ${ }^{3}$ ), der im Jahre 1145 , non sine omni curiali exactione' die Regalien erbalten hatte, verwertet. Danit ist auch ein terminus ad quem für den Vorläufer von M. 132 gegeben, von welchem die erste Fassung der Ottonentälschung bereits Kenntnis zeigt. Der gleiche terminus gilt auch für M. 4774) infolge der Erwähnung desselben in DO. I. 453.

1) Zur Beurtheilung dieser Divergenz vgl. unten die Bemerkungen über die Urkunde Lothars III. S. 100.

2) Veroneser Zeugenverhör von 1181 in Neues Archiv 19, 598 Anw. 2, wo diecelbe Ansj.ht andeutungsweise ausgespochen ist.

3) Vgl. seinen Bericht in den Annales Isingrimi min. (MG. SS. 17. 315).

4) Diese argebliche Schenkungsurkunde Karls des Grossen ist m. E. in den Regesten nnmittelbar nach M. 132 einzureihen; ihre Datirung geben die einleitenden Worte des Chronisten als mit jener von $M$. 132 gleichlaurend an: He sunt donationes; quibus imperator Karolus Outenburrense monasterium ditavit et per minus fundatorum dato quo supra privilegio prinitus transmisit ac delegavit hoc modo. (MG. SS. 23, 614, wo die beiden Beistriche vor dato und nach privilegio zu streichen sind). 
Auch das angebliche Diplnm Lothars III. 1) trifft noch keine Schutzmassregeln gegen die Trinkgelderfurderungen der Höflinge; das Jahr 1145 bebält bei der Zeithestinımung seine begrenzende Kraft. Als Insert in dem Diplom Friedrichs I. überliefert, reicht es sichtlich von ,Privilegia venerandae - defensores esse sciat ' ${ }^{2}$ ). Für die ol bezeichneto Herstellungszeit spricht auch die Textirung. Der erste Theil bis ,delata eodem tradantur' steht DO. I. 453 nüher als DO. I. $423^{\text {a }}$ : Der Abtbischnf Udalrich fübrt nur den Bischofstitel, der Befreiung ,ab omni regio negotio feblt noch die Erweiterung durch, non muneris quippiam nec curialis exactionis‘. Das einzige mit DO. I. $423^{\mathrm{a}}$ gemeinsume Plus gegenüber dem alteren Ottonenuliplom, Advocatia aecclesiae in Stainhaim - in Kirctorf: wird eher dlurch Benützung der Lotharfälschung für DO. I. 42:3 $\mathrm{zu}$ erklären sein. Von ,Precipiendo vero praecipimus - sine spe recuperationis privatus deponatur" herr-cht Uebereinstimmung mit M. 132, jedoch nur mit von uns als sicher ursprünglich erkannten Theilen desselben, nämlich mit den voyt unil dienstrechtlichen Bestimmungen. Der letzte erhaltene Passus in Lothars Diplum ist $=$ DO. I. $453=$ D0. I. $423^{\mathrm{a}}$.

In Stumpf 3:362, entstanden vor der Unarbeitung Jer Spuria Karls d. Gr. unil Ottos I., baben wir ein Hilfsmittel gewonnen, um den Inhalt des Vorläufers von M. $132 \mathrm{zu}$ erschliessen: Er scheint sich auf Abtwahl und Vogtrecht beschränkt zu haben. Die von M. 158 alweichende specielle Rücksicht auf die Ministerialen dürfte ursprünglich sein. Unsere zeitliche Ansetzung rler Ottubeurener Privilegien mit Vogteibestimmungen wird auch dadurch unterstützt, dass Eugen III. bereits im J. 1152 (Juffé 2. ell. n. 9615) auf solche privilegia imperatorum Bezug nimmt. Einen terminus a quo bietet für DO. I. 45:3 dus Wormser Concordat (1122), für St. 3362 die Wahl Lothars III. (1125). Auf M. 132 sen. ist der terminus 1122 nicht anwendbal, weil auch der Passus ,nobisque ac successorilus - confirmetur" spätere Zuthat sein dürfte. Die ältere Fassung von M. 132, ferner DO. I. 453 and St. 3362 scheinen eine einheitliche, vor 1145 entstandene Gruppe von Fälschungen auszumachen: kann man dieses Verbältnis für die beiden letzteren als höchstwahrscheinlich bezeichnen, so wird man sich bezüglich der verlorenen Karlslälschung mit einem „vielleicht * begnügen müssen. Der Inhalt aller drei wurde 1171 von Friedri:h I. durch Ertheilung von St. 4124 bestätigt. An dessen Echtbeit wird nach Scheffer-Boicborst.s Untersuchung nicht mehr gezweifelt werden dürfen; auf Grund von Autupsie balte ich mit Ficker, Brandi und Schum ${ }^{3}$ ) auch die Originalität für gesichert ${ }^{4}$ ).

K. Friedrich I. fügt der Besiätigung des Privilegiums Lothars noch das Verbot an den Abt hinzu, Güter des Klosters als Lehen auszuthun, $29^{2}, 399$.

1) Das Stück jst wohl auch unecht. Vgl. Scheffer-Boichorst a. a. 0.601.

2) Vgl. den Abdruck des Fridericiunischen Orjginals in Monumenta Boica Text 408

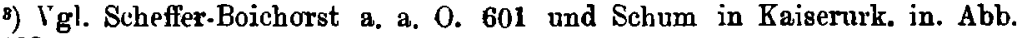

4) Die Chronikeintragung (f. 20'-2?') weist erhebliche (formelle) Varianten gegenüber den Ur ginal auf. Die Hand, welche nach 12:27 - und wohl nicht länge darnach - f. 14' bis f. 23 schrieb, ist mit jener von f. 1 bis $f 10$ in Ductus und Buchstalenformen (Nachahmung diplomatischer Sthrift) nahe verwandt, ohne dass ich beide $z u$ identificiren wagte. 
gebietet an der Hirschauer Regel festzuhalten und befreit die Ministerialen wie Hofleute ,a regali expe.litione et a servitio, quod vulgo dicitur herstiurec.

$\mathrm{Nach} 1171$ Mai 7 muss die Ueberarbeitung der älteren Fälochúngen auf Karls und Ottos Namen vorgenommen worlen sein. Als sich im Jabre 1179.1) der neugewählte Abt Bernold zur Wablbestätigung und Regalienbelebnung vor dem Kaiser zu Ulm einfand, verlangte der Kanzler von ihm die üblichen Geldgeschenke in der eines Ottoheurener Abtes würdigen Höhe. Der Abt verweigerte sie unter Berufung auf seine mitgebrachten - Privilegien. Da wurden sie verlesen, die privilegia imperatornm, Ottonis videlicet et Lotarii necnon ipsius triterici imperatoris ${ }^{2}$ ), Wenn der Abt selbst ${ }^{3}$ ) in wörtlicher Anlehnung an D0. I. 453 und St. 3362 seine Freiheit dahin definirt, se ab omni regio negocio esse liberum, preter quod . . duos canes pariles . . afferre deberet, wenn die Hofbeamten behaupten konnten, die Befreiung von den pflichtgemässen Geschenken sei in den Privilegien nicht ausgesprochen, wenn endlich der Kaiser sith selbst ülıer die Auslegung nicht klar war: So beweist das m. E. auf das bestimmteste, dass die verlesenen Urkunden noch jene der ursprünglichen Fassung gewesen waren. Hätte Bernold damals DO. I. $423^{\mathrm{a}}$ vorgelegt ${ }^{4}$ ), so wären bei der ausdrücklichen Bestimmung, ut post adeptam dignitatem non muneris quippiam vel curialis exaction is ab eo exigatur, preter quod duos canes etc. seine eigenen Worte, der Zweifel der Holbeamten und des Kaisers Schwanken unverständlich. Der Kaiser verschob die Entscheidung auf den anfangs 1180 stattfinclenden Reichstag. Nach abermaliger Verlesung der Privilegien entschied das Reichshofgericht unter dem Vorsitz des Erzbischofs von Trier: abbatem securum fore de curiali exactione seu de remota itineratione atque de omni regia servitute Genau dasselbe sagt DO. I. 423a, genau dasselbe in der Gebührenfrage ${ }^{5}$ ) auch M. 132. Beide sind in dem spätestens um 1201 geschriebenen Theile der Klosterchronik bereits enthalten. Sie sind zwischen 1179 unil der Anlegung des Chronıkons entstanden. Sollten die Ottobeurener die Zwischenzeit von Ende 1179 auf $1180 \mathrm{zu}$ ihrer Herstellıng lienützt hahen? Sollte dadurch der günstige Entscheid erzielt worden sein? Ich halte dus nicht für wahrseheinlich. Dieser Erklärungsversuch hiesse dem Alt eine ül,ergrosse Dreistigkeit zutrauen, dem Kaiser und den Holheamten ein zu schlechtes Gedächtnis imputiren. Mir scheint plausibler die Annuhme, im Kloster babe man sich unter dem unmittelbaren Eindrucke des günstig ausgegangenen Streitfalles, in Hinblick auf das hofrichterliche Urtheil nicht ohne einen Schein von Berechtigung zu einer rectificirten Neuausfertigung der älteren Privilegien entschlossen, um sa für alle Zukunft gesichert zu sein. Dass man bei

1) MG. SS. 23, 62048.

2) Warum er das übrigens in der Urkunde Ottos und Lothars erwähnte Karlsprivileg nicht vorwies, wissen wir nicht; vielleicht eben deshalb, weil es über Wahlbestätigung und Regalieubelehnung nichts enthielt.

3) Nach dem Berichte des gewiss gut uuterrichteten Ottobeurener Annaliaten. Annales Ottenburani minores ad 1180 (MG. SS. 17, 316).

4) Die Echtheit der vargewlenenen Privilegien soll von niemandem angezweifelt worden sein.

5) Vou der Pflicht zum Besuch der Hoftage und dem Heerdienst spricht M. 132 nicht. 
dieser Gelegenheit auch die wohl ohnehin besessene Zollfreiheit verbriefte, darf uns nicht wundern.

Fassen wir unter Benützung der Ergebnisse die eingangs angeführten Ottobeurener Königsurkunden nochmals einzeln ins Auge: M. 132 ist eine am Ende des 12. Jahrhunderts hergestellte Ueberarbeitung einer älteren vor 1145 fabricirten Fälschung beschränkteren Inhalts. MI. 447 ist vor 1145 entstanden; in der chronologischen Anordnung der :Karolingerurkunden gebübrt ihr der Platz unmittelbar nach M. 132. M. 1799 ist die alteste erhaltene echte Urkunde für Ottobeuren. D0. I. 453 ist eine zwischen 1122 und 1145 entstandene Urschrift. DO. I. $423^{3}$ ist eine am Ende des 12. Jahrhunderts, mit M. 132 gleichzeitig gefertigte Ueberarbeitung von DO. I. 453. Stumpf 3362 bildet mit. DO. I. 453 eine einheitliche Fälschungsgruppe; ob auch die ursprüngliche Fassung von M. 132 dazu gehört, ist nicht zu entscheiden. St. 4124 ist ohne Zweifel echt und Original.

Zum Schlusse sei noch einer Vermuthung ïber den Zusammenhang der in M. 132 und DO. I. $423^{\mathrm{a}}$ vorliegenden Neuredaction alterer Fälschungen mit den gleichzeitig abgefassten erzählenden Geschichtsquellen der Abtei Ottoheuren Raum gegeben: Ich meine mit dem auffallend ausführlichen Bericht der Annales Ottenburani minores ad a. 1180 und mit dem ersten bis zur Wahl des Abtes Rudung reichenden Theil des Chronicon Ottenburanum 1), das nur die neuen Fassungen enthält, ohne über die Existenz älterer auch nur ein Wort zu verlieren. Wer immer von neueren Forschern sich, mit diesen Ottobeurener Geschichtsquellen näher befasste, wurde auf ihre Uebereinstimmung autmerksam ${ }^{2}$ ); allejn ohne Einblick in die Stadien der Fälschungen konnte man sich darüber nicht klar werden. Die völlige Concordanz zwischen dem von den Ann. Ottenb. min. berichteten Urtheilsspruch und DO. I. 423 ${ }^{a}$ konnten wir bereits beobachten. Prüft man Ausdruck und Stil des.Verfassers, so fällt dieselbe Vorliebe für coordinirende Conjunctionen und adverbielle Füllwörter auf wie in der überarbeiteten Ottonenurkunde: nihilominus, pariter, itemque, igitur, siquidem u. a. Hier finden wir auch den Ausdruck, inbeneficiare wieder, der sich in DO. I. $4^{2} 3^{\mathrm{a}}$ (abstracta (seu inbeneficiata〉 scil. predia) als Erweiterung darstellt. Gebraucht der Verfusser des Berichtes zum J. 1180 die Wendung ,s e cur um fore de curiali exaction $e^{6}$, so gestattet die in M. 132 eingeschaltete Zollfreiheit den Ottenbeurener Leuten, im ganzen Reiche sine exactione thelonei cum pace securi transire et pergere. Dass wir in der zweifellosen Interpolation von M. 132 (Investitus-pergant) auch einem ,siqui dem' und einem ,amplius' begegnen, kommt dazu. Die gleiche Erscheinungzeigt das chronicon Ottenb. Das grosse Interesse, das der erste Chronist für die neuaufgelegten Fälschungen hat, offenbart or in der Einleitung und in den Glossen, die er in Dreizahl zu M. 132, in Zweizahl zu DO. I. 423 $^{\mathrm{a}}$ macht. Ueber den für die Anlegung massgebenden Plan spricht er

1) Abschnittweise untex Abt Konrad (1193-1228) entstanden. Vgl. Wattenbach, Geschichtsquellen $I^{\mathrm{a}}, 389$.

2) Vgl. auch R. Detiloff: Der erste Römerzug Kaiser Friedrichs I. 69; Wattenbach, Geschichtsquellen II $391^{\prime}$. 
sich folgendermassen aus: . . . dignitates ${ }^{1}$ ) privilegiorum denuo ac libertates vel etiam donationes seu predia per manus imperatorum: evidenter collata ostendemus. Rursus quo regni ac principum consilio predictus locus ${ }^{2}$ ) ab expedicione regali ac servitute sive hostili clipeo relaxatus sit et abstractus, autenticis regum scriptis uno denotabimus. Auch die Interpolation in DO. I. $423^{\mathrm{a}}$ : item investituram ecelesiarum Stainhaim et Kyrchtorf hat er sorglich vermerkt ${ }^{3}$ ). Wie sehr es auch hier von nihilominus, pariter, item, igitur u. a. wimmelt, entgeht keinem Ieser. Nimmt man des Chronisten incorrectes Citat aus dem Wormser Concordat 4) hiezu, so kennen wir den Mann auch von dieser Seite.

Das alles sind nur Indicien. Den Wahrscheinlichkeitsschluss aber dürften sie erlauben, dass wir in dem Chronisten, dem Berichterstatter von 1180 und dem Umarbeiter der Fälschungen eine Person vor uns haben ${ }^{5}$. Ein solcher Zusammenhang stünde keineswegs vereinzelt da. Wie die Wahrung klösterlicher Interessen besonders im 12. Jahrhundert hänfig einerseits die Anlegung von Chartularen veranlasste, andrerseits nicht minder bäufig zur Herstellung von Fülschungen greifen liess, so bediente man sich bisweilen beider Hilfsmittel gleichzeitig: Ich nenne Fulda, Rheinau, Ebersheim ${ }^{6}$ ). Die Aufschlüsse, welche sich aus unserer Betrachtung für das literarische Leben in Ottobeuren, die freundschaftlichen Beziehangen zu Kempten, für rechts- und wirtschaftliche Zustände und Strebungen gewinnen lassen, sind bereits oben angedeutet worden.

\section{B e i l a g e. \\ Hadrian I. nimmt das Kloster Kempten in apostolischen Schutz, bestätigt frühere Privilegien und verleiht freie Abtwahl.}

773 April 197).

Mänchen Reichsarchiv, Kemptener Chart. f. 1-3', auf später vorgebundenem Quaternio von gleicher Hand wie M. 157 u. M. 158 noch im 12. Jh. (etwa Mitte) nachgetragen. Zwei weitere, gleichfalls in München RA. befindliche Ueberlieferangsiormen, eine deutsche Uebersetzung des 15 . Jh. auf pgt. und ein besiegeltes Vidimus des Notars Adam Hiemer v. 1643 Oct. 8 (pap.) sind von der Chartulareintragung abgeleitet.

v. Pflingk-Harttung in Forschungen z. d. G. 21, 230 (deutsche Uebersetzung des 15. Jh.) und darnach Jaffé-Ewald 2406.

Die Klammern sollen nur im allgemeinen anf die Stellen mit freiem Fälscherdictat aufmerksam machen.

1) MG. SS. 23, 611 .

2) Vgl. den Zusatz tantus locus in DO. I. 4232.

3) MG. SS. 23, 612: item ecclesias Stainhaim et Kirchtorf cum praediis quibusdam.

4) Vgl. MG. Constit. 1, 156 Vorrede.

5) Gẹstiitzt wird diese Vermuthung auch dadurch, dass die erste Hand des Chronikons diplomatische Schrift nachahmt. Vgl. SS. 23, 609. lst die Eintragung des 1180 er Berichtes in einem jetzt Donaneschinger Codex üler Ostercyklen (vgl. SS. 17, 312) Original, so könnte der Schrifivergleich die Entscheidung erleichtern.

6) Vgl. Dopsch in dieser Zeitschr. 17, 32 und 19,.603.

ग) So nach luna $\mathrm{XXI}$, 
Adrianus a) episcopus servus servorum dei $\Lambda$ udogario religioso abbati venerabilis monasterii quod vocatur Campi lona et perb) jpsum ${ }^{b}$ ) in eodem munasterio degentibus monachis elericis et laicis salutem et apostolieam benedictionem ia perpetuum. Convenit apostoliro moderamini pia religione pollentibus benivola conpassione succurrere et poscentium animis alacri devocione impertiri as-ensum. Ex hoc enim lucii potissimum premium a eonditore omnium domino promeremur, dum venerahilia loca per nos ad meliorem fuerint sine dubio statum perducta. Igitur omnibus sancte dei ęclesię fidelibus presentibus scilicet et futuris notum esse volumus, <qualiter dilectus et spiritualis filius noster Karolus gloriosus rex et imperator et pitricius Romanorum eum sua cara coniuge Hildegarda et aliis multis principibus) suggessit nostro apostolatui, quod <venerabile Campilonense monasterium in honore sanctę et super exaltate dei genitricis semper virginis Marie dominę nostre constructum et consecratum aliquo sanctarum reliquiurum> munere ditaremus, ac apostolice confirmationis et auctoritatis nostrę paivilegio muniremus. Cuius salubribus moti precibus omniumque ęcclesiarum dei statum augeri et nullius sacri loci ius aliquo modo violari volentes (corpora sanctorum martyrum Gordiani et Epimachi 1) Audogario Campidonensis cenobii abbati et post magnume) primo fundatori ob amorem ibi dei cultum et regularis discipline meritum omnibus nostris annuentibus et consentientibus $>$ tradimus hoc apostolice auctoritatis privilegio decernentes ob honorem ipsius beatę dei genitricis et stabilitatem eiusılem venerandi loci ipsum iam fatum monasterium cum ${ }^{d}$ ) casis casalibus curtibus mansis colonis fundis terris pratis pascuis aquis aquarumque decursibus piscationibus molendinis alpibus ingressibus et regressibus mohilibus et inmobilibus sive etiam familiis utriusque sexus salvum et in cunctis quietum sub Romane sedis tuicione perpetualiter consistere <et presentem abbatem cum suis suciessoribus ab omni regum expeditione absolventes> sub anathematis vinculo sanctimus et confirmamus, ut nullus imperatorum ${ }^{6}$ ) vel regum ducum comitum advocatorum vel quarumcumque personarum <contra hoc apostolicum statutum presumat ante fatum monasterium cum suis pertinentis cuiquam hominum more beneficiali quomcdoeumque concelere ant a dicione et gubernatione abbatis et fratrum quolibet modo alienare $>$. Pocius autem ad profectum monachorum et domino sedulas laudes persolvendas necnon et ad ${ }^{f}$ ) mercedis nostre augnentum sub iure et dicione ac semper dispositione abbatis consistat sine cuiuslibet quacumque contradictione. < Et quando abbas eiusdem sepedicti monasterii de hac luce migruverit, non aliunde veniens eligatur aut consecraetur, sed ipsi monachi facta statim inter se electione de suis,

a) Am oberen Kande von einer Hand des 16. Jh. ,Ducalis monasterii Campidonensis sum' im ch.

b) p. i. anf Rasur von ders Hand im ch.

c) ch., soll wohl heissen: magno.

d) Ueber der Zeile von späterer Hand zur Hervorhebung ein fünfpassartiges Zeichen im ch.

e) Im Innenrand des Blattes halbkrei-förmiges Loch mit Durchmesser von 4 Zeilenabstïnden: die Sehrift weicht dem Loch aus im ch.

f) Ueber der Zeile von ders. Hand nachgotragen im $\mathrm{ch}$.

') Vgl. Herm. contr. ad ann. 774 (MG. SS. V, 100). 
qualem deo concedente previlerint et ad tale opus idoneum agnoverint, ad sibi more ecclesiastico abbatem consecrandum eligant, nisi forte aptus et utilis illic non inveniatur: tunc demum alius sciens novi et veteris testamenti aliunde assumatur $>$. Statuimus preterea apostolica censura sub divini iudicii obtestacione et anathematis interdictu, ut, si quicumque homo cuiuslibet potestatis existens ausu temerario presumpserit contra hoc apostolice confirmationis privilegium agere, <aut prefatum venerabile monasterium cum omnibus appendiciis eius cuiquam concedere et violenter destruere, vel homines ubiubi locorum commanentes iniuste opprimere $>$, nisi resipuerit. ${ }^{a}$ ) et his monitis nostris et preceptis adquieverit, auctoritate dei et nostra non solum anathematis vinculo innodetur, sed a regno dei alienus existat, <fiat habitacio eius deserta et in tabernaculo eius non sit qui inhabitet, fiant filii eius orfani et uxor eius vidua, ipse et filii eius menticent et eiciantur foris de habitacionibus suis, orbis terrarum pugnet contra eum et cuncta elementa sint ei contraria $b)>$. Observatores autem huius nostri decreti omnipotentis dei gratia protegat, et meritis sanctojum Gordiuni et Epimachi ab omnium peccatorum vinculis absolvat. <Et ut hęc firmius credantur et omni tempore inconvulsa observentur, iussimus, ut signo bulle nostrę imposito roborentur〉. Scriptum 〈quidem est〉 per manum Gregorii notarii et seriniarii 〈huius〉 Romanę sedis et apostolicę in mense aprili, indictione undecima, 〈luna XX prima, anno ab incarnatione domini DCCLXXIII $\left.{ }^{\circ}\right\rangle$, pontificatus vero domni Adriani summi pontificis et universalis papę secundo, 〈presente Karolo imperatore et Hildegarda imperatrice et aliis innumerabilibus $>$ feliciter amen.

a) Ein Zeichen verweist auf eine, jetzt zum grössten 'Theil abgeschnittene Nachtragung von ders. Hand am unteren lande, die wahrscheinlich eine Fristangabe enthirlt: zu lesen ist nur mehr dierum im ch.

b) Mit Verweisungszeichen am rechten Rande von einer Hand des 14. Jk. hinzugefïgt im $\mathrm{ch}$ : Alscondita peccata fiant manifesta; tellus qne calcabitur ab eis, arescat et cinerescut, et de libro viventitum deleantur. Liesen Lusatz hat die deutsche Uebersetzung des 15 . Jh. bereits in den Text übernommen. 
Uebersicht der besprochenen Kaiserurkunden.

Ich reihe hier auch die beiden Haurmeierurkunden ein; die eingeklammerten Zahlen bei den Mühlbachernummern beziehen sich auf die zweite Auflage. Die Cursive bezeichnet echte Diplome.

Karl Martell. M. 371 u. 2 S. 76.

Karl d. Gr. M. 132 (135) S. 53;

M. 157 (161) S. 42:

M. 154 (157) S. $47 \mathrm{ff}$.;

M. $(230)=$ Brandi n. 4 S. 83 f.; M. $1701_{2}$ (23I) S. 77 f.;

M. 297 (306) S. 85 ;

M. $465(478)$ S. $79 \mathrm{ff}$.

Ladwig d. Fr. M. 674 (695) S. 54 f.; $\quad$ M. 961 (992) S. 60 ft

Ludwig d. D. M. 1361 S. $56 \mathrm{ff}$.:

M. 1435 S. $36 \mathrm{f}$.

Karl III

M. 1567 S. $69 \mathrm{ff}$;

M. 447 (460) S. 40 ;

M. $1700 \mathrm{~S} .30 \mathrm{ff}$.

M. 1699 S. 29 ff.;

Arnolf.

M. 1722 S. 86 ;

M. 1766, S. 71 ;

M. 1768 S. 52 ;

M. 1817 S. 86 ;

M. 1867 S. 78.

Otto I. $\quad$ DO. I. n. 277 S. $35 \mathrm{ff}$; DO. I. $423^{*}$ S. $97 \mathrm{ff}$.

DO. I. .n. 453 S. 97 ff.;

Ọtto III. $\quad$ DO. III. n. 437 S. 79 ;

Brandi n. 58 S. 87.

Heinrich II. St. 1412 S. $63 \mathrm{ff}$.

St. 1485 S. 64 ff.;

St. 1675 S. 79.

Heinrich IV. St. 2785 S. 92.

Lothar III. St. 3362 S. $100 \mathrm{ff}$.

Friedrich I. St. 4124 S. $100 \mathrm{ff}$.

Papsturkunden.

Jaffé-Liwald 2401 S. 49 ff.; J.-E. 2406 S. 45, 103. 